\title{
Investigations of genetic variation of teak (Tectona grandis Linn. f.) in Myanmar for conservation and sustainable utilization of genetic resources
}

\section{Dissertation}

Submitted in partial fulfillment of the requirements for the degree of Doctor of Philosophy (Ph.D.)

at Forest Genetics and Forest Tree Breeding, Büsgen Institute Faculty of Forest Sciences and Forest Ecology Georg-August-Universität Göttingen

By

\section{Yazar Minn}

(Born in Amarapura, Myanmar)

Göttingen, 2012 
Supervisor:

Referee:

Co-referee:

Date of disputation:
Prof. Dr. Reiner Finkeldey

Prof. Dr. Reiner Finkeldey

Prof. Dr. Holger Kreft

17.09.2012 


\section{Dedications}

To

My parents, U Nyunt Tin and Daw Than

My wife, Daw Khaing Hnin Ko

My son, Khant Tikyi 


\section{Acknowledgements}

I would like to take this great opportunity to sincerely acknowledge people who helped me and involved in important parts of my study and my life. First of all, my heartfelt thanks go to Prof. Dr. Reiner Finkeldey who gave me his utmost understanding, patience, help, excellent academic guidance and supervision throughout my study in Goettingen. Without his help, my dreams and my works would not have been materialized at all. Dear Professor, please accept my deepest thanks! I owe you a lot.

My special thanks go to Prof. Dr. Holger Kreft who agreed to be my co-referee and Prof. Dr. Dirk Hölscher who agreed to be a member of examination team.

I am very much grateful to Dr. Kathleen Prinz for her endless help, suggestion and advice during my study. She helped me translating manuscripts and presentations into German. Dr. Prinz, thank you very much indeed!

I am thankful to Dr. Sarah Seifert who also helped me translating manuscripts into German language. My thanks also go to Regina Berkeley who always gave a wide range of help to me and my family. I am also grateful to Alexandra Dolynska who gave me enormous help in my lab works.

I am very much indebted to Prof. Dr. Martin Ziehe, Prof. Dr. Hans Heinrich Hattemer (Emeritus), Dr. Elizabeth M. Gillet, Dr. Ludger Leinemann, Dr. Barbara Vornam, Christine Radler, August Capelle, and Gerold Dinkel from the Institute for their help and support. And I am also grateful to Dr. Oleksandra Kuchma, Dr. Amaryllis Vidalis, Essy Harnelly, Markus Müller, Martin Wiehle, Rajendra K.C., Randy Villarin and Chunxia Zhang for friendship, help and support. My special thanks also go to Marius R. M. Ekue who kindly supplied me teak samples from Benin.

I would like to sincerely acknowledge Deutsche Bundesstiftung Unwelt (DBU) for financial support to my study. They gave me extraordinary understanding and support throughout my study. Thank you very much, Dr. Hedda Schlegel-Starmann and all DBU staff for your help and support.

I do thank University of Forestry (UOF) for support and help. My special thanks go to Prof. Dr. Nyunt Htun (retired Pro-rector) who taught me and inspired me in the field of forest genetics. His help and support in my academic life shall never be forgotten. 
My sincere thanks are due to officials as well as all supporting staff of the Ministry of Environmental Conservation and Forestry. Particularly, I received enormous support and help from officials, friends, colleagues and local people from Myanmar throughout the field data collection. Let me express my sincere thanks to U Swe Tint, U Ye Myint Lwin, U Aung Htay Win, U Sai Than Naing, U Tin Maung Aye, U Tin Kyaw Moe, U Kyaw Soe Lin, Daw Myint Myint Aung, U Zeya Htun, U Kyaw Htun Min, U Zay Ko Latt and U Min Myat Aung from Myanmar Timber Enterprise (MTE), and U Thein Htun, Daw Zin Myo Thu, Daw Kyawt Kyawt Aung, U Yan Myo Aung and U Okka Ko Ko from the Forest Department (FD) for their generous help.

Many friends helped me and my family a lot during the study in Goettingen. Particularly, I deeply thank U Aung Myat San, Daw Nyunt Khaing, Daw Tin Zar Kywe, U Myo Min Latt, U Tun Tun Thein, Daw Phyu Phyu Lwin and Daw Phyo Kay Khine for their friendship, support and help. And my thanks also go to all my friends and colleagues who supported me in one way or another.

My deepest and heartfelt thanks go to my beloved late father, U Nyunt Tin and my beloved mother, Daw Than, for their endless support, understanding and unrivalled love. I sincerely dedicate every piece of my work and every achievement of my life to them. Thank you very much, Aphay and Amay!

I am also grateful to my younger brother, Zaw Lin Aung. Without his support, my life and study would not have been so smooth. Thanks a lot, Zaw Zaw, for your help and support.

I would like to extend my sincere gratitude to my parents-in-law, U Ko Ko Lay and Daw Than Myint Oo, for their kind understanding and support.

My heartfelt thanks go to my beloved wife, Khaing Hnin Ko. She always supports me whenever I am in need. She deserves every success and achievement of mine too. Thank you, sweetheart for your enormous love, understanding, encouragement and kind support.

Last but not least, I would like to thank my dearest son, Khant Tikyi. He is always a major force to keep me moving forward. He also deserves all my achievement and success too. Thank you, Thar Thar, for your love! Everything is always for you! 


\section{TABLE OF CONTENTS}

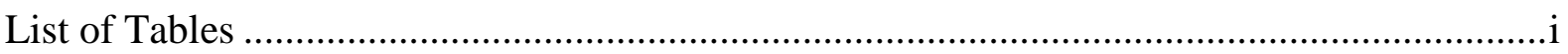

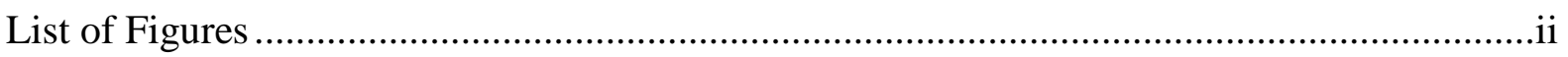

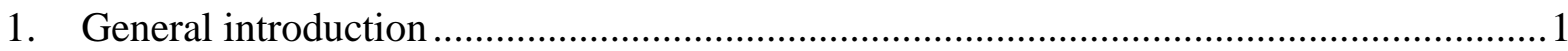

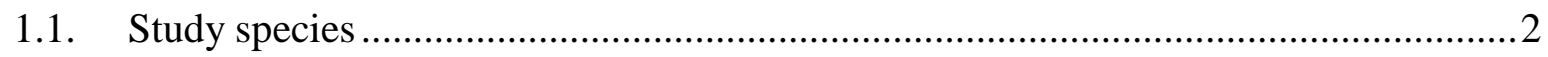

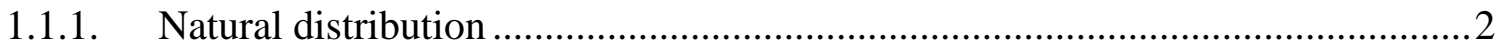

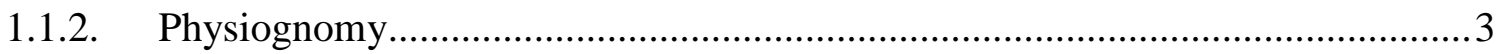

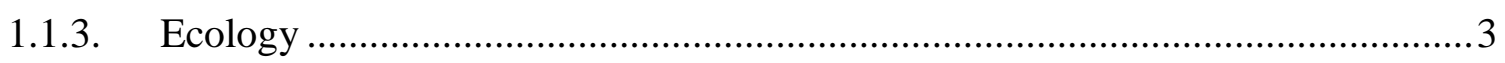

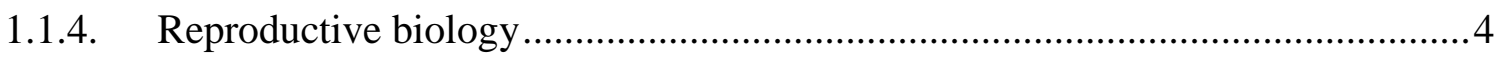

1.1.5. Management systems in natural teak forests ...............................................

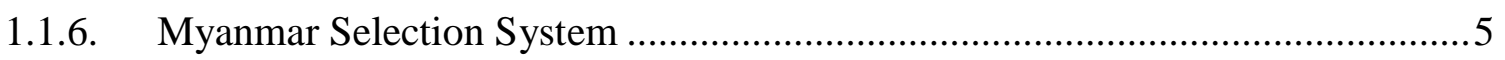

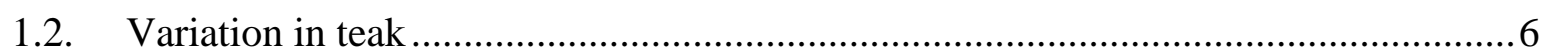

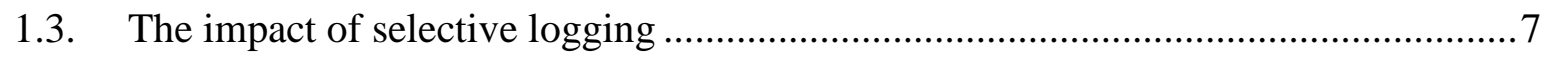

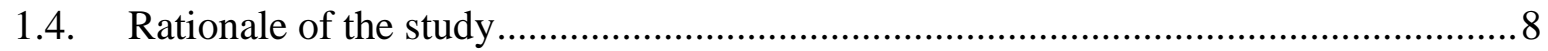

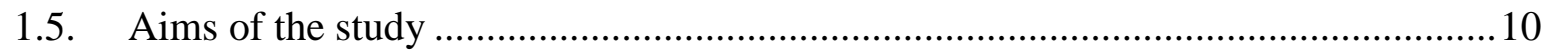

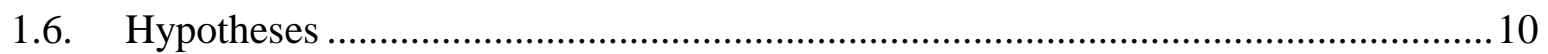

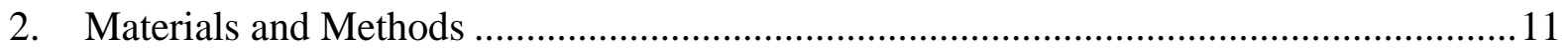

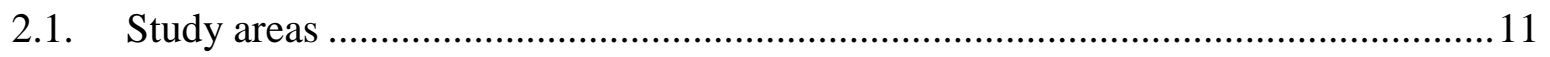

2.1.1. Unlogged and selectively-logged teak forests .......................................... 13

2.1.2. Teak populations in the southern region of Myanmar .................................... 14

2.1.3. Teak populations in the northern region of Myanmar .................................... 15

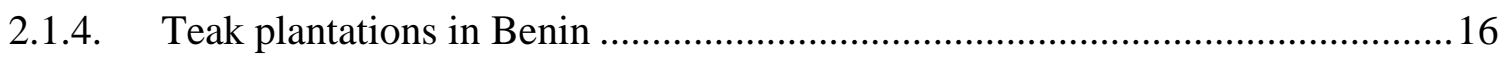

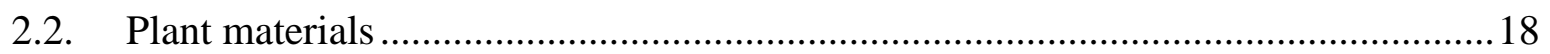

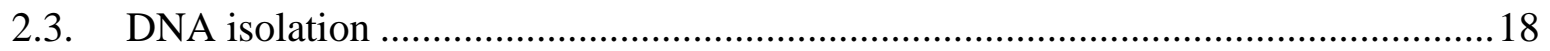

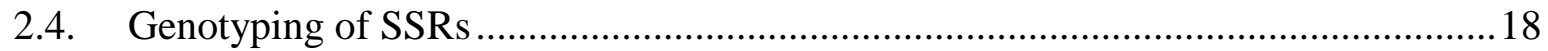

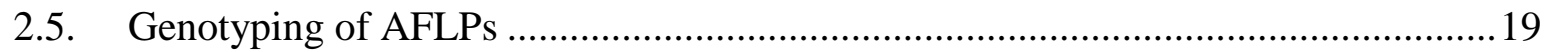

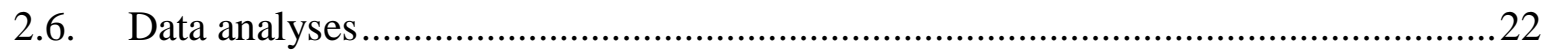




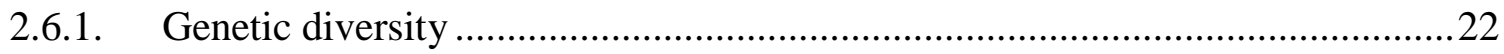

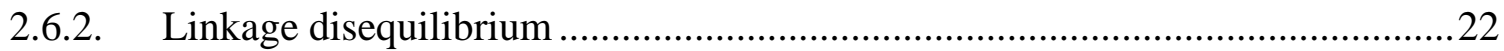

2.6.3. Significant tests for estimates of genetic diversity .......................................22

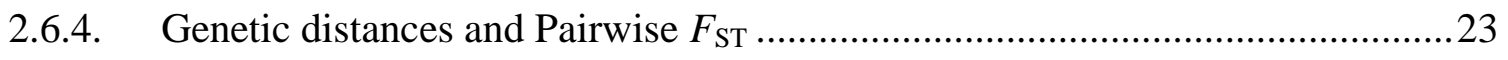

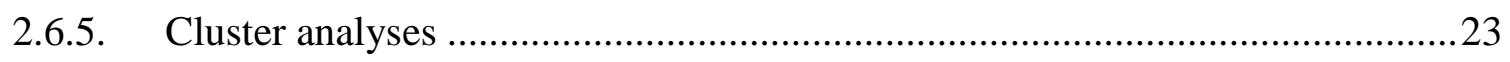

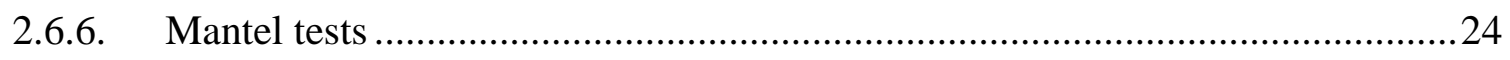

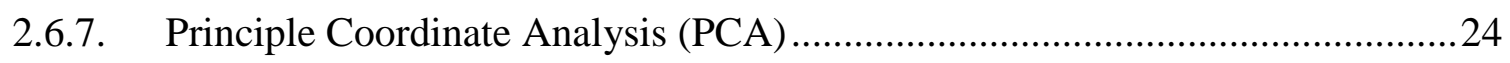

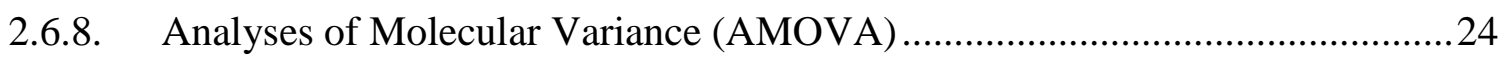

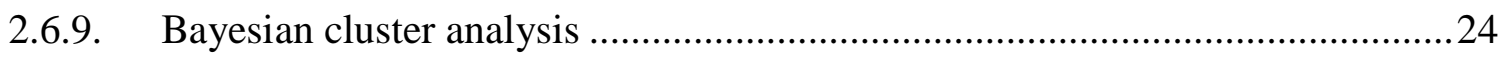

2.6.10. Locus-wise genetic differentiation $\left(G_{\mathrm{ST}}\right)$ for adults and regeneration ................25

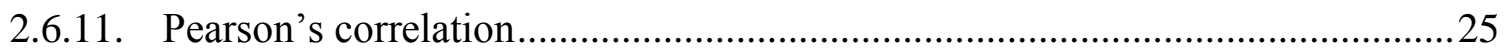

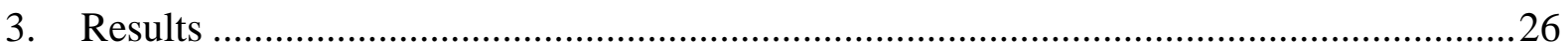

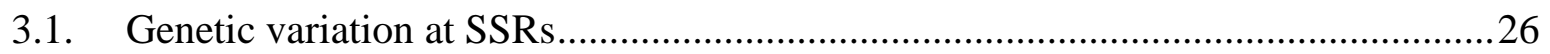

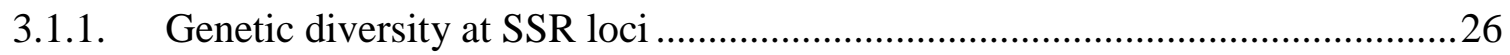

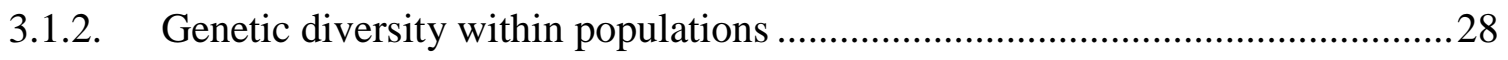

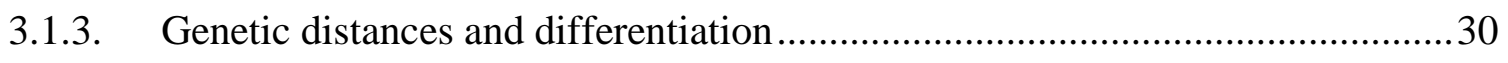

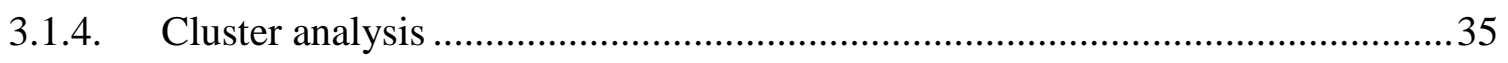

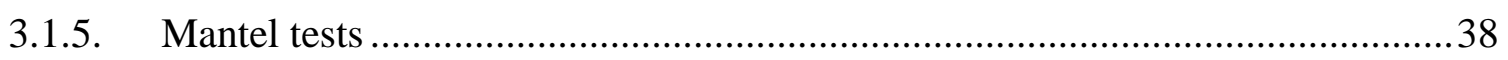

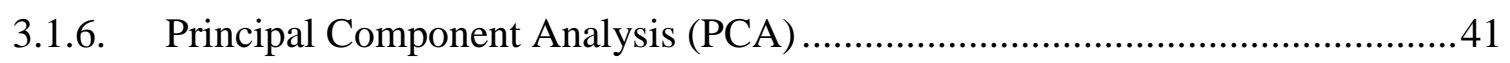

3.1.7. Analyses of Molecular Variance (AMOVA) .................................................. 44

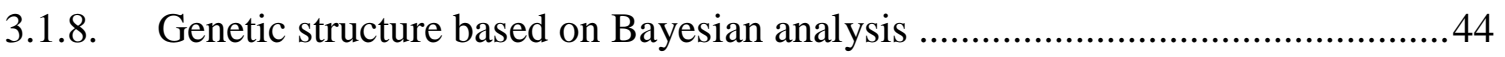

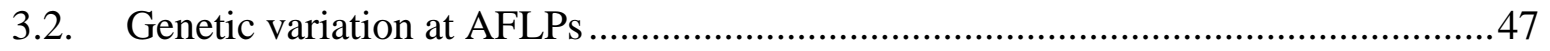

3.2.1. Genetic diversity within populations ...................................................... 47

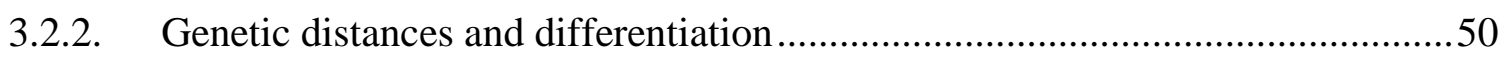

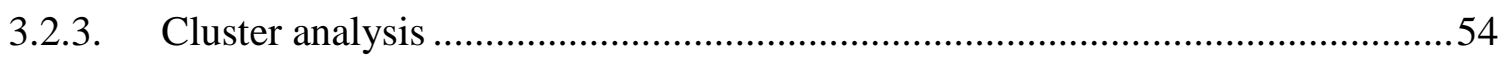

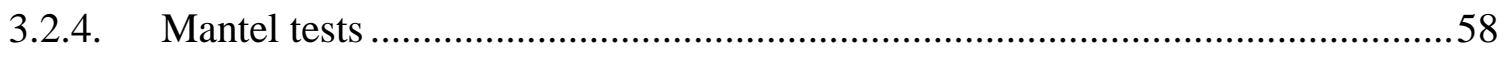

3.2.5. Principle Coordinate Analysis (PCA) …...................................................5 


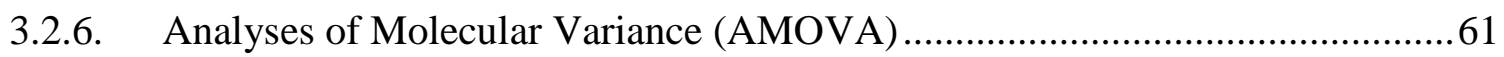

3.2.7. Genetic structure based on Bayesian analysis .................................................. 61

3.2.8. Genetic differentiation between adults and regeneration...................................62 62

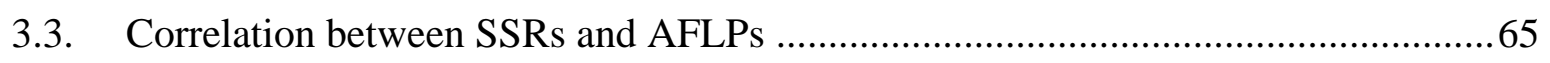

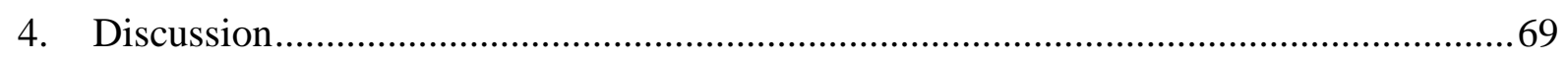

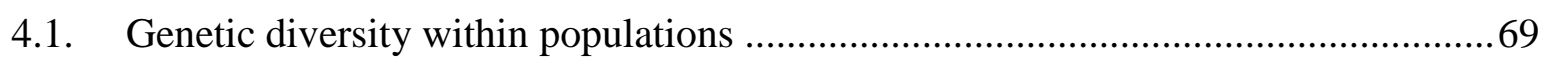

4.2. Genetic structure of $T$. grandis plantations and linkage disequilibrium ..................70

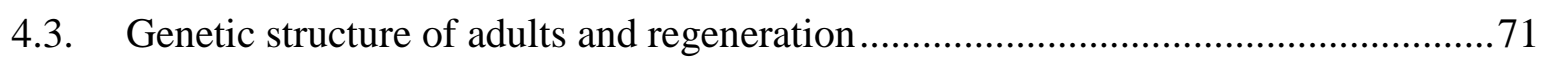

4.4. The impacts of selective logging on genetic variation of $T$. grandis .......................73

4.5. Genetic variation and structure of $T$. grandis among populations and regions ........75

4.6. Congruency and discrepancy between SSRs and AFLPs ..................................... 79

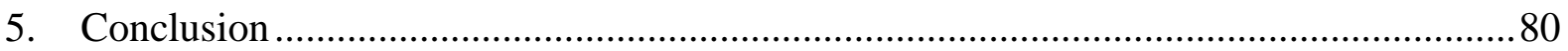

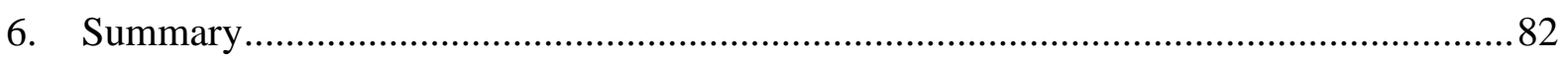

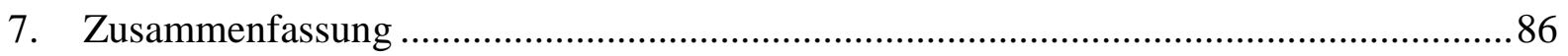

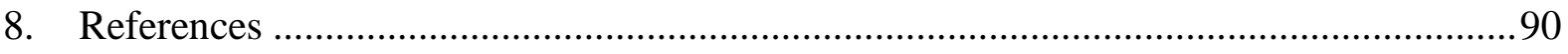

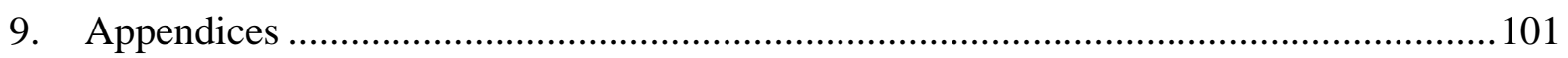




\section{List of Tables}

Table 1 Populations, regions, logging types, sample types, geographic information and logged years of the sampled populations of $T$. grandis. .17

Table 2 Multiplexes of 10 SSR primers, their respective labelled dyes and primer sequences. .21

Table 3 Genetic diversity of $T$. grandis at 10 SSR loci. .26

Table 4 Genetic diversity within populations of $T$. grandis at SSRs...................................27

Table 5 Differences in genetic diversity of $T$. grandis at SSRs. .29

Table 6 Nei's unbiased genetic distances (1978) for adults (below diagonal) and regeneration (above diagonal) in $T$. grandis populations at SSRs.

Table 7 Pairwise $F_{\text {ST }}$ for adults (below diagonal) and regeneration (above diagonal) in $T$. grandis populations at SSRs

Table 8 Analyses of Molecular Variance (AMOVA) for each group of T. grandis at SSRs. 42 Table 9 Analyses of Molecular Variance (AMOVA) among different groups of T. grandis at SSRs.

Table 10 Genetic diversity within populations of $T$. grandis at AFLPs. 48

Table 11 Differences in genetic diversity within T. grandis at AFLPs. 49

Table 12 Nei's unbiased genetic distances (1978) for adults (below diagonal) and regeneration (above diagonal) in T. grandis populations at AFLPs.

Table 13 Pairwise $F_{\text {ST }}$ for adults (below diagonal) and regeneration (above diagonal) in $T$. grandis populations at AFLPs.

Table 14 Analyses of Molecular Variance (AMOVA) for each group of T. grandis at AFLPs.

Table 15 Analyses of Molecular Variance (AMOVA) for different groups of $T$. grandis at AFLPs.

Table 16 Comparison of SSRs and AFLPs for genetic diversity and differentiation of natural populations of different tree species. .78 


\section{List of Figures}

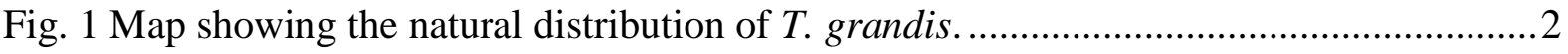

Fig. 2 Map showing locations of sampled T. grandis populations in Myanmar. .................... 12

Fig. 3 Sampling design for populations of $T$. grandis in Myanmar....................................... 12

Fig. 4 An adult (A) and regeneration (B) in T. grandis forests of Myanmar.......................... 13

Fig. 5 Teak tree in an unlogged stand (A) and a selectively-logged stand (B) in Myanmar... 14

Fig. 6 Electropherogram showing SSR markers of $T$. grandis ............................................2 20

Fig. 7 Electropherogram showing AFLP markers of T. grandis. ........................................20

Fig. 8 Neigbor Joining tree based on DC genetic distances (Cavalli-Sforza and Edwards,

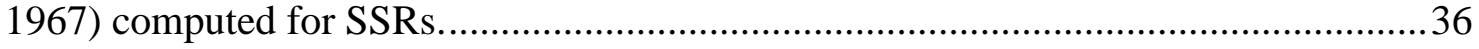

Fig. 9 UPGMA dendrogram based on DC genetic distances (Cavalli-Sforza and Edwards, 1967) computed for SSRs

Fig. 10 Relationship between geographic and genetic distances among adult and regeneration populations of $T$. grandis at SSRs .38

Fig. 11 Relationship between geographic and genetic distances among adult and regeneration populations of $T$. grandis in the sourthern region of Myanmar at SSRs. .39

Fig. 12 Relationship between geographic and genetic distances among adult and regeneration populations of $T$. grandis in the northern region of Myanmar at SSRs .40

Fig. 13 Principal Component Analysis (PCA) for T. grandis populations at SSRs. 41

Fig. 14 Clusters of $34 T$. grandis populations based on the admixture model at SSRs..........45

Fig. 15 Population structure of 34 T. grandis populations at SSRs ...................................... 45

Fig. 16 Clusters of 34 T. grandis populations based on the no-admixture model at SSRs......46

Fig. 17 Population structure of 34 T. grandis populations at SSRs.......................................46

Fig. 18 UPGMA dendrogram based on Nei's genetic distances (1978) at AFLPs.................54

Fig. 19 Relationship between geographic and genetic distances among populations of $T$. grandis at AFLPs

Fig. 20 Relationship between geographic and genetic distances among populations of $T$. grandis in the southern region of Myanmar at AFLPs..............................................56

Fig. 21 Relationship between geographic and genetic distances among populations of $T$. grandis in the northern region of Myanmar at AFLPs................................................57

Fig. 22 Principal Coordinate Analysis (PCA) of T. grandis populations at AFLPs................58

Fig. 23 Clusters of 34 T. grandis populations based on the admixture model at AFLPs. .......62

Fig. 24 Population structure of 34 T. grandis populations at AFLPs. 
Fig. 25 Difference in AFLP band frequency between adults and regeneration in T. grandis populations in the southern region

Fig. 26 Genetic differentiation between adults and regeneration at 71 AFLP markers in $T$. grandis populations in the southern region (A) and in the northern region (B) of Myanmar.

Fig. 27 Spearman's correlation between $H_{\mathrm{E}}$ from SSRs and $H_{\mathrm{j}}$ from AFLPs for $T$. grandis populations. .65

Fig. 28 Spearman's correlation between $H_{\mathrm{E}}$ from SSRs and $H_{\mathrm{j}}$ from AFLPs for $T$. grandis populations. (A) adults $(\mathrm{B})$ regeneration. .66

Fig. 29 Spearman's correlation between $H_{\mathrm{E}}$ from SSRs and $\mathrm{Br}$ from AFLPs for $T$. grandis populations.

Fig. 30 Spearman's correlation between $F_{\mathrm{ST}}$ from SSRs and $F_{\mathrm{ST}}$ from AFLPs for $T$. grandis populations .68 


\section{General introduction}

Genetic variation is prerequisite for evolutionary adaptability of forest tree (White et al., 2007; Lundqvist et al., 2008). Species with low level of genetic variation are unlikely to adapt to drastic environmental changes and are more susceptible to become extinct (Boshier and Amaral, 2004 ; White et al., 2007). Moreover, the amount of genetic variation within the tree species determines the potentials for improving the tree species through tree improvement programs (White et al., 2007; Lundqvist et al., 2008). Thus, conservation of genetic variation becomes increasingly importance not only for the stability and survival of forest ecosystems (White et al., 2007) but also for many possible uses in future (Boshier and Amaral, 2004 ).

Forest management systems, which usually involve alteration of stand structures for better yield and economic reasons, influence the historical patterns of genetic variation of the tree species by altering the effects of evolutionary factors (Finkeldey and Ziehe, 2004; Boshier and Amaral, 2004 ; White et al., 2007). Hence, knowledge of patterns of genetic variation of the tree species and their evolutionary factors are of great practical significance (White et al., 2007).

The patterns of genetic variation of forest trees are being assessed using genetic markers: isozymes, Amplified Fragment Length Polymorphisms (AFLPs), Simple Sequence Repeats (SSRs), Random Amplified Polymorphic DNA (RAPD), etc (Finkeldey and Hattemer, 2007). Due to different natures of markers, SSRs and AFLPs are widely applied in assessing the patterns of genetic variation of forest tree species nowadays.

Teak (Tectona grandis Linn. f.) is a tropical tree species which has important ecological and economic values. There is no comprehensive information on the patterns of genetic variation of this tree species in Myanmar. Moreover, information on genetic variation and temporal genetic structure of teak in managed forests is still lacking. Hence, investigations of the patterns of genetic variation of teak will provide information for conservation and sustainable utilization of this valuable tree species.

The present study thus deals with the application of SSRs and AFLPs to assess the patterns of genetic variation of teak in adult and regeneration stages in unlogged and selectively-logged forests in Myanmar, and additionally, in two teak plantations in Benin, West Africa. 


\subsection{Study species}

\subsubsection{Natural distribution}

Teak (Tectona grandis Linn. f.) belongs to the family Verbenaceae (also placed in the family Lamiaceae (Cantino, 1992 ; Anon., 2012)). It is one of the most valuable tropical tree species which naturally occurs in the South and South East Asian countries, within the range of latitudes between $9^{\circ}-25^{\circ} 30^{\prime} \mathrm{N}$ and longitudes between $73^{\circ}-104^{\circ} 30^{\prime} \mathrm{E}$ (Kaosa-ard, 1986; Gyi and Tint, 1998). Teak mostly occurs in the central and western parts of India, in the most parts of Myanmar, the northern parts of Thailand and some western parts of Laos (Troup, 1921; Kaosa-ard, 1986; Gyi and Tint, 1998). According to Gyi and Tint (1998), the total area of natural teak forests in those countries was about 27.9 million ha: 8.9 million ha in India, 16,000 ha in Laos, 16.5 million ha in Myanmar and 2.5 million ha in Thailand. High deforestation rates across the region lead to the actual occurrence of natural teak forests mostly in some parts of India and Myanmar nowadays (Gyi and Tint, 1998). Teak is naturalized in Indonesia, and the probable introduction of teak in Indonesia was during the period of Hindus in the beginning of fourteen century to sixteen century (Troup, 1921; Kadambi, 1972; White, 1991; Kaosa-ard, 1999).

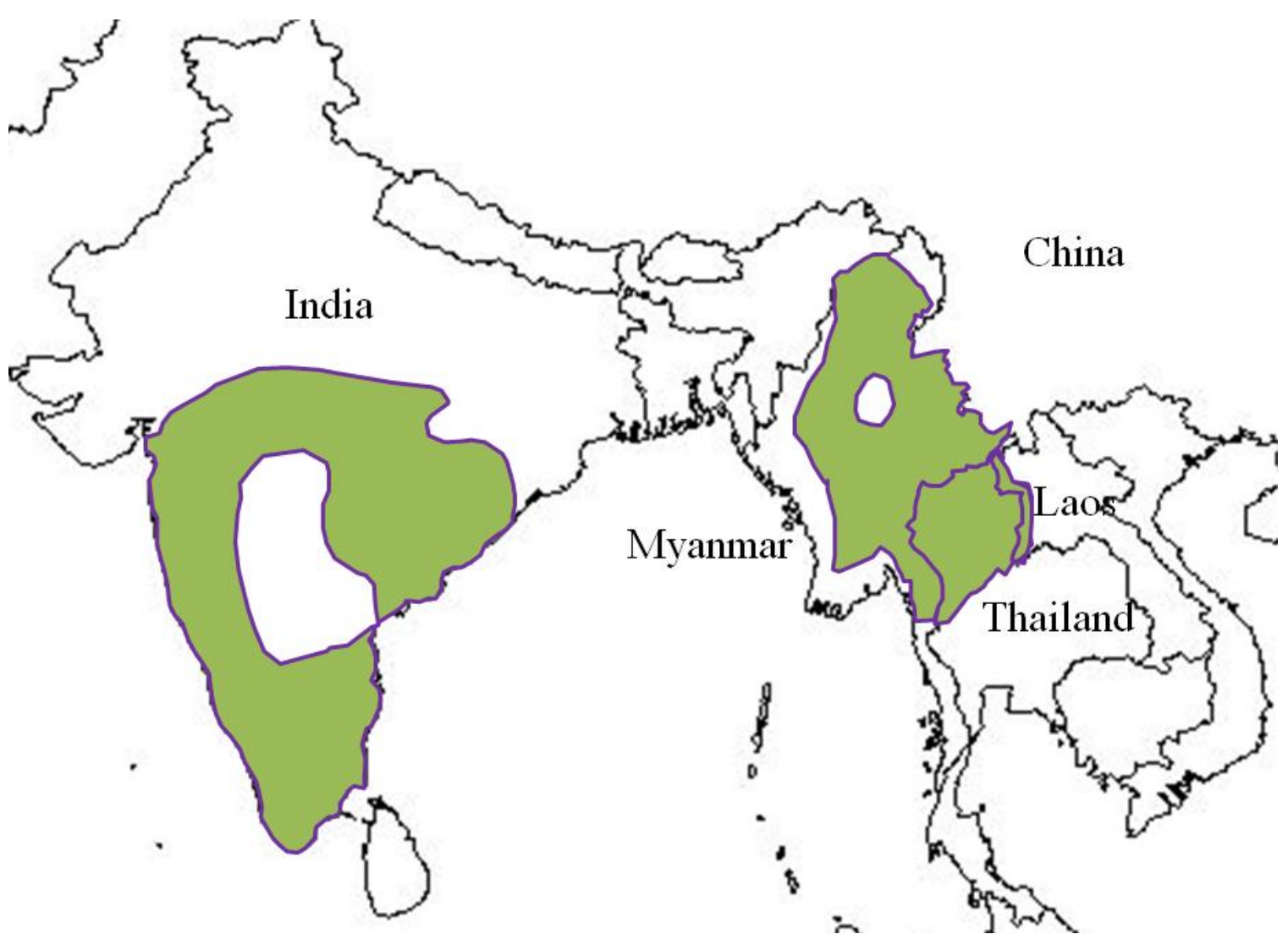

Fig. 1 Map showing the natural distribution of T. grandis (after Gyi and Tint, 1998). 


\subsubsection{Physiognomy}

Teak is a large deciduous tree with clean and straight bole (Troup, 1921) and it can grow up to more than $100 \mathrm{~mm}$ in diameter at breast height and $30-35 \mathrm{~m}$ in height. The sapwood is white-colored; the colors of the heartwood range from light brown, golden brown to dark brown (Tewari, 1992). The heartwood sometimes composes of dark stripes, oily, with characteristic odor, and it is extremely durable, seasons well and does not warp or split (Tewari, 1992). Bark is grey or light greyish brown (Troup, 1921). The fruit is round-shaped and stony or drupe type with a diameter of 5-20 mm and it has four seed chambers (Troup, 1921; Tewari, 1992).

\subsubsection{Ecology}

Teak naturally grows in a wide range of environmental conditions from the dry areas where annual rainfall is about $500 \mathrm{~mm}$ to moist areas where annual rainfall is about $5000 \mathrm{~mm}$ (Kaosa-ard, 1981). The areas having annual rainfall between $1200 \mathrm{~mm}$ and $2500 \mathrm{~mm}$ accompanied with a dry season (monthly rainfall less than $50 \mathrm{~mm}$ ) of three to five months are optimal for the growth of the species (Kaosa-ard, 1981).

Teak grows best on well-drain alluvial soils derived from limestone, schist, genesis, shale, some volcanic rocks and basalt (Kaosa-ard, 1981). The species is frequently referred as a calcareous species as it thrives best on soil with a high amount of calcium (Ca) (Kaosa-ard, 1981; Tewari, 1992). Soil $\mathrm{pH}$ in teak forests ranges from 5.0 to 8.0 (Kulkarni, 1951) and the optimum pH for best growth and quality lies between 6.5 and 7.5 (Kaosa-ard, 1981; Tewari, 1992). Teak does not grow in persistent inundated soil.

Teak is a pronounced light demanding tree species which always requires high intensity of light for its growth and development (Troup, 1921; Kaosa-ard, 1998). Teak regeneration is abundantly found on the sites with open canopy, where overhead light is available to them (Troup, 1921; Lwin, 2001). It will not tolerate suppression at any stages of life, and requires fair amount of side room for its proper development (Troup, 1921). Improved light condition followed by logging and bamboo flowering in natural teak stands induces significant abundance of teak regeneration and growth of teak saplings (Thein et al., 2007).

Temperature plays an important role for the growth and development of teak. The optimal temperature usually lies between $27^{\circ} \mathrm{C}$ and $36^{\circ} \mathrm{C}$ (Gyi, 1972; Kaosa-ard, 1977). Teak does 
not tolerate frost (Troup, 1921). Under the frosty condition, seedlings and saplings are highly damaged. Thus, teak occurs below 700 m above sea level (Troup, 1921; Kaosa-ard, 1981).

The growth and development patterns of teak differ with local climatic conditions and seasonal patterns. For instances, active growth of teak generally occurs between April and September in India, Laos, Myanmar and Thailand but between November and March in Indonesia (Tewari, 1992). In Myanmar, teak sheds leaves from November to January and remains leafless until March. New leaves appear from April to June. Flowering always takes place from June to August or September and the fruits ripen from November to January and fall between February and April (Troup, 1921; Tewari, 1992).

\subsubsection{Reproductive biology}

Teak is a diploid species $(2 \mathrm{n}=36)$ (Gill et al., 1983). Flowers are bisexual and hermaphroditic (Finkeldey and Hattemer, 2007). The tree has white and small (6-8mm in diameter) flowers having six sepals, six white petals, six stamens and a pistil. These small flowers occur in a large terminal panicle (Troup, 1921); each panicle has 1,200- 3,700 flowers (Bryndum and Hedegart, 1969).

The opening of teak flowers lasts for one day and flowers will open in the morning, and they will drop in the evening or the next morning if there is no pollination (Bryndum and Hedegart, 1969). Pollination is optimal between 11.30 a.m and 13.00 p.m (Hedegart, 1973).

Teak is a mainly insect-pollinated (Hedegart, 1976) and cross-pollinating species (Bryndum and Hedegart, 1969; Hedegart, 1973). Low success rates have been reported for controlled self-pollination (Bryndum and Hedegart, 1969). Thus, teak is noted as partially selfincompatible tree species (Tangmitcharoen and Owens, 1997). The extent of selfcompatibility is as low as $5.5 \%$ in this self-pollination experiment (Bryndum and Hedegart, 1969; Hedegart, 1973). Only few self-pollinated flowers (less than 1\%) develop into fruits (Hedegart, 1976). Nonetheless, a genetic marker-based study suggests that teak has mixed mating system (Finkeldey and Hattemer, 2007). 


\subsubsection{Management systems in natural teak forests}

Forest management systems in the natural teak forests are not quite variable among India, Laos, Myanmar and Thailand. For example, in India, selection systems with improvement felling are applied in moist semi-evergreen forests, coppice systems are practiced in low quality forests, and clear fellings are employed together with conversion to uniform system in high teak forests (Kumaravelu, 1991; Gyi and Tint, 1998). In Laos and Thailand, selection systems were reported to be the major forest management systems (Kaosa-ard, 1991; Pengduoang, 1991). Due to severe deforestation, commercial felling in the natural teak forests of those two countries has been prohibited nowadays (Kaosa-ard, 1991; Pengduoang, 1991). In Myanmar, selection system is the major forest management system being employed in natural teak forests.

\subsubsection{Myanmar Selection System}

In Myanmar, scientific forest management has been started with the introduction of so-called Brandis Selection System which has gradually evolved to what is now known as Myanmar Selection System (MSS) since 1856 (Dah, 2004). Since then, the MSS has been the main forest management system being practiced in the natural teak forests in Myanmar.

The MSS is a system based on the selective removal of trees with fixed minimum diameters from multi- tree species forests. The system is effectively practiced by division of forest lands into a felling series which contain 30 blocks of approximately equal yield. The whole felling series is completed in a felling cycle of 30 years. Thus, selective felling is carried out in specific block in a given year. The amount of timber volume is controlled by annual allowable cut which is determined for every felling series based on sustained yield management.

Under the MSS, extractable diameter limit of teak trees differ with regards to the type and growth condition of forests: $73 \mathrm{~cm}$ dbh in moist teak forest types with good growth and 63 $\mathrm{cm}$ dbh in drier types (Dah, 2004). For other hardwoods in teak forests, diameter limit varies by species.

Teak trees are girdled and left standing dry for 3 years before felling. Girdling is a centuryold practice being employed in harvesting of teak trees in Myanmar. This practice helps girdled teak well seasoning and floating in the river which has been one of the major 
transportation systems of teak logs since former times. Nowadays, green felling is increasingly practiced in most teak working circles due to the increased demand of teak timber and improved transportation conditions.

Under the MSS, some teak trees which have reached target diameter limit are intentionally left if there are no enough seed trees. Unhealthy but marketable trees are also removed if the trees are unlikely to survive until the next felling cycle. The MSS is not solely a system for selective logging of target diameter trees but also a system integrated with other cultural and silvicultural operations (Kyaw, 2003) to assist growth of natural regeneration and to protect young and immature trees.

\subsection{Variation in teak}

Teak differs in phenology in natural provenances (Bedell, 1989; Kaosa-ard, 1999) and also varies in floral biology and seed biology (Tangmitcharoen and Owens, 1997; Gunaga and Vasudeva, 2002; Vasudeva et al., 2004 ). Moreover, it varies greatly in fruit size, weight and viability among natural provenances with different ecological conditions (Palupi and Owens, 1998; Indira, 2003). Teak varies greatly in wood quality among provenances in India (Kjaer et al., 1999; Varghese et al., 2000; Bhat and Priya, 2004).

In Myanmar, teak provenances show significant differences in growth, morphological characteristics and correlation with geo-climatic factors (Lwin et al., 2010). Most of the morphological traits in teak provenances are negatively correlated with the latitude, and growth traits and crown diameter of teak are positively correlated with the mean annual rainfall (Lwin et al., 2010). Local provenances in Bago Yoma of Myanmar show superior performances than others and hence, the local provenances are suggested as the best seed sources for the plantation program in the Bago Yoma (Lwin et al., 2010).

Genetic variation of teak has been investigated using isozyme markers (Kjaer et al., 1996), RAPD (Nicodemus et al., 2003; Parthiban et al., 2003), AFLPs (Shrestha et al., 2005; Minn, 2007) and nuclear SSRs (Fofana et al., 2009). Genetic variation of teak mostly occurs within populations in those studies. Teak from India provenances exhibits a strong genetic differentiation from Thailand, Indonesian and African provenances (Nicodemus et al., 2003; Shrestha et al., 2005). Four main clusters of genetic variability have been reported based on SSR markers: two clusters in India with high level of genetic diversity, one cluster in 
Thailand and Laos with lower genetic diversity and another cluster in central Laos with very low genetic variability (Fofana et al., 2009).

Minn (2007) investigated genetic variation of teak in Myanmar with three populations in the Bago Yoma and an additional population in another area using AFLP markers. Genetic diversity of teak populations in Myanmar is found to be relatively high as revealed by AFLPs, and genetic variation mostly occurs within populations (Minn, 2007). However, there is no variation among teak populations revealed by chloroplast SSR markers (Minn, 2007). The author suggested conducting further investigation to cover the whole natural range of teak in Myanmar.

\subsection{The impact of selective logging}

The effects of logging on tropical forest ecosystem are manifold, from significant alterations of physical structure of the forest to changes in species abundance and species composition (Bawa and Seidler, 1998). Selective logging is frequently referred as dysgenic selection due to selection against desirable phenotypic trees. It is also argued that selective logging reduces genetic diversity (drift) and increases inbreeding of the forest tree species. For example, logging significantly reduces genetic diversity of Pinus strobus (Buchert et al., 1997) and outcrossing rate in Pterocarpus macrocarpus (Liengsiri et al., 1998). Similarly, sharp reduction in genetic variability have been reported for Araucaria angustifolia Kuntze in selectively-logged stand and progenies (Medri et al., 2003).

On the other hand, no impact of logging has been reported for some tree species. For examples, selective logging does not significantly affect inbreeding in Shorea megistophylla (Murawski et al., 1994), inbreeding and gene dispersal in Carapa guianensis Aubl. (Cloutier et al., 2007) and the breeding system of Dryobalanops aromatica (Kitamura et al., 1994) and Dipterocarpus obtusifolius (Chaisurisri et al., 1997). Correspondingly, logging does not significantly induces changes in genetic structure of Scaphium macropodum stands before and after logging in the same stands though there is significant impact in regenerated stands compared with adjacent unlogged Scaphium macropodum stands (Lee et al., 2002).

Furthermost, different tree species and their temporal stages reveal different intensity of changes on the level of genetic diversity after logging activities. For example, the impacts of logging on Shorea curtisii, Dryobalanops aromatica and Scaphium macropodum are 
different at their temporal stages (Wickneswari et al., 2004). The authors reported no significant change in genetic diversity for adults of Scaphium macropodum and saplings of Dryobalanops aromatica and Shorea curtisii immediately after logging. However, they observed a significant reduction in genetic diversity of seedlings and adults of Shorea curtisii and also a substantial genetic erosion in adults of Shorea curtisii and Scaphium macropodum (Wickneswari et al., 2004).

The impact of selective logging on genetic variation of teak in Myanmar is not known yet. I am also not aware of any studies related to the impact of selective logging on genetic structure and variation of teak in natural populations in other countries.

\subsection{Rationale of the study}

Myanmar has a forest cover of 31.7 million ha (FAO, 2011) which is approximately half of the total area of the country, serving as a major source for production of valuable wood and non-wood products and protective functions. High deforestation and non-sustainable use of forests are serious problems in Myanmar. Hundreds of thousand hectares of forests are annually lost (435,000 ha/year (1990-2000) and 310,000 ha/year (2000-2010) (FAO, 2011), and the growing stock of teak has been increasingly declined from 107 million $\mathrm{m}^{3}$ to 91 million $\mathrm{m}^{3}$ within the last 20 years (FRA, 2010). Consequently, the long-term existence and sustainability of teak forests and the genetic resources of teak in the country are at risk.

The forests in Myanmar are being managed under Myanmar Selection System (MSS). The system is based on the selective removal of the best trees having already attained the target diameter. This system is expected to affect the remnant forest structure since the best trees are taken out and consequently young and lower diameter trees are deliberately left in the forest. The selection system has been frequently referred as dysgenic selection (Finkeldey and Hattemer, 2007) since it favors the reproduction of inferior trees in the forest. However, the intensity and impact of selective logging on genetic structure of teak forests in Myanmar are still not known.

Not only genetic variation of adult trees but also genetic variation of regeneration are equally important because regeneration plays an important role for shaping the genetic structures of future forests and sustainable productivity (Koski and Stahl, 2000). Currently, genetic structures of teak regeneration in natural populations are still unknown. Hence, the 
assessment of genetic variation of not only adults but also teak regeneration will help us to develop sustainable management strategies for teak forests.

The patterns of genetic variation of forest trees are being assessed using different genetic markers. Molecular markers are the most advanced and effective genetic tools to assess the level of polymorphisms of organisms as they provide reliable information than morphological and isozyme markers do. These markers are nowadays widely applied in detecting genetic variation of forest trees. The application of molecular markers to study the genetic variation within tropical trees is, for example, reviewed by Finkeldey and Hattemer (2007).

The two genetic markers, SSRs and AFLPs, are widely applied markers in population genetics. Simple Sequence Repeats (SSRs) are highly variable markers which have a codominant mode of inheritance. These selectively neutral SSRs have become one of the most popular marker types in population genetics (Freeland, 2005; Weising et al., 2005). Generally, SSR primers are species-specific and the development of primers are costly (Freeland, 2005). Fifteen teak specific SSR markers have been successfully developed (Verhaegen et al., 2005). These markers can be used as a tool for investigating the mating system, gene flow, and population dynamics for sustainable management of teak forests and for in situ conservation purposes (Verhaegen et al., 2005). Genetic variation of teak in India, Laos and Thailand have been investigated using these SSR markers (Fofana et al., 2009), but teak in Myanmar has not been investigated yet. Thus, the investigation of genetic variation of teak using these SSR markers will provide invaluable information for the conservation and management of genetic resources of teak in Myanmar, and it will fill up information gaps for genetic structure and variation of teak for the whole range of the natural distribution.

Amplified Fragment Length Polymorphisms (AFLPs) are anonymous biallelic markers which have been frequently used to characterize genetic variation in species with few or no genomic resources developed (Vos et al., 1995). AFLPs can be studied in any species even if no sequence knowledge is available. A large number of polymorphic DNA fragments can be separated in a single run. Information obtained at a single locus is limited since only the presence or absence of a fragment with a particular length is recorded. Thus, AFLPs are interpreted as dominant markers (Weising et al., 2005). The AFLP technique was successfully used to characterize genetic variation of four teak populations in Myanmar (Minn, 2007). The author suggests conducting further studies with populations from different geographical regions to cover most parts of the distribution of teak in the country. 
Minn (2007) also applied chloroplast SSR (cpSSR) markers together with AFLPs to characterize genetic variation of teak in Myanmar. Apart from his investigation, I am not aware of the combined application of the two types of markers in population genetics of teak. More importantly, no investigation has been conducted to assess genetic variation of teak in Myanmar using the combined application of SSRs and AFLPs before. Since these two markers show differences with regard to variation levels, numbers of investigated loci, mode of inheritance, and other features, a combined application of these two markers will provide a comprehensive view on patterns of genetic variation of the tree species at least at putatively 'neutral' loci. (Stefenon et al., 2007).

\subsection{Aims of the study}

The main objectives of the study are as follows:

- To examine the patterns of genetic variation of teak in natural populations.

- To examine the impact of selective logging on genetic structures of teak.

- To investigate the genetic differentiation among adult teak trees and natural regeneration.

\subsection{Hypotheses}

The following hypotheses are tested:

- There is high genetic variation of teak in natural populations.

- There is no impact of selective logging on genetic structure of teak.

- There is no genetic differentiation between adult trees and regeneration.

- There is genetic differentiation between populations in the northern and southern region of Myanmar. 


\section{Materials and Methods}

\subsection{Study areas}

Myanmar is a Southeast-Asian country located between $9^{\circ} 53^{\prime} \mathrm{N}$ and $28^{\circ} 25^{\prime} \mathrm{N}$ latitudes and $92^{\circ} 10^{\prime} \mathrm{E}$ and $101^{\circ} 10^{\prime} \mathrm{E}$ longitudes. It has a total area of $676,577 \mathrm{~km}^{2}$, stretching for $936 \mathrm{~km}$ from east to west to $2051 \mathrm{~km}$ from north to south.

In Myanmar, natural teak mostly occurs between $25^{\circ} 30^{\prime} \mathrm{N}$ and $10^{\circ} \mathrm{N}$ latitude (Gyi and Tint, 1998). In the east, teak occurs throughout the Shan State and extends beyond Thailand and Lao borders. In the northwest, it does not extend beyond the western watershed of Irrawaddy and Chindwin rivers; in the southwest, it occurs on the west bank of Irrawaddy into the foothill of the Rakkhine Yoma in decreased abundance to approximately $18^{\circ} \mathrm{N}$ latitude (Gyi and Tint, 1998). Teak does not occur in the drier parts in the central region of the country, in the southern most parts and in the extremely northern most parts of the country, in the tidal areas in the Irrawaddy delta and in the areas of altitude higher than $914 \mathrm{~m}$ (Troup, 1921; Gyi and Tint, 1998).

Teak is associated with other tree species in the forests of Myanmar. Teak is reported to be the most abundant and dominant species of mixed deciduous forests, comprising $34.6 \%$ and $13.9 \%$ of the total number of tree species $(\geq 5 \mathrm{~cm} \mathrm{DBH})$ in the eastern exposure and western exposure of typical Bago Yoma teak forests, respectively (Lwin, 2001). Teak grows well in the upper mixed deciduous forests of Myanmar, producing teak trees with cleaner and straight boles (Kermode, 1964). Depending on moist or dry sites of these teak forests, teak may be associated with Xylia dolabriformis, Terminalia tomentasa, Terminalia chebula, Terminalia pyrifolia, Pterocarpus macrocarpus, Adina cordifolia, Pentaceme siamensis, Shorea oblongifolia, and other tree and bamboo species (Kermode, 1964).

In the present study, sampled locations cover large parts of the distribution range of teak in the country: four population pairs in the northern region of Myanmar and another four population pairs in the southern region of Myanmar (Fig. 2). Sampling was conducted between October 2009 and January 2010. 


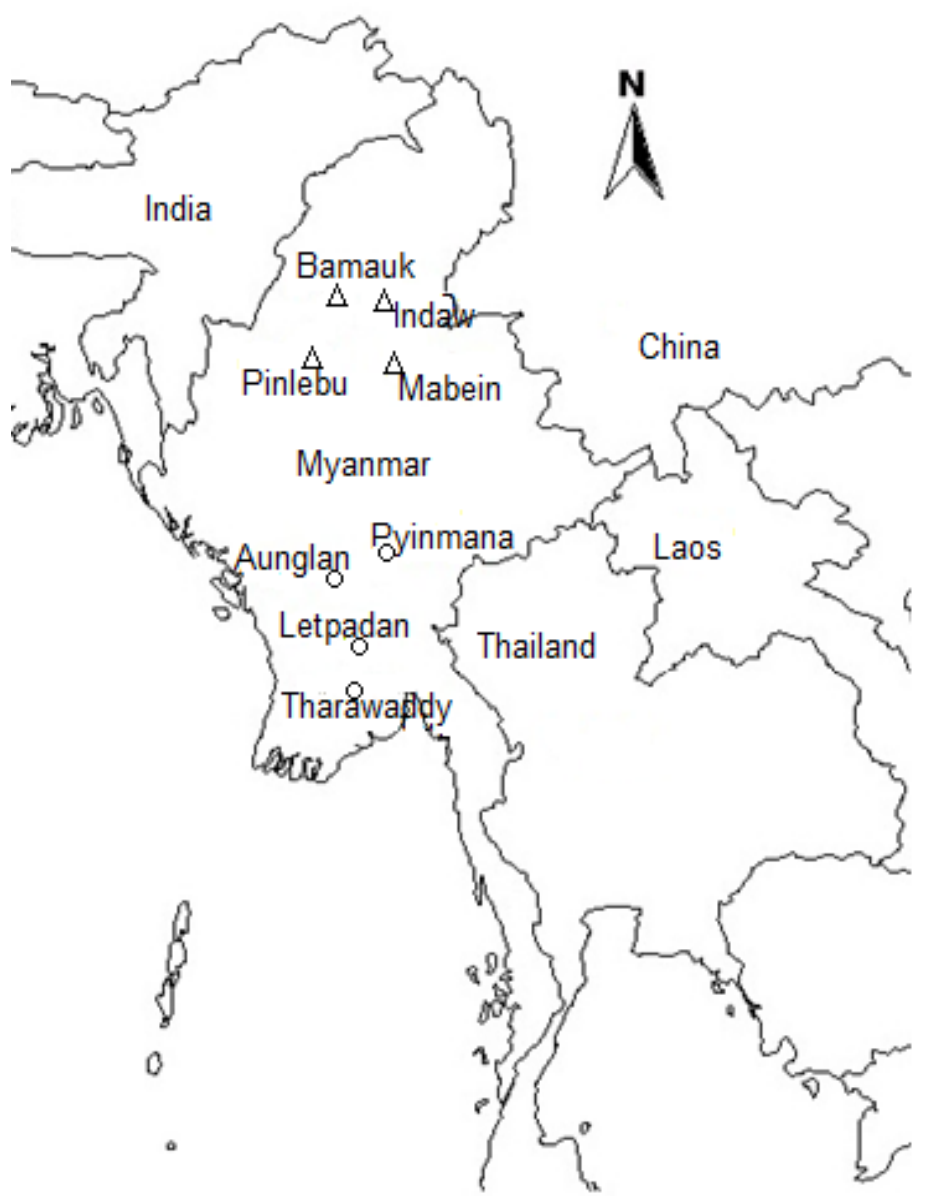

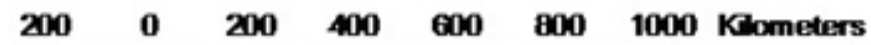

Fig. 2 Map showing locations of sampled T. grandis populations in Myanmar.

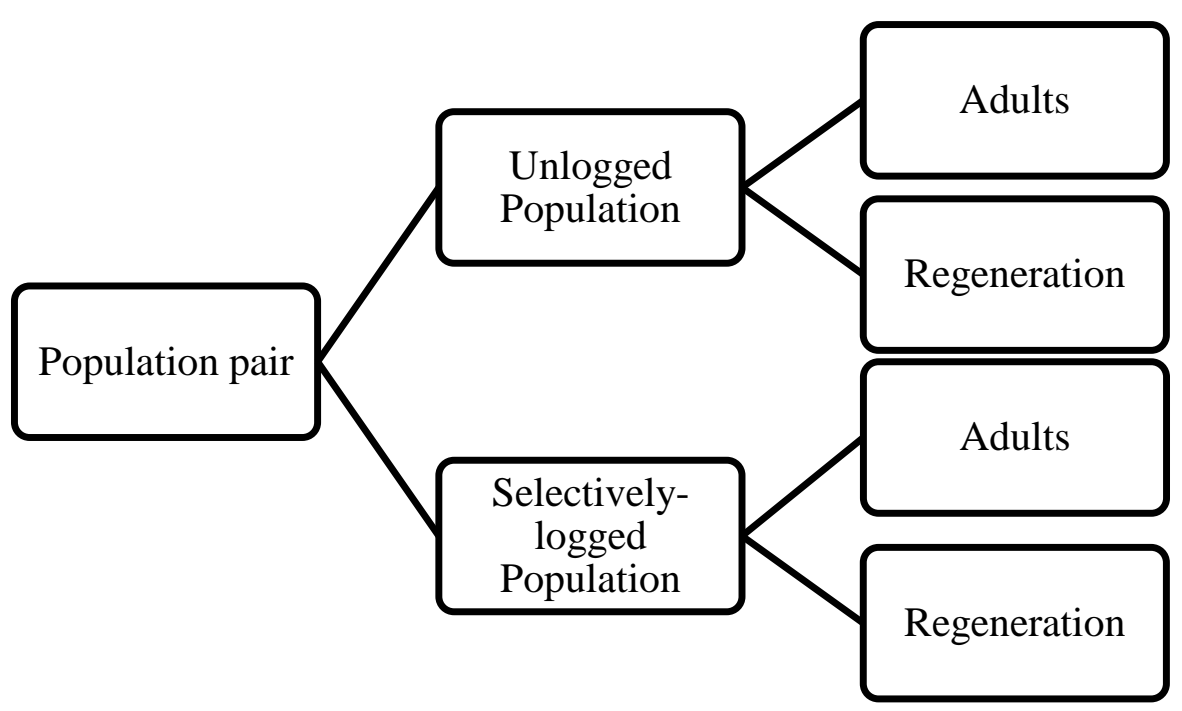

Fig. 3 Sampling design for populations of T. grandis in Myanmar. 


\subsubsection{Unlogged and selectively-logged teak forests}

A population pair consists of unlogged and selectively-logged teak stands (Fig. 3). These two populations are situated adjacent to each other in the area. In each population, adult and regeneration samples were collected (Fig. 4). A population was selected as an unlogged population if there was no recent logging but target diameter trees were highly abundant (Fig. 5). In most cases, information for previous logging in the unlogged populations was not available. Nonetheless, most unlogged populations were designated by the Forest Department for subsequent logging in a few years. In the same region, another adjacent natural population was selected as a selectively-logged population where there had been recent teak logging operations in the stand. Generally, target diameter teak trees were scarce in these selectivelylogged stands (Fig. 5).

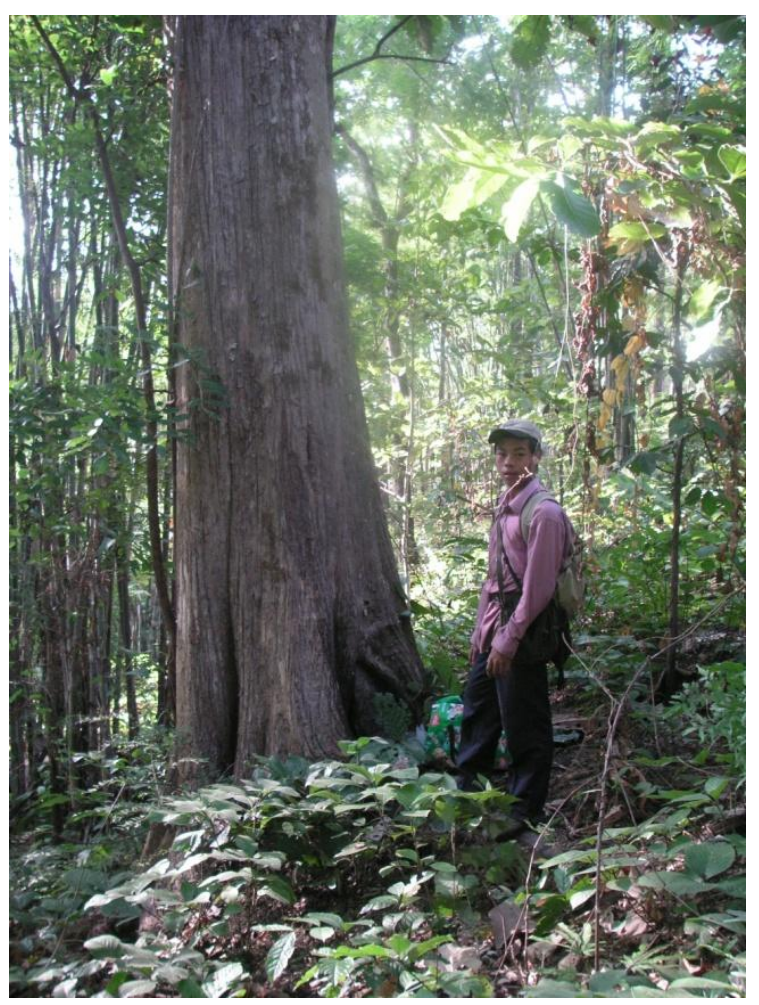

(A)

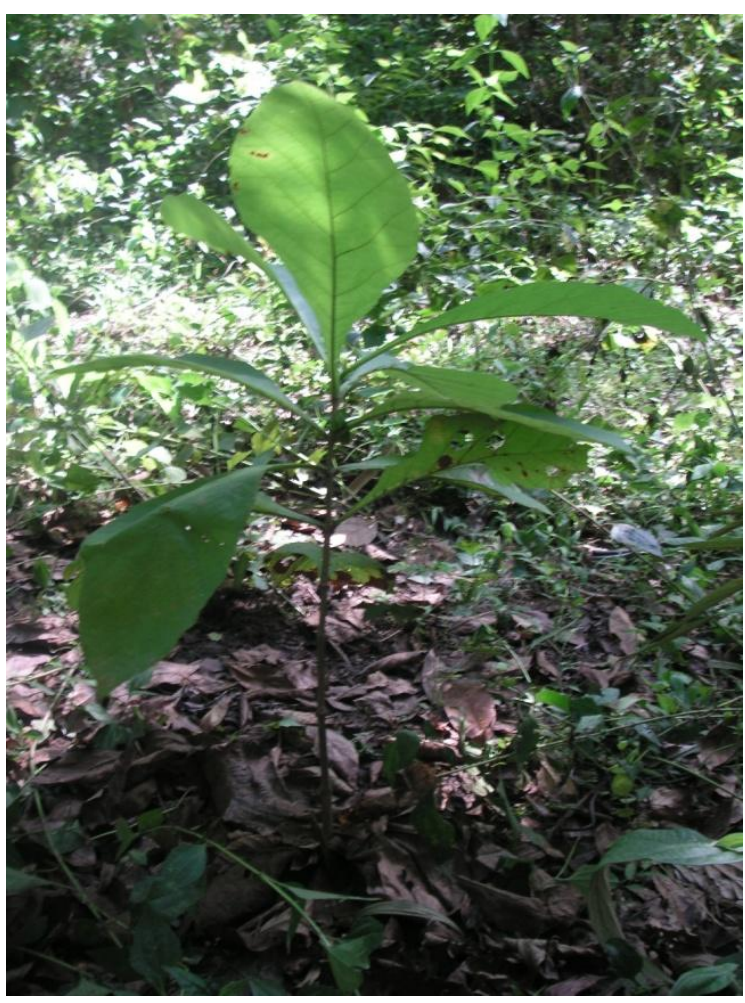

(B)

Fig. 4 An adult (A) and regeneration (B) in T. grandis forests of Myanmar. 

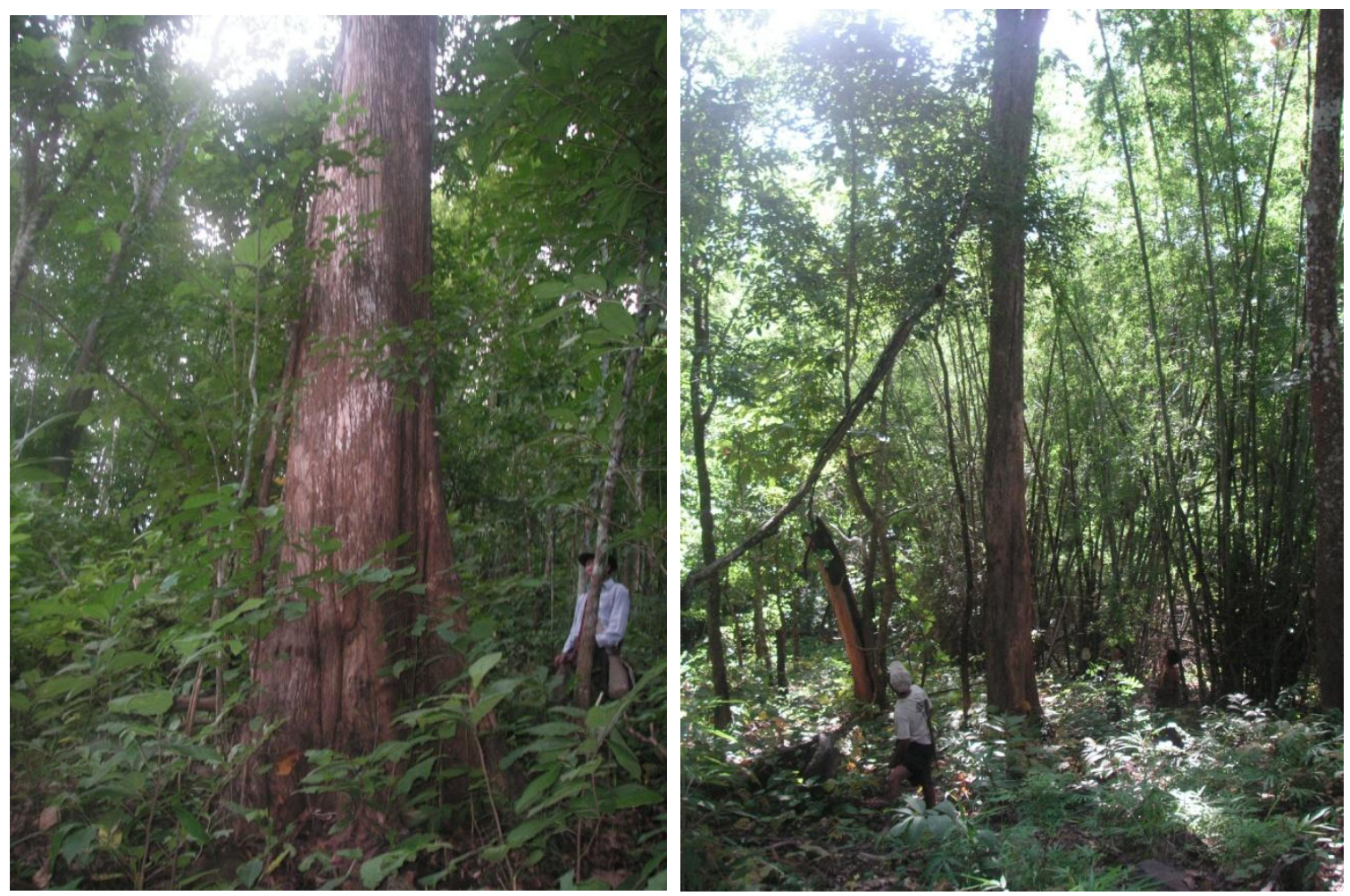

(A)

(B)

Fig. 5 Teak tree in an unlogged stand (A) and a selectively-logged stand (B) in Myanmar.

\subsubsection{Teak populations in the southern region of Myanmar}

Sampling was conducted in the four areas in the southern parts of Myanmar: Aunglan, Pyinmana, Letpadan and Tharawaddy (Fig. 2 and Table 1). Geographically, teak populations in Aunglan, Letpandan and Tharawaddy lie within Bago Yoma which is said to be home of teak forests in Myanmar. Teak populations in Pyinmana lie within the Shan Plateau.

In Aunglan, adult and regeneration samples were collected in unlogged (AUA and AUR) and selectively-logged (ASA and ASR) teak populations which were located in compartment No. 58 and No. 68 in the East Yoma Reserved Forest (RF), respectively. These populations lie in the northern part of Bago Yoma.

In Pyinmana, adults and regeneration in unlogged (PMUA and PMUR) and selectivelylogged (PMSA and PMSR) teak populations were sampled in Mel-Haw Protected Public Forests (PPF). 
In Letpadan, samples for adults and regeneration in unlogged (LUA and LUR) and selectively-logged (LSA and LSR) teak populations were collected in compartment No. 71 and No. 68 in the North Zarmari RF, respectively. These populations lie in the central part of the Bago Yoma.

Sampling for teak populations was conducted in Thonze RF in Tharawaddy in the southern part of Bago Yoma. Adults and regeneration in unlogged (TUA and TUR) and selectivelylogged (TSA and TSR) populations were sampled in compartment No. 93 and No. 95, respectively.

\subsubsection{Teak populations in the northern region of Myanmar}

Teak populations in the northern parts of Myanmar were sampled in Bamauk, Pinlebu, Indaw and Mabein (Fig. 2 and Table 1). Bamauk, Pinlebu and Indaw are located on the western side of the Irrawaddy River and Mabein is located on the eastern side of the River.

In Bamauk, adult and regeneration samples were collected in unlogged (BUA and BUR) and selectively-logged (BSA and BSR) teak populations in Mankat-M PPF and Manmaw-A PPF, respectively.

In Pinlebu, adults and regeneration were sampled in Kansalakar RF. The unlogged (PLUA and PLUR) and selectively-logged (PLSA and PLSR) populations were sampled in compartment No. 112 and No. 57, respectively.

In Indaw, unlogged (IUA and IUR) and selectively-logged (ISA and ISR) teak populations were sampled in compartment No. 16 and No. 12 in Kalon RF, respectively.

In Mabein, unlogged (MUA and MUR) and selectively-logged (MSA and MSR) teak populations were selected in compartment No. 38 and 178-179 in Nanme RF, respectively. In this selectively-logged stand, minimum diameter limit ( $\mathrm{dbh}$ ) for previous logging was $39 \mathrm{~cm}$. 


\subsubsection{Teak plantations in Benin}

Teak is one of the most widely planted tree species in its natural ranges and outside (Troup, 1921; Ball et al., 1999). Teak plantations have been established in Central America (e.g., Honduras, Guatemala, Panama, Costa Rica), Asian countries (e.g., Indonesia, India, Lao, Malaysia, Myanmar, Thailand) and African countries (e.g. Tanzania, Ghana, Togo, Nigeria, Benin) (Ball et al., 1999). In this study, leaves were sampled from two teak plantations which were successfully established in Benin. Samples were collected from Agrimery area for BEN1 plantation (Table 1). India was reported to be the seed source for the plantation which was established between 1949 and 1969 by the Taungya method (Ganglo and Lejoly, 1999). Samples for BEN2 plantation were collected from the Lama teak plantation which was established using seeds from former teak plantations in Benin and in Tanzania between 1985 and 1995 (Table 1) (Ganglo and Lejoly, 1999). 
Table 1 Populations, regions, logging types, sample types, geographic information and logged years of the sampled populations of T. grandis.

\begin{tabular}{|c|c|c|c|c|c|c|c|c|c|}
\hline No. & Populations & Region & UL/SL & $\begin{array}{l}\text { Adults } \\
\text { Abbr. }\end{array}$ & $\begin{array}{l}\text { Regen. } \\
\text { Abbr. }\end{array}$ & Latitude & Longitude & Altitude (m) & $\begin{array}{l}\text { Year } \\
\text { (Logged) }\end{array}$ \\
\hline 1 & Aunglan & $\mathrm{S}$ & $\mathrm{UL}$ & AUA & AUR & N19²1'10.5" & E9548'06.8" & 448 & NA \\
\hline 2 & Aunglan & $S$ & SL & ASA & ASR & N19¹9'10.7" & E9547'38.2" & 355 & 2005 \\
\hline 3 & Letpadan & $\mathrm{S}$ & UL & LUA & LUR & $\mathrm{N} 18^{\circ} 04^{\prime} 42.0^{\prime \prime}$ & E9606'55.9" & 219 & N/A \\
\hline 4 & Letpadan & $\mathrm{S}$ & SL & LSA & LSR & N1805'33.6" & E9606'53.3" & 253 & 2008 \\
\hline 5 & Tharawaddy & $\mathrm{S}$ & UL & TUA & TUR & N17º53'55.0" & E9600'57.6" & 177 & N/A \\
\hline 6 & Tharawaddy & $S$ & SL & TSA & TSR & N17º54'23.9" & E96 $01^{\prime} 03.5^{\prime \prime}$ & 167 & 2007 \\
\hline 7 & Pyinmana & $\mathrm{S}$ & UL & PMUA & PMUR & N19³2'23.7" & E96 29'08.9" & 794 & N/A \\
\hline 8 & Pyinmana & $\mathrm{S}$ & SL & PMSA & PMSR & N19³1'49.5" & E96 $29^{\prime} 03.2^{\prime \prime}$ & 512 & 2005 \\
\hline 9 & Bamauk & $\mathrm{N}$ & UL & BUA & BUR & $\mathrm{N} 24^{\circ} 13^{\prime} 41.0^{\prime \prime}$ & E95 $55^{\prime} 44.8^{\prime \prime}$ & 203 & N/A \\
\hline 10 & Bamauk & $\mathrm{N}$ & SL & BSA & BSR & $\mathrm{N} 24^{\circ} 22^{\prime} 51.2^{\prime \prime}$ & E95 $55^{\prime} 10.0^{\prime \prime}$ & 132 & 2008 \\
\hline 11 & Indaw & $\mathrm{N}$ & UL & IUA & IUR & N24이'35.3" & E96²10'36.4" & 281 & N/A \\
\hline 12 & Indaw & $\mathrm{N}$ & SL & ISA & ISR & $\mathrm{N} 24^{\circ} 07^{\prime} 26.1^{\prime \prime}$ & E96 $10^{\circ} 03.0^{\prime \prime}$ & 196 & 2007 \\
\hline 13 & Pinlebu & $\mathrm{N}$ & UL & PLUA & PLUR & N2349'54.7" & E95'22'51.7" & 249 & N/A \\
\hline 14 & Pinlebu & $\mathrm{N}$ & SL & PLSA & PLSR & N2349'57.6" & E95'34'21.7" & 566 & 2007 \\
\hline 15 & Mabein & $\mathrm{N}$ & UL & MUA & MUR & N2352'41.3" & E96²3'51.9" & 102 & N/A \\
\hline 16 & Mabein & $\mathrm{N}$ & SL & MSA & MSR & N23⒌'42.6" & E96³8'58.1" & 171 & 2007 \\
\hline 17 & Agrimery & Benin & & BEN1 & & N 7²'16.96" & E2 ${ }^{\circ} 10^{\prime} 8.65^{\prime \prime}$ & N/A & \\
\hline 18 & Lama & Benin & & BEN2 & & N 656'23.89" & E2 $2^{\circ} 9^{\prime} 57.97 "$ & N/A & \\
\hline
\end{tabular}

$S$ Southern Myanmar, $N$ Northern Myanmar, UL unlogged population, SL selectively-logged population, Regen. regeneration, Abbr. abbreviations, N/A data not available. 


\subsection{Plant materials}

Genomic DNA was extracted from dried leaves. Sampled leaves were immediately stored in silica gel to prevent fungal contamination. Silica gel was periodically checked and replaced to keep material dry.

To minimize the risk of sampling related trees, minimum distance between consecutive sampled adult trees was approximately $100 \mathrm{~m}$. Leaf samples were collected from teak regeneration which were the nearest to sampled adult teak trees.

Samples were collected from 50 adults and 50 seedlings from natural regeneration in each population. The total numbers of leaf samples collected from Myanmar were 1600. The total numbers of samples from Benin were 80. Therefore, the total number of samples was 1680 . However, due to unambiguous amplification of some samples at different analyses, the number of sample size used for the analyses varied.

\subsection{DNA isolation}

Genomic DNA was isolated from dried leaves by using the protocol of Qiagen DNA isolation Plant Mini Kit (Qiagen, Hilden, Germany). DNA was stored at $-20^{\circ} \mathrm{C}$.

\subsection{Genotyping of SSRs}

Teak specific SSR primers were applied in three different multiplex PCR (Verhaegen et al., 2005) (Table 2). The PCR amplification of SSRs was carried out in Peltier Thermal Cycler (PTC-0200 version 4.0, MJ Research) in a volume of $15 \mu$ l containing $2 \mu \mathrm{l}$ of DNA (10 ng) template DNA, $1.5 \mu$ of 10x PCR buffer (0,8 M Tris-HCl, 0,2 $\mathrm{M}\left(\mathrm{NH}_{4}\right)_{2} \mathrm{SO}_{4}$, Detergent), 1 $\mu \mathrm{l}$ of $\mathrm{MgCl}_{2}(25 \mathrm{mM}), 1 \mu \mathrm{l}$ of $\mathrm{dNTP}(2,5 \mathrm{mM}), 1 \mu \mathrm{l}$ of each forward and reverse primer (5 pM), $0.2 \mu \mathrm{l}$ of HOT FIREPOL ${ }^{\circledR}$ Taq-Polymerase $(5 \mathrm{U} / \mu \mathrm{l})$ and $7.3 \mu \mathrm{l}$ of $\mathrm{H}_{2} \mathrm{O}$ (HPLC).

The amplification was performed under the following conditions: initial denaturation at $95^{\circ} \mathrm{C}$ for $15 \mathrm{~min}, 30$ cycles of denaturation at $94^{\circ} \mathrm{C}$ for $30 \mathrm{~s}$, primer annealing at $52^{\circ} \mathrm{C}$ for $45 \mathrm{~s}$, primer extension at $72^{\circ} \mathrm{C}$ for $45 \mathrm{~s}$, and final extension at $72^{\circ} \mathrm{C}$ for $20 \mathrm{~min}$. The annealing temperature for primers $\mathrm{B} 02, \mathrm{~F} 01, \mathrm{Da} 12$ and $\mathrm{B} 03$ was increased to $57^{\circ} \mathrm{C}$ for better 
amplification. The forward primers were fluorescently labelled with 6-FAM, HEX or TAMRA (see Table 2).

The SSR markers were scanned on ABI 3100 Genetic Analyzer with an internal size standard (GS 500 ROX fluorescent dye) from Applied Biosystems. The sizes of fragments were identified by Gene Scan ver. 3.7 and scored by Genotyper ver. 3.7 computer programs (Applied Biosytems) (Fig. 6).

\subsection{Genotyping of AFLPs}

AFLP analysis was performed according to the protocol of Vos et al. (1995) with slight modifications. Two restriction enzymes EcoRI and $M s e$ I were used to digest total genomic DNA. The EcoRI and MseI adaptors were ligated to the ends of the restriction fragment. The restriction-ligation reaction was performed overnight at room temperature to generate DNA templates for PCR amplification consisting of two successive steps. The pre-selective amplification was carried out by using the primer combination of E01/M03, each consisting of one selective nucleotide A and G, respectively. The selective amplification was conducted by the primer combination of E41/M74 having the three selective nucleotides AGG and GGT, respectively. E41 was labelled with 6-FAM at its 5'-end in order to analyze fragment sizes on a capillary sequencer (ABI 3100 Genetic Analyzer). Both PCRs were carried out in a Peltier Thermal Cycler (PTC-0200 version 4.0, MJ Research). Amplified fragments were resolved on an ABI 3100 Genetic Analyzer with an internal size standard (GS 500 ROX fluorescent dye) from Applied Biosystems.

The size of AFLP fragments were identified by Gene Scan ver. 3.7 and were scored by Genotyper version 3.7 computer programs (Applied Biosytems) (Fig. 7). The fragments were manually scored and controlled from $50 \mathrm{bp}$ to $500 \mathrm{bp}$. A reproducibility test was carried out with 8 samples from three different independent runs. Seventy-one reproducible and reliable fragments were observed and chosen for the data analyses. 


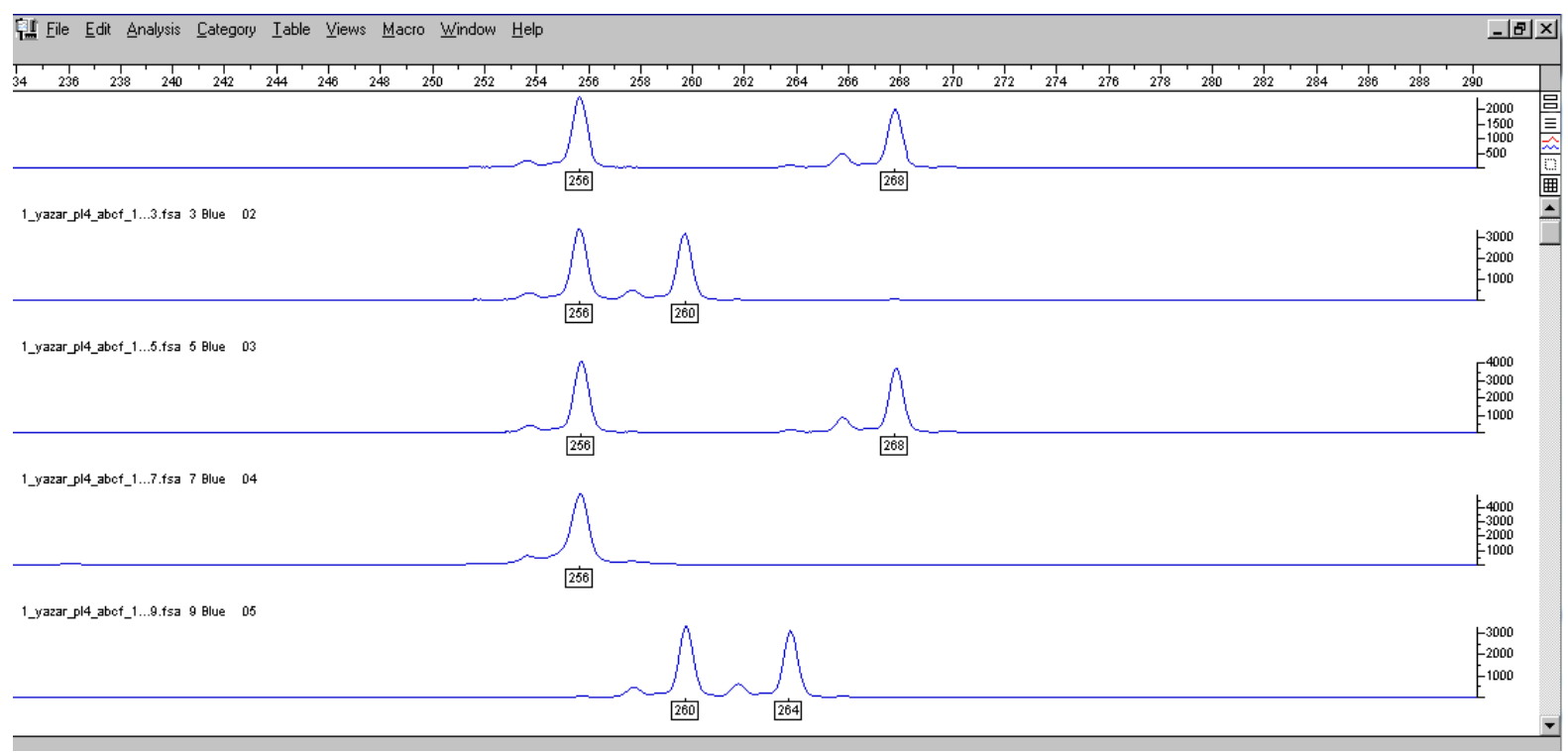

Fig. 6 Electropherogram showing SSR markers of T. grandis as visualized by GeneScan ver. 3.7 and Genotyper ver. 3.7.

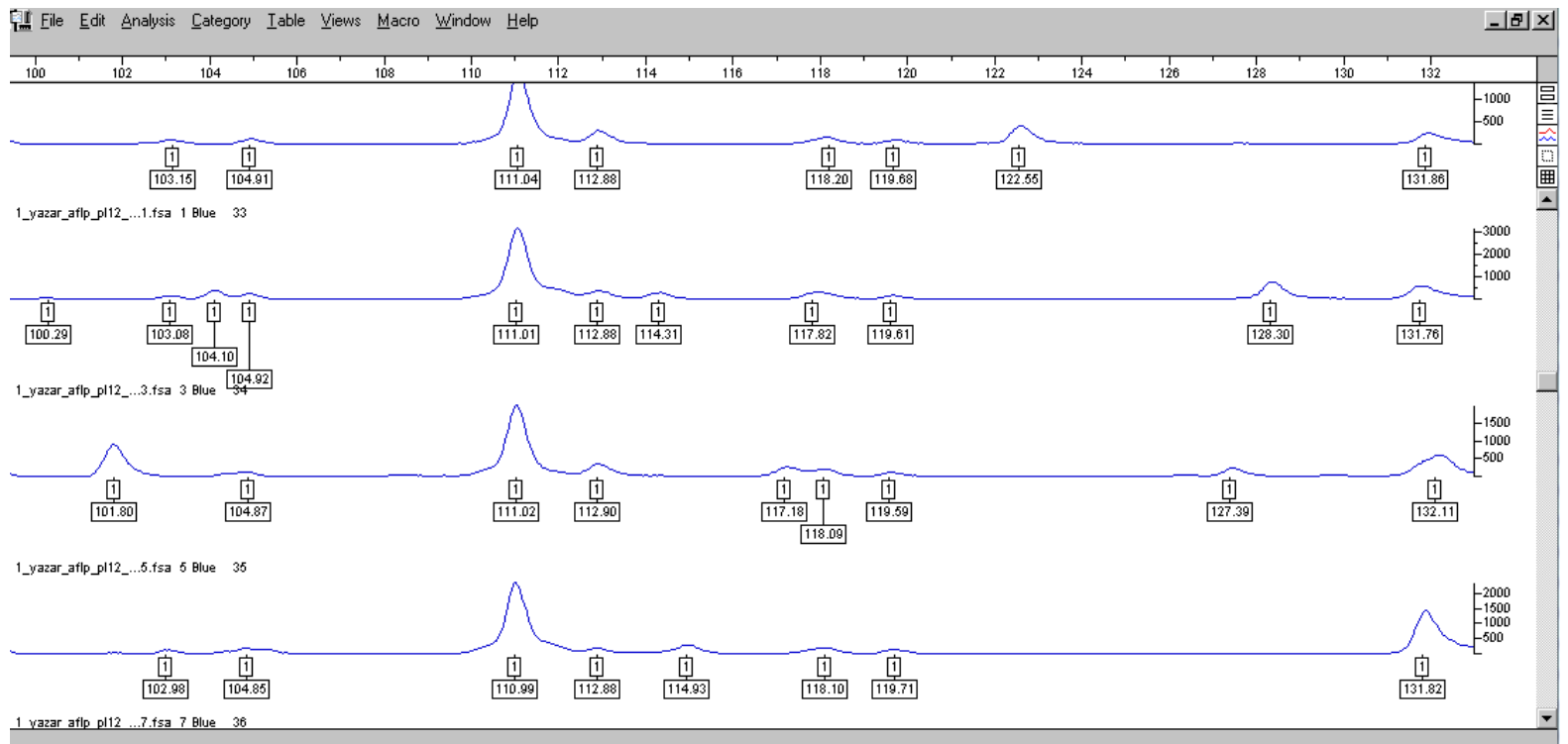

Fig. 7 Electropherogram showing AFLP markers of T. grandis as visualized by GeneScan ver. 3.7 and Genotyper ver. 3.7. 
Table 2 Multiplexes of 10 SSR primers, their respective labelled dyes and primer sequences.

\begin{tabular}{|c|c|c|c|}
\hline \multirow[t]{2}{*}{ Primers } & \multicolumn{3}{|c|}{$5^{\prime}$ dye } \\
\hline & Multiplex & label & Primer sequences \\
\hline \multirow[t]{2}{*}{ CIRAD1TeakA06 } & $\mathrm{A}$ & HEX & F: 5'-CAAAACAAAACCAATAGCCAGAC-3' \\
\hline & & & R: 5'-TTTCATCATCATCATCAACATCC-3' \\
\hline \multirow[t]{2}{*}{ CIRAD2TeakB07 } & A & TAMRA & F: 5'-GGGTGCTGATGATTTTGAGTT-3' \\
\hline & & & R: 5'-CTAAGGAGTGAGTGGAGTTTT-3' \\
\hline \multirow[t]{2}{*}{ CIRAD2TeakC03 } & A & 6-FAM & F: 5'-AGGTGGGATGTGGTTAGAAGC-3' \\
\hline & & & R: 5'-AAATGGTCATCAGTGTCAGAA-3' \\
\hline \multirow[t]{2}{*}{ CIRAD4TeakFO2 } & A & TAMRA & F: 5'-CCGGTAAAAAGGTGTGTCA-3' \\
\hline & & & R: 5'-GAGTGGAAGTGCTAATGGA-3' \\
\hline \multirow[t]{2}{*}{ CIRAD3TeakDa09 } & $\mathrm{B}$ & 6-FAM & F: 5'-CTCGCTTCTTTCCACATT-3' \\
\hline & & & R: 5'-ATCATCGCGCATCGTCAA-3' \\
\hline \multirow[t]{2}{*}{ CIRAD1TeakG02 } & $\mathrm{B}$ & TAMRA & F: 5'-TTAACGCCAAATCCCAAAG-3' \\
\hline & & & R: 5'-CACAAAGAGAACCGACGAG-3' \\
\hline \multirow[t]{2}{*}{ CIRAD3TeakB02 } & $\mathrm{C}$ & TAMRA & F: 5'-ATGAAGACAAGCCTGGTAGCC-3' \\
\hline & & & R: 5'-GGAAGACTGGGGAATAACACG-3' \\
\hline \multirow[t]{2}{*}{ CIRAD3TeakF01 } & $\mathrm{C}$ & 6-FAM & F: 5'-GCTCTCCACCAACCTAAACAA-3' \\
\hline & & & R: 5'-AAAACGTCTCACCTTCTCACT-3' \\
\hline \multirow[t]{2}{*}{ CIRAD4TeakDa12 } & $\mathrm{C}$ & TAMRA & F: 5'-CGCACACCAGTAGCAGTAGCC-3' \\
\hline & & & R: 5'-GCCGGAAAAAGAAAAACCAAA-3' \\
\hline \multirow[t]{2}{*}{ CIRAD1TeakB03 } & $\mathrm{C}$ & HEX & F: 5'-ATGAAGACAAGCCTGGTAGCC-3' \\
\hline & & & R: 5'-CACTACCACTCATCATCAACACA-3' \\
\hline
\end{tabular}

Multiplex A, B and C: the same letter stands for the same PCR multiplex. All primers were developed by Verhaegen et al. (2005). 


\subsection{Data analyses}

\subsubsection{Genetic diversity}

For SSRs, expected heterozygosity $\left(H_{\mathrm{E}}\right)$ (Nei, 1978), observed heterozygosity $\left(H_{\mathrm{O}}\right)(\mathrm{Nei}$, 1978), number of alleles $(A)$ and fixation indices $(f)$ were calculated to estimate genetic diversity within populations using Genetic Data Analysis (GDA) ver. 1.0 (Lewis et al., 2001). Inbreeding coefficients $\left(F_{\text {IS }}\right)$ for each population were estimated using FSTAT ver. 2.9.3.2 software (Goudet, 2001) after 1000 permutations. Allelic richness $\left(A_{\mathrm{R}}\right)$ for each population was calculated using FSTAT ver. 2.9.3.2 for comparative assessment with other studies to account for different sample sizes. The presence of null alleles was estimated with MICROCHECKER ver. 2.2 .3 (Van Oosterhout et al., 2004).

For AFLP markers, the percentage of polymorphic loci (PPL) and Nei's (1978) gene diversity $\left(H_{\mathrm{j}}\right)$ estimated with AFLP-SURV ver. 1.0 (Vekemans, 2002) considering only loci with frequencies of band presence below $1-(3 / \mathrm{N})$, where $\mathrm{N}$ is the total sample size (Lynch and Milligan, 1994). Allelic frequencies were computed using a Bayesian approach with nonuniform prior distribution of allele frequencies (Zhivotovsky, 1999) with slight deviation from Hardy-Weinberg equilibrium using an inbreeding value $f=0.037$ (mean value computed by SSRs). Band richness per locus (Br) (Coart et al., 2005) was computed based on a sample size of 35 individuals using AFLPDIV ver. 1.1 (Petit, 2007).

\subsubsection{Linkage disequilibrium}

Linkage disequilibrium between SSR loci pairs for each population was calculated by means of Fisher's exact test (Markov chain parameters in 10000 dememorizations, 1000 batches and 10000 iteration per batches) in GENEPOP ver. 4.0 (Rousset, 2008).

\subsubsection{Significant tests for estimates of genetic diversity}

For SSRs, significant tests between adults and regeneration, between unlogged and selectively-logged, and between the northern and southern populations for expected heterozygosity $\left(H_{\mathrm{E}}\right)$, observed heterozygosity $\left(H_{\mathrm{O}}\right)$, allelic richness $\left(A_{\mathrm{R}}\right)$, inbreeding 
coefficient $\left(F_{\mathrm{IS}}\right)$ and fixation index $\left(F_{\mathrm{ST}}\right)$ were calculated after 1000 permutations using FSTAT ver. 2.9.3.2 software (Goudet, 2001)

For AFLPs, analyses of variance (ANOVA) were applied to analyze variance components to detect significant differences between estimates of genetic diversity (Sokal and Rohlf, 1994). Significant values were estimated for differences between adults and regeneration, the logging types and the two regions based on the estimators of $P P L, H_{\mathrm{j}}$ and $\mathrm{Br}$ using MICROSOFT EXCEL 2007.

\subsubsection{Genetic distances and Pairwise $\boldsymbol{F}_{\mathrm{ST}}$}

Nei's unbiased genetic distances (1978) for both markers were calculated using GENALEX ver. 6.4 (Peakall and Smouse, 2006). Pairwise $F_{\mathrm{ST}}$ and significant values were estimated based on 1000 permutations using ARLEQUIN ver. 3.5.1.2 (Excoffier and Lischer, 2010).

\subsubsection{Cluster analyses}

For SSRs, cluster analyses were conducted using Neighbor Joining (NJ) method and unweighted pair-group method with arithmetic means algorithm (UPGMA) (Sneath and Sokal, 1973) based on the chord genetic distances (Cavalli-Sforza and Edwards, 1967). The genetic distance matrices were calculated using POPULATIONS ver. 1.2.32 (Langella, 2002) and statistical support of the clusters was assessed by means of 1000 bootstrap replicates over loci. The dendrograms were visualized by TREEVIEW ver. 1.6.6 (Page, 1996).

For AFLPs, the cluster analysis was performed based on the UPGMA method (Sneath and Sokal, 1973) derived from Nei's genetic distances (1978). One thousand bootstrapped replicated matrices of pairwise Nei's genetic distances were calculated using AFLP-SURV ver. 1.0 (Vekemans, 2002) and the results were used as inputs for computing UPGMA dendrogram using NEIGHBOUR (UPGMA algorithm) and CONSENSE (expanded majority rule approach) of the package PHYLIP ver. 3.69 (Felsenstein, 1989). The dendrogram was visualized by TREEVIEW ver. 1.6.6 (Page, 1996). 


\subsubsection{Mantel tests}

Mantel test (Mantel, 1967) was used to estimate correlation between genetic $\left(F_{\mathrm{ST}} /\left(1-F_{\mathrm{ST}}\right)\right)$ and natural logarithm of geographic distances between sampled populations using GENALEX ver. 6.4 (Peakall and Smouse, 2006). Slaktin's (1995) pairwise genetic differentiation $\left(F_{\mathrm{ST}} /\left(1-F_{\mathrm{ST}}\right)\right)$ was calculated using ARLEQUIN ver. 3.5.1.2 (Excoffier and Lischer, 2010).

\subsubsection{Principle Coordinate Analysis (PCA)}

PCAs for both markers were generated by Nei's (1978) genetic distances among populations using GENALEX ver. 6.4 (Peakall and Smouse, 2006).

\subsubsection{Analyses of Molecular Variance (AMOVA)}

For both markers, genetic diversity at each level (i.e., adult, regeneration, each management type and each region) and two or more hierarchical levels (i.e., between adults and regeneration, between unlogged and selectively-logged populations, between regions) was partitioned by ARLEQUIN ver. 3.5.1.2 (Excoffier and Lischer, 2010) after estimating Analyses of Molecular Variances (AMOVA) based on pairwise differences between molecular phenotypes using the estimators of Weir and Cockerham (1984). The $P$-values were estimated for both markers after 1000 random permutations.

\subsubsection{Bayesian cluster analysis}

Bayesian clustering approaches implemented in STRUCTURE ver. 2.3.1 (Pritchard et al., 2000) were used to infer the population structure. Both admixture and no-admixture model for SSRs and only admixture model for AFLPs were applied. For AFLP analysis, the second alleles were entered as missing data, and each band was treated as haploid allele. The number of populations $(K)$ was estimated with 5 replicates each for $K=1$ to $K=10$ using 100000 iterations of Markov Chain and 100000 iterations of burn-in periods. The best estimated $K$ was determined with the highest $\operatorname{Ln}(P(\mathrm{D}))$ with lowest deviation. Delta $K$ was also estimated 
using Evanno et al. (2005) method by the web-based STRUCTURE HARVESTER program (Earl and vonHoldt, 2011).

\subsubsection{Locus-wise genetic differentiation $\left(G_{\mathrm{ST}}\right)$ for adults and regeneration}

Genetic differentiation (Nei, 1973) among adult and regeneration populations within the southern and northern regions was calculated by POPGENE ver. 1.32 (Yeh and Boyle, 1997) for each locus. The differences in marker frequencies between adults and regeneration were checked and compared based on the presence of AFLP fragments at each locus.

\subsubsection{Pearson's correlation}

The Pearson's correlations between estimates of genetic diversity $\left(H_{\mathrm{E}}, H_{\mathrm{j}}, \mathrm{Br}\right)$ and between genetic differentiations $\left(F_{\mathrm{ST}}\right)$ for both markers were calculated to assess congruency and discrepancy between the two markers. 


\section{Results}

\subsection{Genetic variation at SSRs}

\subsubsection{Genetic diversity at SSR loci}

Genetic diversity of $T$. grandis varied among ten SSR loci (Table 3). The number of alleles ranged from 10 at $\mathrm{G} 02$ to 35 at $\mathrm{B} 03$. The expected heterozygosity $\left(H_{\mathrm{E}}\right)$ ranged from 0.362 at Da12 to 0.867 at $\mathrm{C} 03$ while the observed heterozygosity $\left(H_{\mathrm{O}}\right)$ ranged from 0.314 at Da12 and 0.786 at CO3. All loci showed heterozygote deficits. The smallest fixation index $(f)$ per locus was observed at C03 (0.094) while the highest fixation index $(f)$ was detected at F02 (0.248). Potential null alleles were detected in 18 out of 34 T. grandis populations (see appendix).

Table 3 Genetic diversity of $T$. grandis at 10 SSR loci.

\begin{tabular}{lccccc}
\hline Locus & $n$ & $A$ & $H_{\mathrm{E}}$ & $H_{\mathrm{O}}$ & $f$ \\
\hline CIRDAT. grandisA06 & 1659 & 28 & 0.726 & 0.644 & 0.113 \\
BCIRDAT. grandisB02 & 1648 & 31 & 0.806 & 0.721 & 0.105 \\
CIRDAT. grandisB03 & 1661 & 35 & 0.763 & 0.612 & 0.199 \\
CIRDAT. grandisB07 & 1653 & 27 & 0.737 & 0.628 & 0.140 \\
CIRDAT. grandisC03 & 1652 & 27 & 0.867 & 0.786 & 0.094 \\
CIRDAT. grandisDa09 & 1660 & 16 & 0.446 & 0.388 & 0.130 \\
CIRDAT. grandisDa12 & 1656 & 16 & 0.362 & 0.314 & 0.133 \\
CIRDAT. grandisF01 & 1661 & 27 & 0.700 & 0.605 & 0.135 \\
CIRDAT. grandisF02 & 1649 & 22 & 0.695 & 0.522 & 0.248 \\
CIRDAT. grandisG02 & 1655 & 10 & 0.537 & 0.435 & 0.189 \\
All & 1655.4 & 23.9 & 0.664 & 0.566 & 0.148 \\
\hline
\end{tabular}

$n$ number of samples, $A$ number of alleles, $H_{\mathrm{E}}$ expected heterozygosity, $H_{\mathrm{O}}$ observed heterozygosity and $f$ fixation index. 
Table 4 Genetic diversity within populations of $T$. grandis at SSRs.

\begin{tabular}{|c|c|c|c|c|c|c|c|c|c|c|}
\hline Location & P.A. & L.T. & S.T. & $n$ & L.D. & $A$ & $A_{\mathrm{R}}$ & $H_{\mathrm{E}}$ & $H_{\mathrm{O}}$ & $F_{\text {IS }}$ \\
\hline \multirow[t]{4}{*}{ Aunglan } & ASA & SL & $\mathrm{AD}$ & 49.9 & & 7.6 & 7.2 & 0.596 & 0.571 & $0.041^{\mathrm{ns}}$ \\
\hline & ASR & SL & $\mathrm{RE}$ & 49.6 & & 7.7 & 7.3 & 0.593 & 0.549 & $0.075^{* *}$ \\
\hline & AUA & UL & $\mathrm{AD}$ & 49.6 & & 7.2 & 6.8 & 0.599 & 0.599 & $0.000^{\mathrm{ns}}$ \\
\hline & AUR & UL & $\mathrm{RE}$ & 46.4 & & 7.2 & 7.0 & 0.588 & 0.539 & $0.084 * *$ \\
\hline \multirow[t]{4}{*}{ Bamauk } & BSA & SL & $\mathrm{AD}$ & 48.6 & & 6.0 & 5.8 & 0.524 & 0.544 & $-0.039^{\mathrm{ns}}$ \\
\hline & BSR & SL & $\mathrm{RE}$ & 48.9 & & 5.7 & 5.5 & 0.535 & 0.552 & $-0.032^{\mathrm{ns}}$ \\
\hline & BUA & UL & $\mathrm{AD}$ & 49.0 & & 6.7 & 6.4 & 0.600 & 0.593 & $0.012^{\mathrm{ns}}$ \\
\hline & BUR & UL & $\mathrm{RE}$ & 49.8 & & 6.6 & 6.4 & 0.585 & 0.529 & $0.097 * * *$ \\
\hline \multirow[t]{4}{*}{ Indaw } & ISA & SL & $\mathrm{AD}$ & 49.4 & & 5.9 & 5.7 & 0.585 & 0.534 & $0.088 * *$ \\
\hline & ISR & SL & $\mathrm{RE}$ & 46.8 & & 5.6 & 5.5 & 0.581 & 0.584 & $-0.005^{\mathrm{ns}}$ \\
\hline & IUA & UL & $\mathrm{AD}$ & 48.8 & & 6.5 & 6.2 & 0.588 & 0.549 & $0.067 *$ \\
\hline & IUR & UL & $\mathrm{RE}$ & 50.0 & & 7.6 & 7.2 & 0.587 & 0.566 & $0.037^{\mathrm{ns}}$ \\
\hline \multirow[t]{4}{*}{ Letpadan } & LSA & SL & $\mathrm{AD}$ & 50.0 & & 6.8 & 6.5 & 0.582 & 0.568 & $0.025^{\mathrm{ns}}$ \\
\hline & LSR & SL & $\mathrm{RE}$ & 48.0 & 2 & 8.1 & 7.6 & 0.593 & 0.579 & $0.024^{\mathrm{ns}}$ \\
\hline & LUA & UL & $\mathrm{AD}$ & 50.0 & & 6.7 & 6.4 & 0.547 & 0.516 & $0.057 *$ \\
\hline & LUR & UL & $\mathrm{RE}$ & 50.0 & & 7.1 & 6.7 & 0.565 & 0.514 & $0.092 * * *$ \\
\hline \multirow[t]{4}{*}{ Mabein } & MSA & SL & $\mathrm{AD}$ & 48.6 & 1 & 5.4 & 5.2 & 0.561 & 0.549 & $0.020^{\mathrm{ns}}$ \\
\hline & MSR & SL & $\mathrm{RE}$ & 49.8 & & 5.3 & 5.9 & 0.605 & 0.566 & $0.117 * * *$ \\
\hline & MUA & UL & $\mathrm{AD}$ & 49.6 & 1 & 5.3 & 5.1 & 0.572 & 0.606 & $-0.060^{\mathrm{ns}}$ \\
\hline & MUR & UL & $\mathrm{RE}$ & 49.8 & & 5.3 & 5.2 & 0.605 & 0.566 & $0.066^{*}$ \\
\hline \multirow[t]{4}{*}{ Pinlebu } & PLSA & SL & $\mathrm{AD}$ & 49.7 & & 7.1 & 6.8 & 0.598 & 0.596 & $0.003^{\mathrm{ns}}$ \\
\hline & PLSR & SL & $\mathrm{RE}$ & 48.6 & & 7.1 & 6.8 & 0.612 & 0.593 & $0.031^{\mathrm{ns}}$ \\
\hline & PLUA & UL & $\mathrm{AD}$ & 49.4 & & 7.1 & 6.8 & 0.591 & 0.578 & $0.022^{\mathrm{ns}}$ \\
\hline & PLUR & UL & $\mathrm{RE}$ & 50.0 & & 7.1 & 6.8 & 0.593 & 0.568 & $0.043^{\mathrm{ns}}$ \\
\hline \multirow[t]{4}{*}{ Pyinmana } & PMSA & SL & $\mathrm{AD}$ & 49.8 & & 7.9 & 7.5 & 0.623 & 0.596 & $0.043^{*}$ \\
\hline & PMSR & SL & $\mathrm{RE}$ & 47.4 & & 7.7 & 7.4 & 0.617 & 0.587 & $0.049 *$ \\
\hline & PMUA & UL & $\mathrm{AD}$ & 49.9 & 3 & 7.5 & 7.2 & 0.618 & 0.629 & $-0.018^{\mathrm{ns}}$ \\
\hline & PMUR & UL & $\mathrm{RE}$ & 49.2 & & 6.9 & 6.6 & 0.573 & 0.541 & $0.056 *$ \\
\hline \multirow[t]{5}{*}{ Tharawaddy } & TSA & SL & $\mathrm{AD}$ & 49.4 & 1 & 6.6 & 6.3 & 0.566 & 0.507 & $0.107 * * *$ \\
\hline & TSR & SL & $\mathrm{RE}$ & 49.9 & & 7.3 & 6.9 & 0.568 & 0.511 & $0.102 * * *$ \\
\hline & TUA & UL & $\mathrm{AD}$ & 49.7 & 12 & 7.0 & 6.7 & 0.599 & 0.582 & $0.029^{\mathrm{ns}}$ \\
\hline & TUR & UL & $\mathrm{RE}$ & 49.8 & & 7.2 & 6.8 & 0.592 & 0.583 & $0.015^{\mathrm{ns}}$ \\
\hline & Myanmar & & & 49.2 & & 6.8 & 6.5 & 0.586 & 0.564 & 0.037 \\
\hline Agrimey & BEN1 & & $\mathrm{AD}$ & 40.0 & 45 & 7.0 & 7.0 & 0.603 & 0.613 & $-0.016^{\mathrm{ns}}$ \\
\hline \multirow[t]{2}{*}{ Lama } & BEN2 & & $\mathrm{AD}$ & 40.0 & 31 & 8.7 & 8.7 & 0.683 & 0.67 & $0.020^{\mathrm{ns}}$ \\
\hline & Benin & & & 40.0 & & 7.9 & 7.9 & 0.643 & 0.642 & 0.002 \\
\hline
\end{tabular}

P.A. population abbreviations, $S L$ selectively-logged populations, $U L$ unlogged populations, L.T. logging types, S.T. sample types, $A D$ adults, $R E$ regeneration, $n$ number of samples, L.D. loci under linkage disequilibrium, $A$ number of alleles, $A_{\mathrm{R}}$ allelic richness, $H_{\mathrm{E}}$ expected heterozygosity, $H_{\mathrm{O}}$ observed heterozygosity, $P$-values: ns $P>$ 0.05 , significant at $P<0.5^{*}, P<0.01^{* *}, P<0.001^{* * *}$ 


\subsubsection{Genetic diversity within populations}

The estimates of genetic diversity of $T$. grandis varied among populations in Myanmar (Table 4). The number of alleles per population $(A)$ ranged from 5.3 at MUA and MUR to 8.1 at LSR while the allelic richness $\left(A_{R}\right)$ ranged from 5.1 at MUA to 7.6 at LSR (Table 4). The expected heterozygosity $\left(H_{\mathrm{E}}\right)$ ranged from 0.524 at BMA to 0.623 at PMSA while the observed heterozygosity $\left(H_{\mathrm{O}}\right)$ ranged from 0.507 at TSA to 0.629 at PMUA. The measures of genetic diversity computed for all samples of $T$. grandis populations in Myanmar $(A=6.8$, $\left.H_{\mathrm{E}}=0.586, H_{\mathrm{O}}=0.564\right)$ were lower than for all samples of $T$. grandis plantations in Benin $(A$ $\left.=7.9, H_{\mathrm{E}}=0.643, H_{\mathrm{O}}=0.642\right)$.

\subsubsection{Inbreeding coefficient $\left(F_{\text {IS }}\right)$}

T. grandis populations showed different levels of inbreeding among populations (Table 4). Adults and regeneration in the same stand showed different level of inbreeding. The highest values of inbreeding were observed in TSA $\left(F_{\text {IS }}=0.107\right)$ and TSR $\left(F_{\text {IS }}=0.102\right)$ (Table 4$)$. The lowest value of inbreeding coefficient was detected in MUA $\left(F_{\mathrm{IS}}=-0.60\right)$. Significant levels of inbreeding were observed in 14 out of 32 T. grandis populations in Myanmar. Nonsignificant levels of inbreeding were observed in the two plantations in Benin. The average value of the inbreeding coefficient for the Myanmar populations was 0.037 , indicating a slight deviation from Hardy-Weinberg equilibrium.

\subsubsection{Linkage disequilibrium}

Significant linkage disequilibrium among 10 pairs of SSR loci was observed in 8 of $34 T$. grandis populations (Table 4). All 45 pairs of loci were significantly associated in BEN1 plantation while 31 pairs of statistically associated loci were detected in BEN2 plantation. Twelve pairs of associated loci were observed in TUA while one pair of associated loci was detected in TSA. 
Table 5 Differences in genetic diversity of $T$. grandis at SSRs.

\begin{tabular}{|c|c|c|c|c|c|c|}
\hline & $N$ & $A_{\mathrm{R}}$ & $H_{\mathrm{O}}$ & $H_{\mathrm{S}}$ & $F_{\text {IS }}$ & $F_{\mathrm{ST}}$ \\
\hline \multicolumn{7}{|c|}{ Sample types (adults vs. regeneration) } \\
\hline Adult & 16 & 6.4 & 0.568 & 0.582 & 0.025 & 0.120 \\
\hline Regen & 16 & 6.5 & 0.552 & 0.583 & 0.053 & 0.116 \\
\hline
\end{tabular}

Management types (UL vs. SL)

$\begin{array}{lllllll}\text { UL } & 16 & 6.5 & 0.564 & 0.585 & 0.037 & 0.114 \\ \text { SL } & 16 & 6.5 & 0.555 & 0.580 & 0.042 & 0.123\end{array}$

Regions (northern vs. southern)

$\begin{array}{lllllll}\text { Northern } & 16 & 6.1^{\mathrm{a}} & 0.561 & 0.579 & 0.031 & 0.027 \\ \text { Southern } & 16 & 7.0^{\mathrm{b}} & 0.559 & 0.587 & 0.048 & 0.034\end{array}$

Adults (UL vs. SL)

$\begin{array}{lllllll}\text { UL } & 8 & 6.5 & 0.581 & 0.589 & 0.013 & 0.119 \\ \text { SL } & 8 & 6.4 & 0.558 & 0.580 & 0.037 & 0.134\end{array}$

Regen. (UL vs. SL)

$\begin{array}{lllllll}\text { UL } & 8 & 6.6 & 0.550 & 0.586 & 0.061 & 0.122 \\ \text { SL } & 8 & 6.6 & 0.557 & 0.584 & 0.046 & 0.126\end{array}$

UL (adults vs. regeneration)

$\begin{array}{lllllll}\text { Adult } & 8 & 6.5 & 0.581 & 0.589 & 0.013^{\mathrm{a}} & 0.119 \\ \text { Regen. } & 8 & 6.6 & 0.550 & 0.586 & 0.061^{\mathrm{b}} & 0.122\end{array}$

SL (adults vs. regeneration)

$\begin{array}{lllllll}\text { Adult } & 8 & 6.4 & 0.558 & 0.580 & 0.037 & 0.134 \\ \text { Regen. } & 8 & 6.6 & 0.557 & 0.584 & 0.046 & 0.126\end{array}$

Adults (northern vs. southern)

$\begin{array}{lllllll}\text { Northern } & 8 & 6.0^{\mathrm{a}} & 0.569 & 0.577 & 0.015 & 0.031 \\ \text { Southern } & 8 & 6.8^{\mathrm{b}} & 0.571 & 0.592 & 0.035 & 0.037\end{array}$

Regen. (northern vs. southern)

\begin{tabular}{lllllll} 
Northern & 8 & $6.1^{\mathrm{a}}$ & 0.558 & 0.584 & 0.045 & 0.028 \\
Southern & 8 & $7.1^{\mathrm{b}}$ & 0.550 & 0.586 & 0.062 & 0.034 \\
\hline
\end{tabular}

$S L$ selectively-logged populations, $U L$ unlogged populations, Regen. regeneration, $A_{\mathrm{R}}$ allelic richness, $H_{\mathrm{O}}$ observed heterozyogsity, $H_{\mathrm{S}}$ gene diversity, $F_{\mathrm{IS}}$ inbreeding coefficient, $F_{\mathrm{ST}}$ fixation index. Values followed by different letters are significantly different at $P<0.05$. All other values are not significant. 


\subsubsection{Significant tests for genetic diversity and differentiation}

The estimates of genetic diversity between management types, sample types (adults and regeneration) and regions were compared using allelic richness $\left(A_{\mathrm{R}}\right)$, observed heterozygosity $\left(H_{\mathrm{O}}\right)$, gene diversity $\left(H_{\mathrm{S}}\right)$, inbreeding coefficient $\left(F_{\mathrm{IS}}\right)$, and fixation index $\left(F_{\mathrm{ST}}\right)$ (Table 5$)$.

Genetic diversity and differentiation of adults and regeneration were not significantly different. Inbreeding coefficients $\left(F_{\text {IS }}\right)$ between all adults and regeneration were not significantly different. However, inbreeding value was significantly higher in regeneration in unlogged populations compared to selectively-logged populations. Generally, inbreeding values of adult trees were higher in selectively-logged than in unlogged populations. Conversely, inbreeding values of regeneration were higher in unlogged than in selectivelylogged populations but those values were not significantly different. T. grandis populations in the southern region had slightly higher level of inbreeding than $T$. grandis populations in the northern region though the estimates were not significantly different (Table 5).

All estimates of genetic diversity for unlogged and selectively-logged $T$. grandis populations were not significantly different $(P>0.05$, Table 5$)$. Generally, the $F_{\mathrm{ST}}$ value was slightly higher in selectively-logged adult populations (0.134) than in unlogged adult populations (0.119) but not significantly different (Table 5). The $F_{\mathrm{ST}}$ values for northern (0.027) and southern (0.034) regions were low and not significant.

Observed and expected heterozygosities $\left(H_{\mathrm{O}}\right.$ and $\left.H_{\mathrm{S}}\right)$ for the southern $T$. grandis populations were slightly higher than for the northern $T$. grandis populations but not significantly different. Nevertheless, allelic richness $\left(A_{\mathrm{R}}\right)$ was significantly higher in the southern region than in the northern region.

\subsubsection{Genetic distances and differentiation}

\subsubsection{Nei's genetic distances among 34 population pairs}

BEN1 plantation possessed the largest genetic distance to all Mabein populations (MUA, MUR, MSA and MSR; see appendix). Genetic distances were higher between the northern and southern regions than within each region (see appendix).

Within the southern populations, the highest value of genetic distance was observed between PMA and TUA (0.131; see appendix). In the same stand, the genetic distances were low, 
ranging from zero between AUA and AUR, between ASA and ASR, and between LUA and LUR to 0.020 between TUA and TUR.

Within the northern populations, the highest genetic distance between MSR and BSA was 0.082, which was lower than the genetic distances computed for southern T. grandis populations (see appendix). There were quite low genetic distances between adults and regeneration in the same stand, ranging from zero between BUA and BUR, between IUA and IUR, between ISA and ISR, and between MSA and MSR to 0.029 between PLSA and PLSR.

\subsubsection{Pairwise $F_{\text {ST }}$ among 34 population pairs}

The pairwise $F_{\mathrm{ST}} \mathrm{S}$ among all population pairs ranged from - 0.003 between MMA and MMR to 0.254 between LUA and MSA (see appendix). Within the same stand, no significant genetic differentiation (pairwise $F_{\mathrm{ST}}$ ) between adults and regeneration was observed in twelve stands (see appendix). However, a low but significant level of genetic differentiation (pairwise $F_{\mathrm{ST}}$ ) of adults and regeneration within the same stand was also observed in the remaining four stands (see appendix).

\subsubsection{Nei's genetic distances among adult and among regeneration populations}

The highest Nei's genetic distances among adult populations and among regeneration populations were observed between the northern and southern regions ( 0.538 for adults (MS vs. LU); 0.491 for regeneration (MS vs. LU); Table 6) while the lowest genetic distances were observed within the region, especially in population pairs in each area ( 0.013 for adults (LU vs. LS); 0.009 for regeneration (LU vs. LS); Table 6).

\subsubsection{Pairwise $F_{\text {ST }}$ among adult and among regeneration populations}

The genetic differentiation (pairwise $F_{\mathrm{ST}}$ ) among adult populations and among regeneration populations were significantly different $(P<0.05$; Table 7). For adult $T$. grandis populations, the highest pairwise $F_{\mathrm{ST}}$ was observed in populations between the northern and southern regions (MS vs. LU; $F_{\mathrm{ST}}=0.254$; Table 7). A similar result was detected in regeneration where the highest pairwise $F_{\mathrm{ST}}$ was found in populations between the two regions (MS vs. 
LU; $F_{\mathrm{ST}}=0.224$; Table 7). Meanwhile, the lowest level of pairwise $F_{\mathrm{ST}}$ was detected in populations within the region $\left(F_{\mathrm{ST}}=0.009\right.$ for adults (LU vs. LS); Table 7) and $\left(F_{\mathrm{ST}}=0.008\right.$ for regeneration (LU vs. LS); Table 7). 
Table 6 Nei's unbiased genetic distances (1978) for adults (below diagonal) and regeneration (above diagonal) in T. grandis populations at SSRs.

\begin{tabular}{lcccccccccccccccc}
\hline & AS & AU & BS & BU & IS & IU & LS & LU & MS & MU & PLS & PLU & PMS & PMU & TS & TU \\
\hline AS & & 0.022 & 0.359 & 0.383 & 0.401 & 0.416 & 0.034 & 0.054 & 0.456 & 0.460 & 0.301 & 0.343 & 0.077 & 0.052 & 0.041 & 0.059 \\
AU & 0.026 & & 0.280 & 0.300 & 0.325 & 0.332 & 0.066 & 0.077 & 0.363 & 0.363 & 0.255 & 0.291 & 0.091 & 0.074 & 0.057 & 0.066 \\
BS & 0.312 & 0.285 & & 0.014 & 0.029 & 0.032 & 0.351 & 0.341 & 0.061 & 0.057 & 0.031 & 0.023 & 0.412 & 0.336 & 0.320 & 0.307 \\
BU & 0.351 & 0.332 & 0.028 & & 0.021 & 0.025 & 0.350 & 0.366 & 0.058 & 0.059 & 0.043 & 0.021 & 0.452 & 0.375 & 0.322 & 0.298 \\
IS & 0.438 & 0.403 & 0.037 & 0.035 & & 0.016 & 0.387 & 0.405 & 0.061 & 0.043 & 0.046 & 0.024 & 0.481 & 0.407 & 0.359 & 0.347 \\
IU & 0.352 & 0.331 & 0.025 & 0.024 & 0.022 & & 0.405 & 0.412 & 0.041 & 0.047 & 0.038 & 0.040 & 0.472 & 0.422 & 0.375 & 0.359 \\
LS & 0.034 & 0.052 & 0.305 & 0.352 & 0.445 & 0.357 & & 0.009 & 0.467 & 0.483 & 0.316 & 0.325 & 0.083 & 0.046 & 0.011 & 0.019 \\
LU & 0.063 & 0.085 & 0.337 & 0.378 & 0.473 & 0.378 & 0.013 & & 0.491 & 0.501 & 0.319 & 0.348 & 0.088 & 0.046 & 0.019 & 0.021 \\
MS & 0.489 & 0.413 & 0.080 & 0.053 & 0.056 & 0.040 & 0.501 & 0.538 & & 0.028 & 0.065 & 0.058 & 0.458 & 0.433 & 0.432 & 0.436 \\
MU & 0.418 & 0.383 & 0.067 & 0.056 & 0.039 & 0.036 & 0.463 & 0.494 & 0.027 & & 0.079 & 0.061 & 0.515 & 0.474 & 0.441 & 0.437 \\
PLS & 0.388 & 0.327 & 0.070 & 0.049 & 0.057 & 0.048 & 0.382 & 0.419 & 0.023 & 0.041 & & 0.021 & 0.348 & 0.303 & 0.300 & 0.297 \\
PLU & 0.320 & 0.279 & 0.044 & 0.046 & 0.050 & 0.034 & 0.311 & 0.346 & 0.046 & 0.068 & 0.024 & & 0.411 & 0.330 & 0.311 & 0.307 \\
PMS & 0.093 & 0.113 & 0.367 & 0.366 & 0.499 & 0.393 & 0.104 & 0.124 & 0.467 & 0.443 & 0.387 & 0.367 & & 0.045 & 0.085 & 0.104 \\
PMU & 0.044 & 0.052 & 0.326 & 0.338 & 0.438 & 0.350 & 0.042 & 0.044 & 0.441 & 0.413 & 0.358 & 0.308 & 0.043 & & 0.050 & 0.070 \\
TS & 0.052 & 0.061 & 0.277 & 0.311 & 0.386 & 0.318 & 0.023 & 0.025 & 0.434 & 0.391 & 0.338 & 0.286 & 0.096 & 0.043 & \\
TU & 0.062 & 0.080 & 0.287 & 0.320 & 0.369 & 0.316 & 0.034 & 0.042 & 0.468 & 0.394 & 0.349 & 0.289 & 0.131 & 0.067 & 0.015 & 0.006 \\
\hline
\end{tabular}

Populations: the last letter; $S$ selectively-logged $T$. grandis population and $U$ unlogged $T$. grandis population; the first letters; $A$ Aunglan, $B$ Bamauk, $I$ Indaw, $L$ Letpadan, $M$ Mabein, $P L$ Pinlebu, $P M$ Pyinmana and $T$ Tharawaddy. 
Table 7 Pairwise $F_{\mathrm{ST}}$ for adults (below diagonal) and regeneration (above diagonal) in T. grandis populations at SSRs.

\begin{tabular}{lcccccccccccccccc}
\hline & AS & AU & BS & BU & IS & IU & LS & LU & MS & MU & PLS & PLU & PMS & PMU & TS & TU \\
\hline AS & & 0.015 & 0.192 & 0.183 & 0.190 & 0.192 & 0.023 & 0.039 & 0.206 & 0.198 & 0.147 & 0.167 & 0.046 & 0.036 & 0.029 & 0.038 \\
AU & 0.017 & & 0.165 & 0.157 & 0.168 & 0.168 & 0.043 & 0.054 & 0.180 & 0.172 & 0.132 & 0.151 & 0.054 & 0.050 & 0.040 & 0.044 \\
BS & 0.174 & 0.163 & & 0.010 & 0.021 & 0.025 & 0.189 & 0.192 & 0.046 & 0.042 & 0.025 & 0.018 & 0.201 & 0.191 & 0.184 & 0.172 \\
BU & 0.170 & 0.163 & 0.026 & & 0.015 & 0.017 & 0.172 & 0.184 & 0.039 & 0.038 & 0.028 & 0.014 & 0.194 & 0.188 & 0.169 & 0.154 \\
IS & 0.198 & 0.187 & 0.029 & 0.024 & & 0.011 & 0.186 & 0.199 & 0.041 & 0.028 & 0.031 & 0.016 & 0.203 & 0.200 & 0.184 & 0.173 \\
IU & 0.170 & 0.162 & 0.020 & 0.016 & 0.016 & & 0.189 & 0.198 & 0.029 & 0.030 & 0.025 & 0.026 & 0.198 & 0.201 & 0.186 & 0.174 \\
LS & 0.023 & 0.035 & 0.175 & 0.175 & 0.205 & 0.175 & & 0.008 & 0.209 & 0.204 & 0.153 & 0.161 & 0.051 & 0.033 & 0.008 & 0.012 \\
LU & 0.041 & 0.056 & 0.200 & 0.197 & 0.227 & 0.195 & 0.009 & & 0.224 & 0.217 & 0.159 & 0.175 & 0.057 & 0.034 & 0.015 & 0.016 \\
MS & 0.222 & 0.199 & 0.061 & 0.037 & 0.039 & 0.028 & 0.230 & 0.254 & & 0.019 & 0.042 & 0.038 & 0.197 & 0.207 & 0.206 & 0.201 \\
MU & 0.197 & 0.185 & 0.052 & 0.039 & 0.029 & 0.025 & 0.215 & 0.238 & 0.020 & & 0.046 & 0.038 & 0.201 & 0.209 & 0.201 & 0.192 \\
PLS & 0.178 & 0.157 & 0.051 & 0.032 & 0.037 & 0.031 & 0.180 & 0.205 & 0.017 & 0.028 & & 0.014 & 0.154 & 0.154 & 0.153 & 0.145 \\
PLU & 0.158 & 0.142 & 0.033 & 0.031 & 0.034 & 0.023 & 0.158 & 0.182 & 0.033 & 0.046 & 0.015 & & 0.179 & 0.170 & 0.162 & 0.154 \\
PMS & 0.054 & 0.065 & 0.187 & 0.166 & 0.205 & 0.175 & 0.062 & 0.078 & 0.207 & 0.196 & 0.170 & 0.166 & & 0.031 & 0.055 & 0.062 \\
PMU & 0.028 & 0.033 & 0.174 & 0.158 & 0.190 & 0.162 & 0.028 & 0.031 & 0.201 & 0.188 & 0.162 & 0.147 & 0.025 & & 0.036 & 0.047 \\
TS & 0.034 & 0.041 & 0.168 & 0.165 & 0.192 & 0.166 & 0.015 & 0.019 & 0.217 & 0.199 & 0.171 & 0.153 & 0.060 & 0.029 & \\
TU & 0.039 & 0.049 & 0.163 & 0.159 & 0.176 & 0.156 & 0.023 & 0.029 & 0.215 & 0.190 & 0.165 & 0.145 & 0.072 & 0.040 & 0.010 & 0.005 \\
\hline
\end{tabular}

Populations: the last letter; $S$ selectively-logged T. grandis population and $U$ unlogged $T$. grandis population; the first letters; $A$ Aunglan, $B$ Bamauk, $I$ Indaw, $L$ Letpadan, $M$ Mabein, $P L$ Pinlebu, $P M$ Pyinmana and $T$ Tharawaddy. All pairwise $F_{\text {ST }}$ are significantly different $(P<0.05)$. 


\subsubsection{Cluster analysis}

The Neighbor Joining (NJ) analysis revealed an obvious split between the northern and southern T. grandis populations with higher bootstrapping values (53\%; Fig. 8). Clusters among populations within the regions were weaker as supported by lower bootstrapping values while clusters between adults and regeneration in each stand were strong as explained by higher bootstrapping values (Fig. 8). The cluster between PLSR and PLSA was weak, and TSA and TUA grouped together rather than grouping of regeneration in their respective stand but their bootstrapping value was less than 50\% (Fig. 8). At the regional level, the neighboring populations within each region were clustered together. T. grandis plantations in Benin were clustered with the southern $T$. grandis populations. Similar patterns were observed in the UPGMA cluster analysis (Fig. 9). 


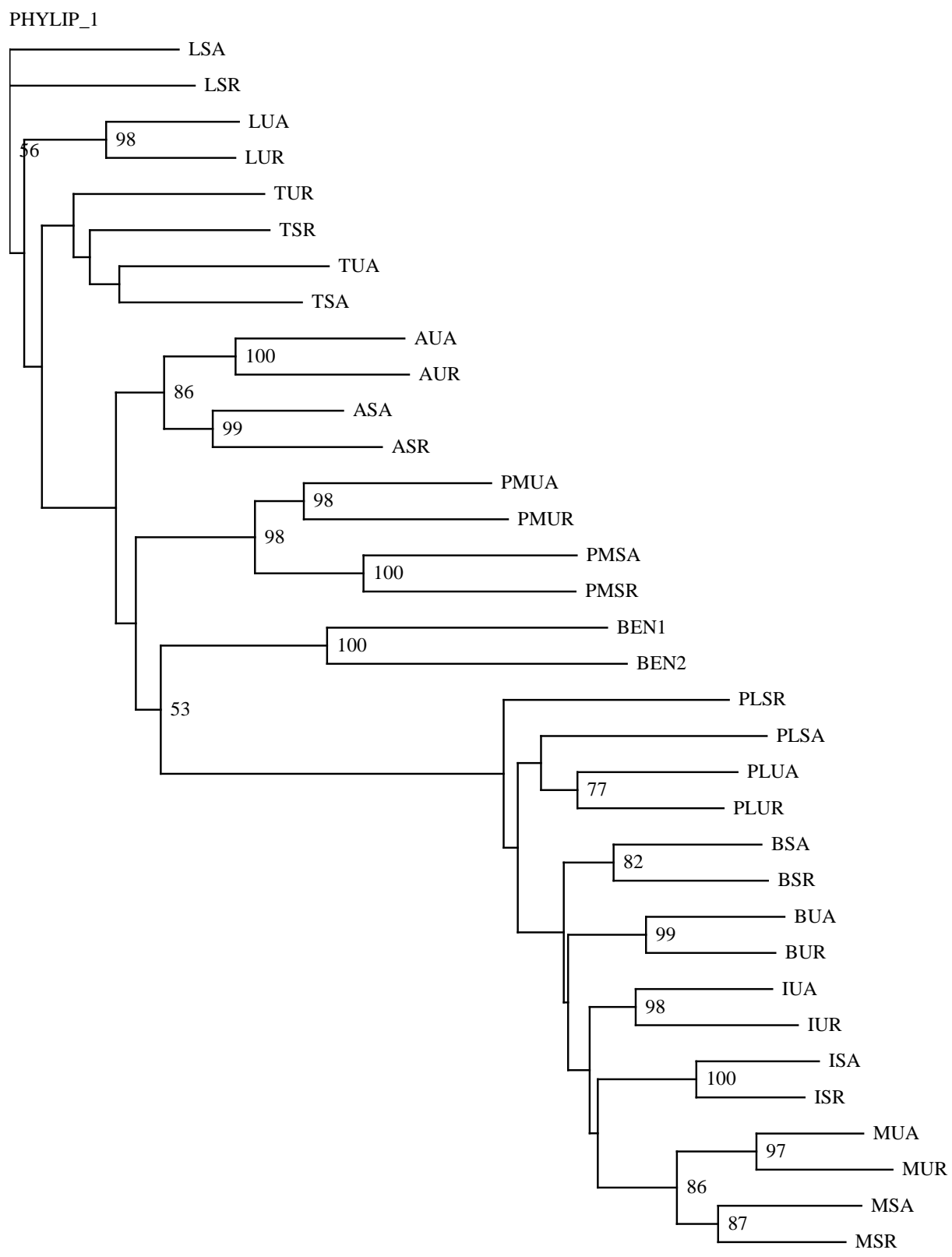

Fig. 8 Neigbor Joining tree based on DC genetic distances (Cavalli-Sforza and Edwards, 1967) computed for SSRs. Numbers at nodes are percentages over 1000 bootstrap replicates. 


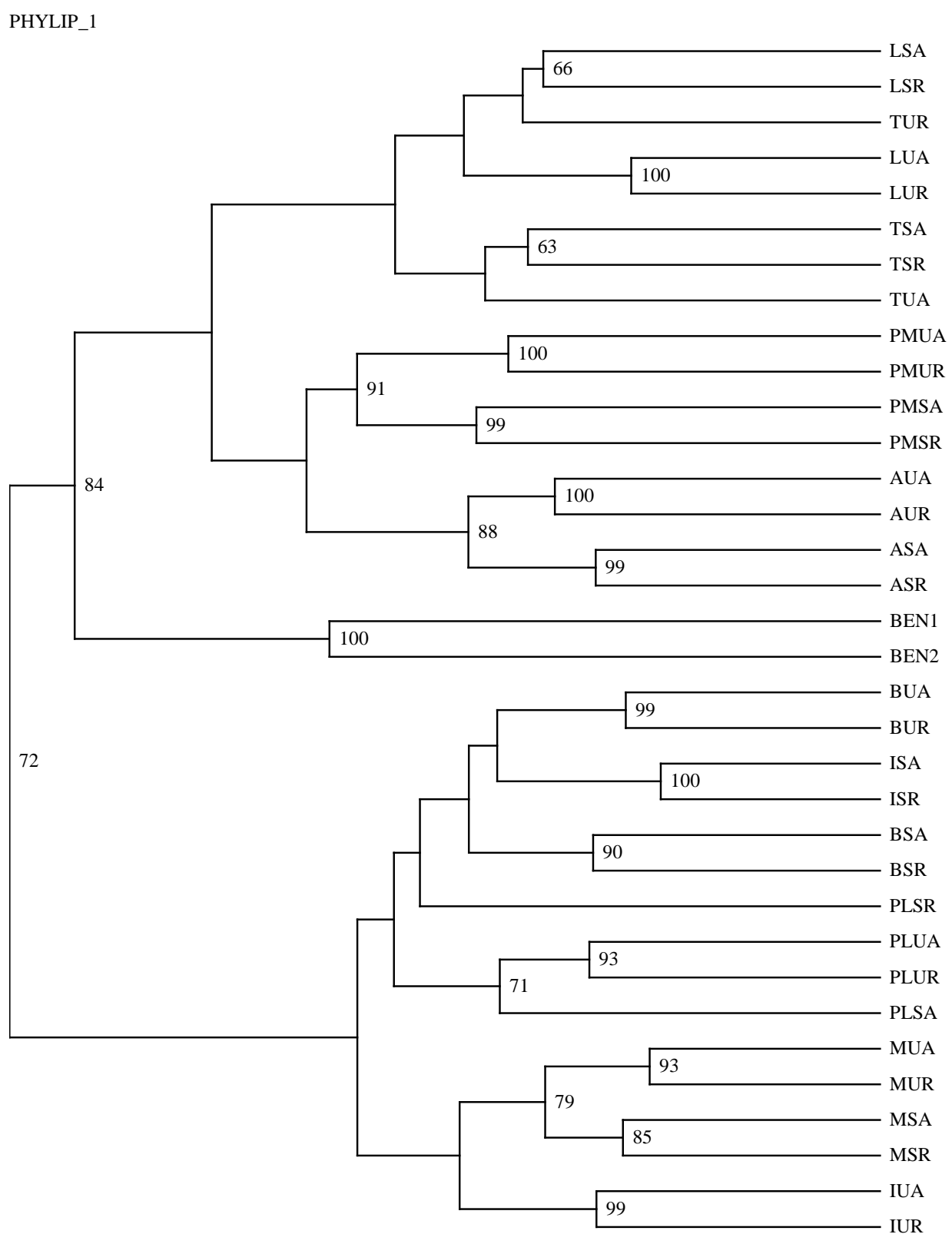

0.1

Fig. 9 UPGMA dendrogram based on DC genetic distances (Cavalli-Sforza and Edwards, 1967) computed for SSRs. Numbers at nodes are percentages over 1000 bootstrap replicates. 


\subsubsection{Mantel tests}

Mantel tests showed significant and positive correlations between geographic and genetic distances among $T$. grandis populations for both adults $(R=0.827, P<0.01)$ and regeneration $(R=0.838, P<0.01)$ (Fig. 10). Similarly, significant and positive correlations were observed for adult and regeneration populations within the southern and northern regions (Fig.11 and Fig. 12).

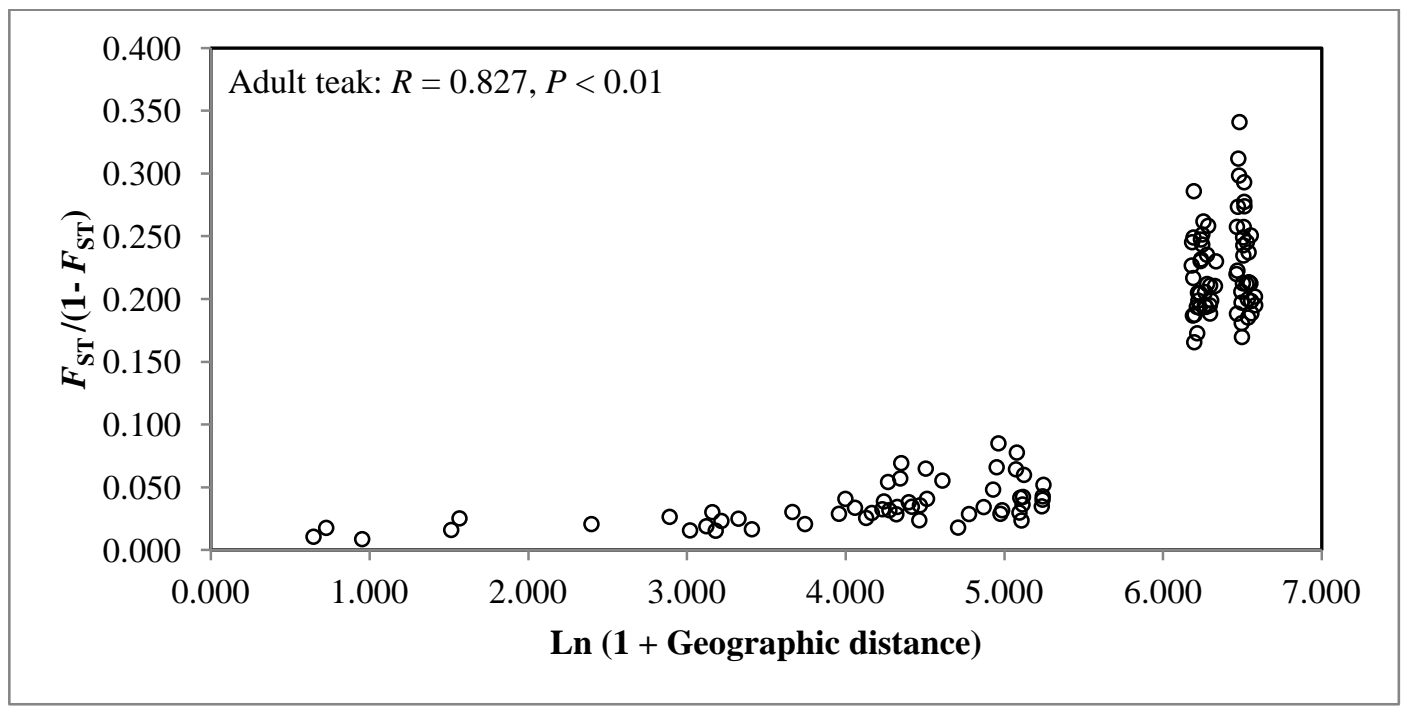

(A)

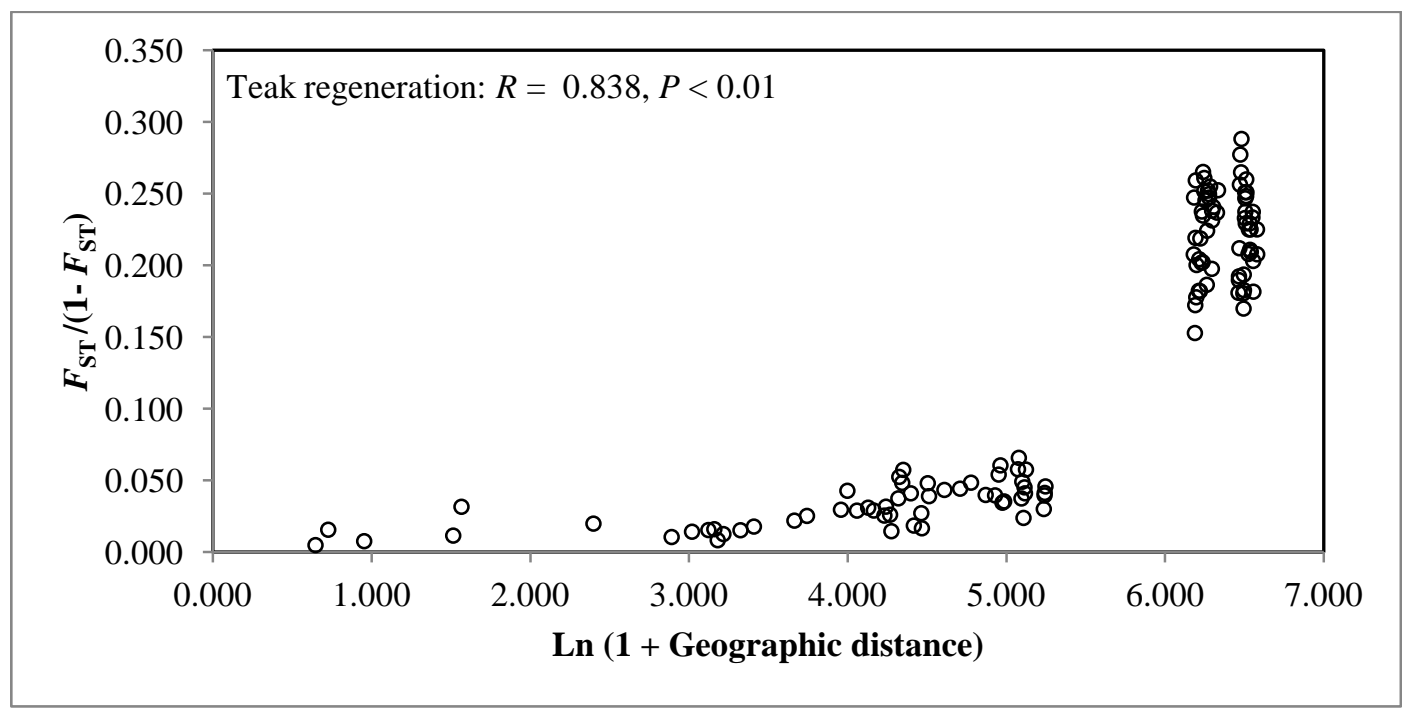

(B)

Fig. 10 Relationship between geographic and genetic distances among adult and regeneration populations of $T$. grandis at SSRs. (A) adults (B) regeneration. 


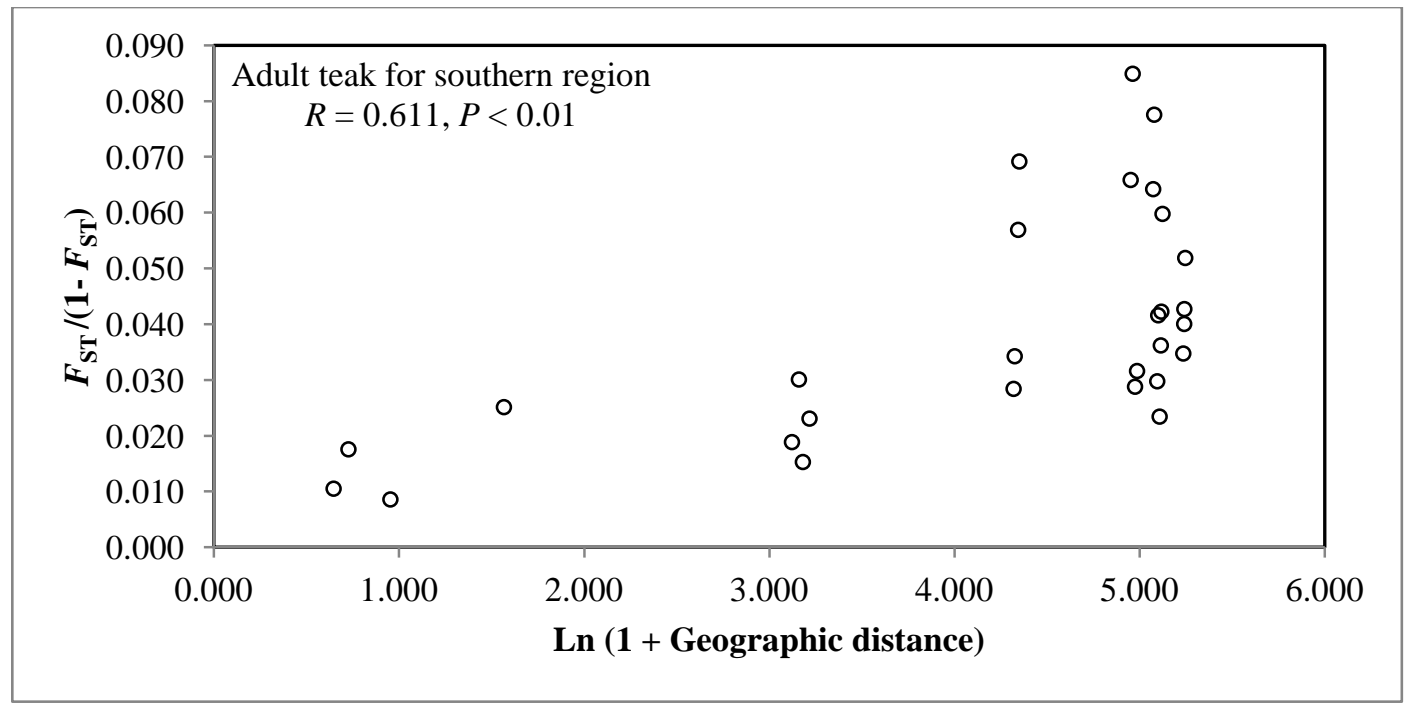

(A)

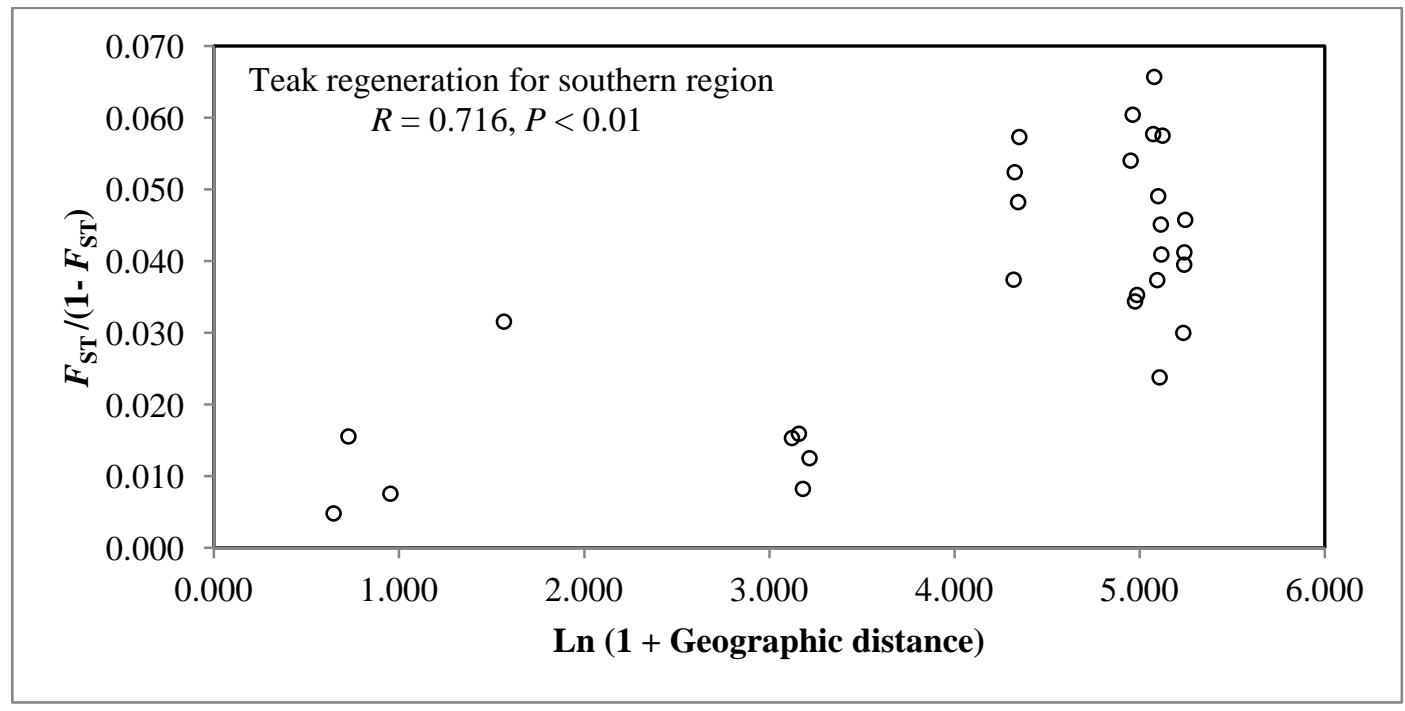

(B)

Fig. 11 Relationship between geographic and genetic distances among adult and regeneration populations of $T$. grandis in the sourthern region of Myanmar at SSRs. (A) adults (B) regeneration. 


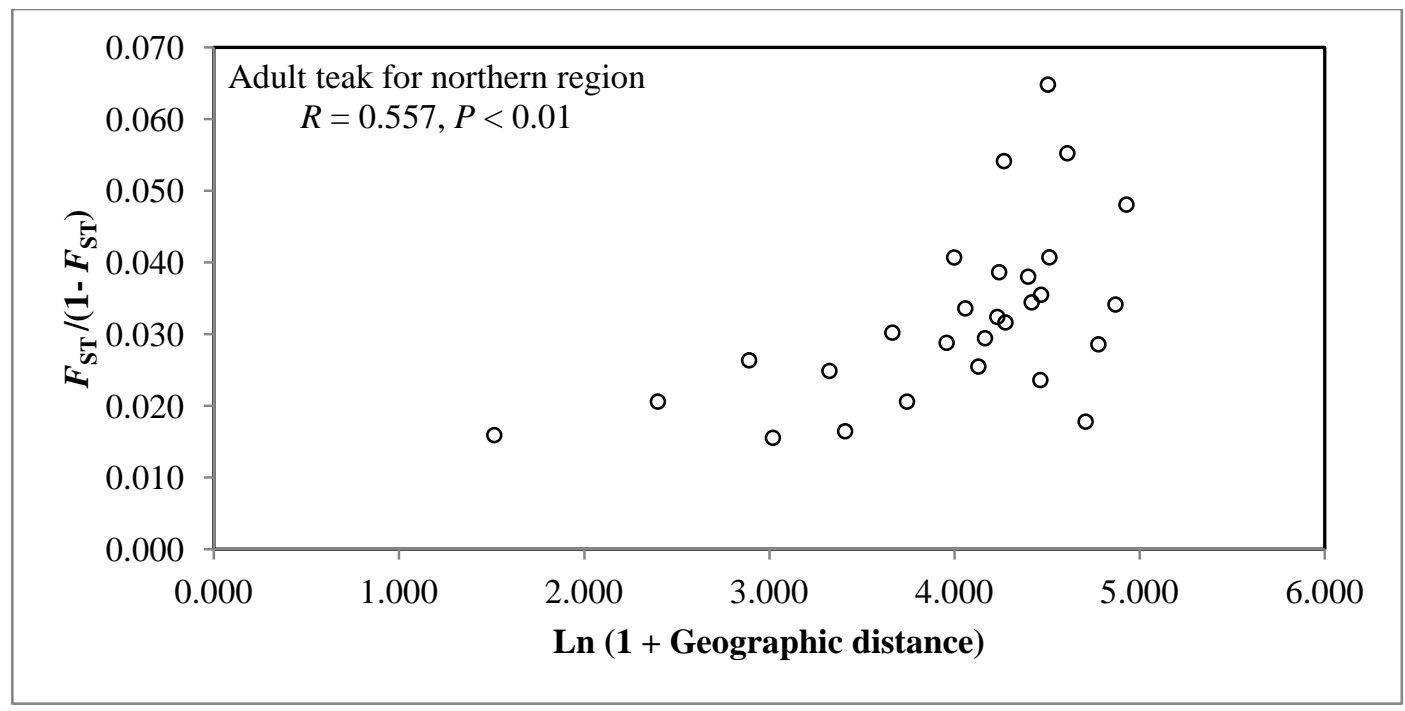

(A)

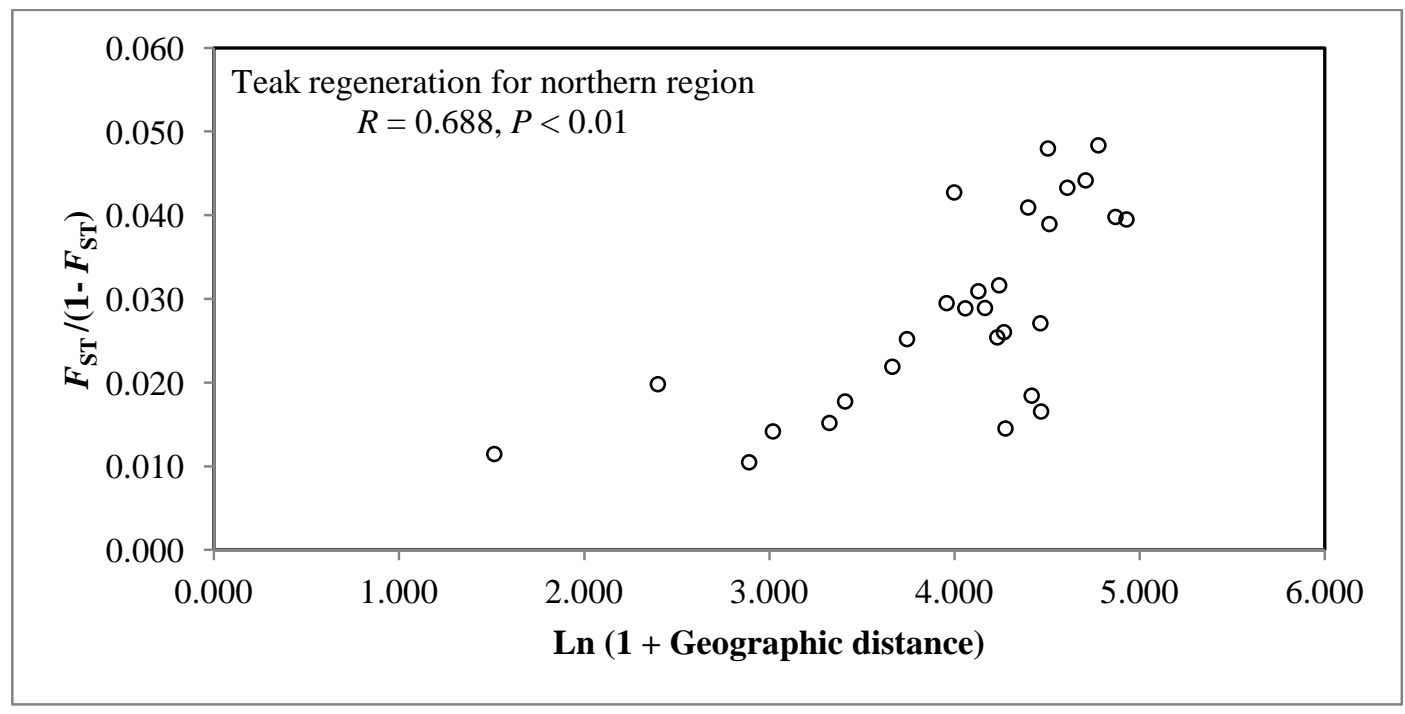

(B)

Fig. 12 Relationship between geographic and genetic distances among adult and regeneration populations of $T$. grandis in the northern region of Myanmar at SSRs. (A) adults (B) regeneration. 


\subsection{6. $\quad$ Principal Component Analysis (PCA)}

The PCA showed that the two axes explained $87 \%$ of the overall genetic variability (Fig. 13). The first axis (79.24\%) separated two groups: one group for the northern populations and another one for the southern populations and Benin plantations. The second axis explained only $7.71 \%$ of genetic variability and it did not clearly separate each region. However, there was a clear separation between the two Benin plantations and the southern populations.

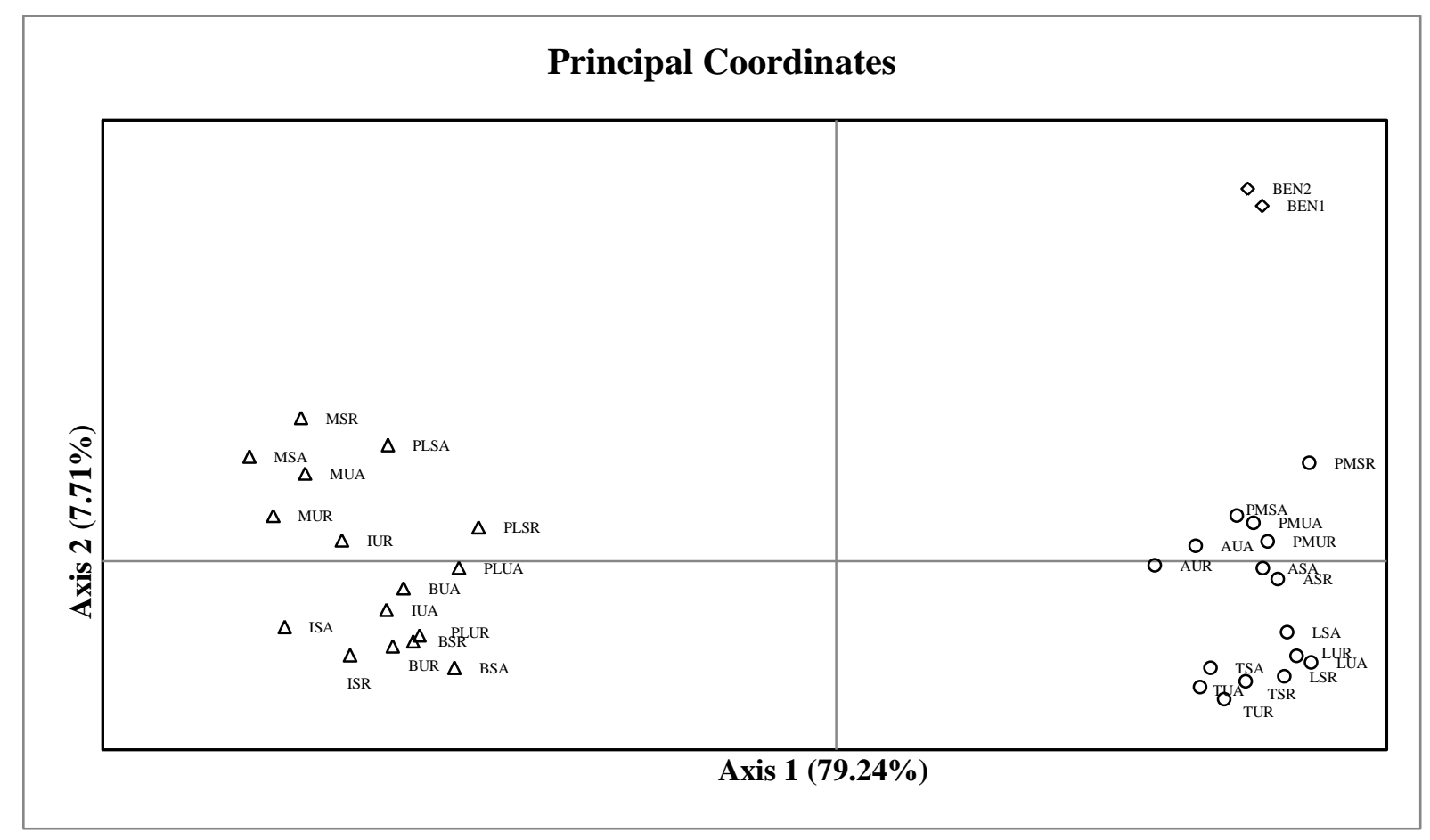

$\Delta$ northern populations, $\circ$ southern populations, $\diamond$ Benin plantations

Fig. 13 Principal Component Analysis (PCA) for T. grandis populations at SSRs. 
Table 8 Analyses of Molecular Variance (AMOVA) for each group of T. grandis at SSRs.

\begin{tabular}{lrrrrrr}
\hline Source of variation & d.f. & S.S. & V.C. & $\% \mathrm{~V}$ & $\Phi_{\mathrm{ST}}$ & $P$ value \\
\hline All Myanmar populations & & & & & & \\
Among populations & 31 & 1248.18 & 0.38 & 11.58 & 0.116 & $<0.001$ \\
Within populations & 3142 & 9039.91 & 2.88 & 88.42 & &
\end{tabular}

Adult populations

$\begin{array}{lrrrrrr}\text { Among populations } & 15 & 628.24 & 0.39 & 11.99 & 0.120 & <0.001 \\ \text { Within populations } & 1580 & 4536.16 & 2.87 & 88.01 & & \end{array}$

Regeneration populations

Among populations

$\begin{array}{llll}15 & 615.42 & 0.39 & 11.82\end{array}$

$0.118<0.001$

Within populations

$\begin{array}{llll}1562 & 4505.93 & 2.88 & 88.18\end{array}$

Unlogged populations

Among populations

Within populations

$\begin{array}{rrrr}15 & 599.99 & 0.37 & 11.4 \\ 1576 & 4566.24 & 2.90 & 88.6\end{array}$

Selectively-logged populations

Among populations

$\begin{array}{lll}15 & 637.68 & 0.40\end{array}$

12.31

0.123

$<0.001$

Within populations

$\begin{array}{llll}1566 & 4475.85 & 2.86 & 87.69\end{array}$

Unlogged populations (adults)

Among populations

Within populations

$\begin{array}{rrrr}7 & 294.47 & 0.39 & 11.93 \\ 790 & 2290.13 & 2.90 & 88.07\end{array}$

0.119

$<0.001$

Selectively-logged populations (adults)

Among populations

$7 \quad 327.02$

Within populations

$\begin{array}{lrrr}790 & 2246.03 & 2.84 & 86.6\end{array}$

Unlogged populations (regeneration)

$\begin{array}{lrrrrrr}\text { Among populations } & 7 & 302.13 & 0.41 & 12.29 & 0.123 & <0.001 \\ \text { Within populations } & 786 & 2276.11 & 2.90 & 87.71 & & \end{array}$

Selectively-logged populations (regeneration)

\begin{tabular}{lrrrrrr} 
Among populations & 7 & 306.42 & 0.42 & 12.68 & 0.127 & $<0.001$ \\
Within populations & 776 & 2229.82 & 2.87 & 87.32 & & \\
\hline
\end{tabular}

d.f degree of freedom, S.S. sum of square, V.C. variance components, $\% V$ percentage of variation, $\Phi_{\mathrm{ST}}$ fixation index (analogous to Wright's $F_{\mathrm{ST}}$ ). 
Table 9 Analyses of Molecular Variance (AMOVA) among different groups of $T$. grandis at SSRs.

\begin{tabular}{|c|c|c|c|c|c|c|}
\hline Source of variation & d.f. & S.S. & V.C. & $\% \mathrm{~V}$ & $\Phi$ statistics & $P$ value \\
\hline \multicolumn{7}{|c|}{ Adults and regeneration } \\
\hline Among groups & 1 & 4.76 & 0.02 & -0.71 & $\Phi_{\mathrm{CT}}=-0.007$ & $>0.05$ \\
\hline \multicolumn{7}{|l|}{ Among populations } \\
\hline within groups & 30 & 1243.42 & 0.39 & 11.99 & $\Phi_{\mathrm{SC}}=0.119$ & $<0.001$ \\
\hline Within population & 3142 & 9039.91 & 2.88 & 88.72 & $\Phi_{\mathrm{ST}}=0.113$ & $<0.001$ \\
\hline \multicolumn{7}{|c|}{ Unlogged and selectively-logged } \\
\hline Among groups & 1 & 10.73 & -0.02 & -0.59 & $\Phi_{\mathrm{CT}}=-0.006$ & $>0.05$ \\
\hline \multicolumn{7}{|l|}{ Among populations } \\
\hline within groups & 30 & 1237.46 & 0.39 & 11.92 & $\Phi_{\mathrm{SC}}=0.119$ & $<0.001$ \\
\hline Within population & 3142 & 9039.91 & 2.88 & 88.67 & $\Phi_{\mathrm{ST}}=0.113$ & $<0.001$ \\
\hline \multicolumn{7}{|c|}{ Northern and southern regions } \\
\hline Among groups & 1 & 886.50 & 0.55 & 15.65 & $\Phi_{\mathrm{CT}}=0.157$ & $<0.001$ \\
\hline \multicolumn{7}{|l|}{ Among populations } \\
\hline within groups & 30 & 361.69 & 0.09 & 2.63 & $\Phi_{\mathrm{SC}}=0.031$ & $<0.001$ \\
\hline Within population & 3142 & 9039.91 & 2.88 & 81.72 & $\Phi_{\mathrm{ST}}=0.183$ & $<0.001$ \\
\hline \multicolumn{7}{|c|}{ Northern, Southern Myanmar and Benin } \\
\hline Among groups & 2 & 984.22 & 0.53 & 15.07 & $\Phi_{\mathrm{CT}}=0.151$ & $<0.001$ \\
\hline \multicolumn{7}{|l|}{ Among populations } \\
\hline within groups & 31 & 371.32 & 0.09 & 2.62 & $\Phi_{\mathrm{SC}}=0.031$ & $<0.001$ \\
\hline Within population & 3300 & 9548.14 & 2.89 & 82.31 & $\Phi_{\mathrm{ST}}=0.177$ & $<0.001$ \\
\hline
\end{tabular}

d.f. degree of freedom, S.S. sum of square, V.C. variance components, $\% V$ percentage of variation. 


\subsubsection{Analyses of Molecular Variance (AMOVA)}

AMOVA revealed that genetic variation mostly resided within populations (88\%; Table 8). Genetic differentiation among all populations in Myanmar was significant $\left(\Phi_{\mathrm{ST}}=0.116, P<\right.$ 0.001). At each level, genetic variation was not considerably different. However, selectivelylogged adult populations had slightly higher level of genetic differentiation than unlogged adult populations.

No significant genetic variation between adults and regeneration was observed $(-0.71, \mathrm{P}>$ 0.05; Table 9). Similarly, no significant genetic variation was observed between selectivelylogged and unlogged populations (-0.59\%, P > 0.05, Table 9). However, there was significant genetic variation between the two regions $(15.65 \%, \mathrm{P}<0.001$; Table 9), and between the two regions and Benin $(15.07 \%, \mathrm{P}<0.001$; Table 9).

\subsubsection{Genetic structure based on Bayesian analysis}

The Bayesian analysis of population structure was conducted using the correlated allele frequency model, detecting two groups $(K=2)$ : one group of the northern $T$. grandis populations and another group of the southern and Benin T. grandis populations (Fig. 14). The number of populations $(K)$ was determined by the highest absolute probability value $L n$ $(P(D))$ (Fig. 15A). Additionally, the optimal number of population $(K=2)$ was also chosen by Evanno et al. method based on the highest $\Delta K$ value (Fig. 15B). Assignment of individual genotypes followed the prior defined sub-populations as most individual genotypes were assigned to the prior cluster of each region. Similar results were obtained with the noadmixture model (Fig. 16 and Fig. 17). The $\Delta K$ values computed based on the no-admixture model were smaller than the $\Delta K$ values based on the admixture model. 

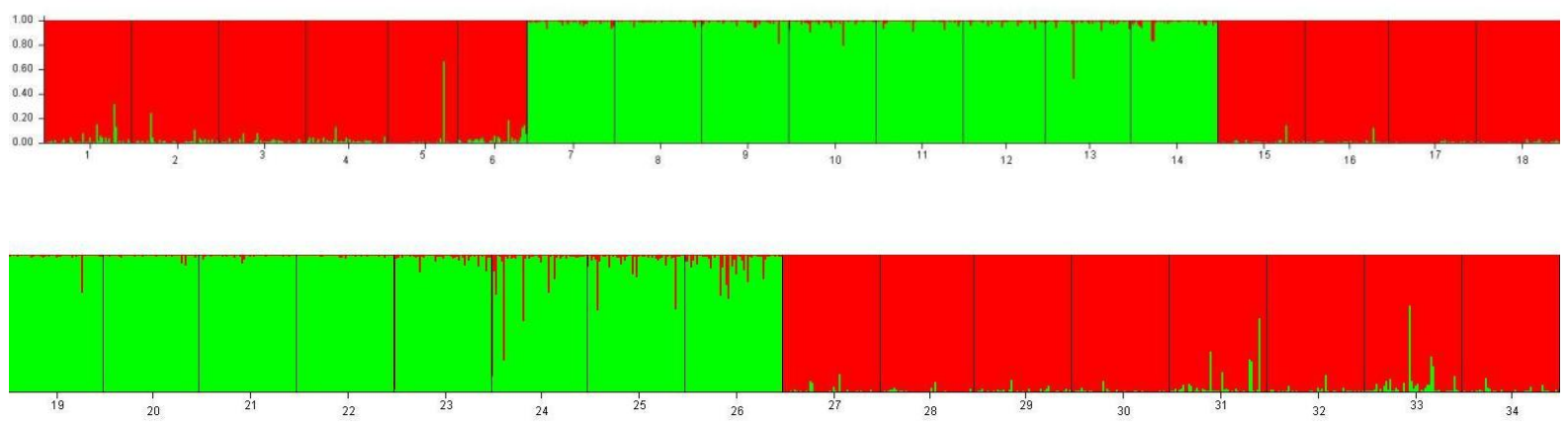

Fig. 14 Clusters of 34 T. grandis populations based on the admixture model at SSRs. Red color represents the southern populations and Benin plantations (No. 5and 6) and green color represents the northern populations.

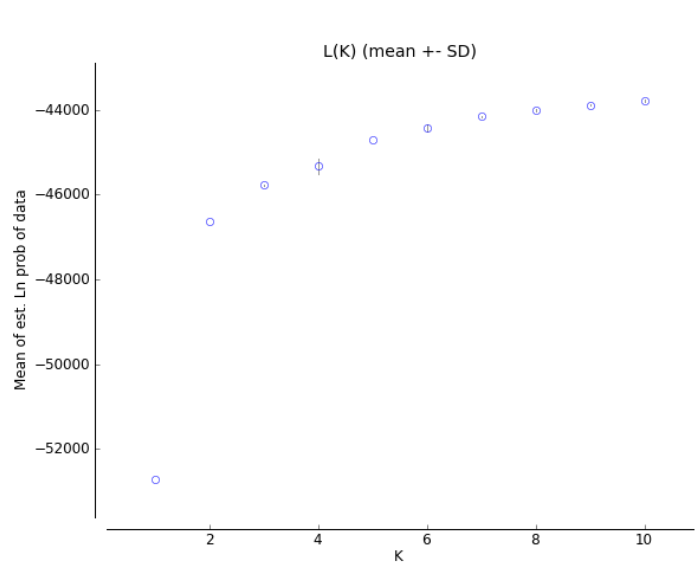

(A)

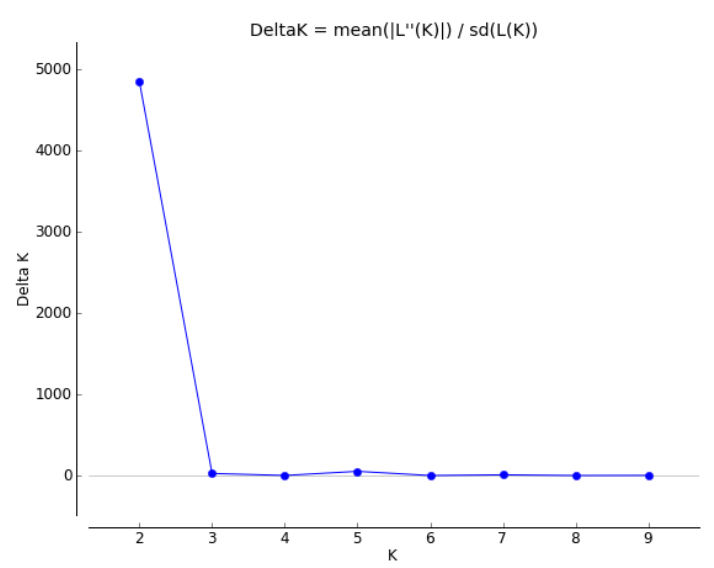

(B)

Fig. 15 Population structure of $34 T$. grandis populations at SSRs. Detection of the true number of clusters $K$. (A) distribution of mean of estimated $L n$ probability of data based on 10 SSR loci for the admixture model (B) magnitude of $\Delta K$ as a function of $K$ (Evanno et al., 2005). 

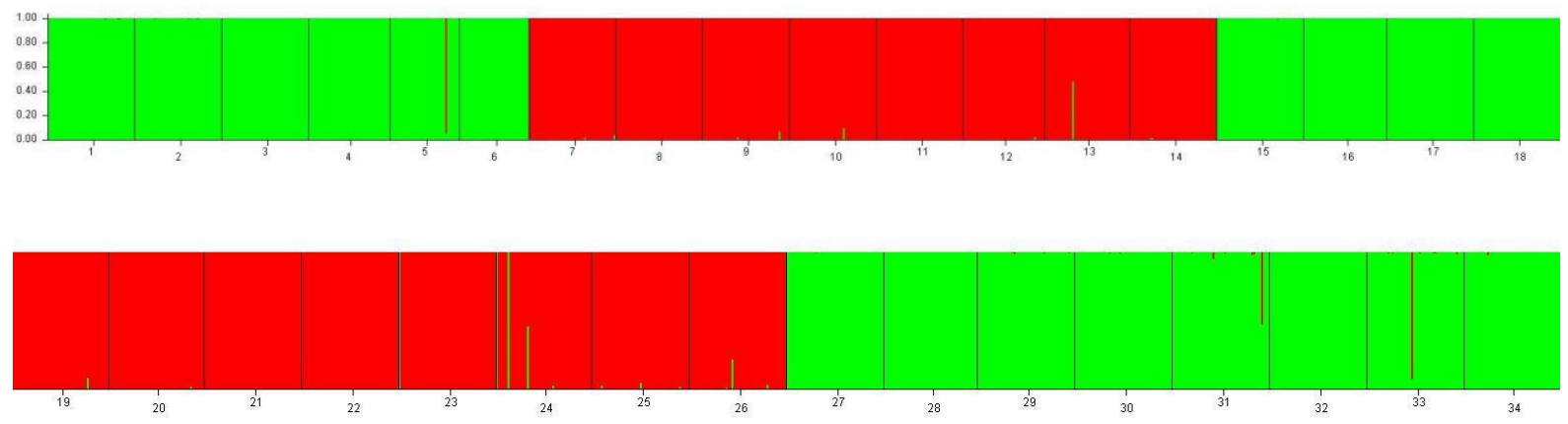

Fig. 16 Clusters of 34 T. grandis populations based on the no-admixture model at SSRs. Green color represents the southern populations and Benin plantations (No. 5 and 6) and red color represents the northern populations.

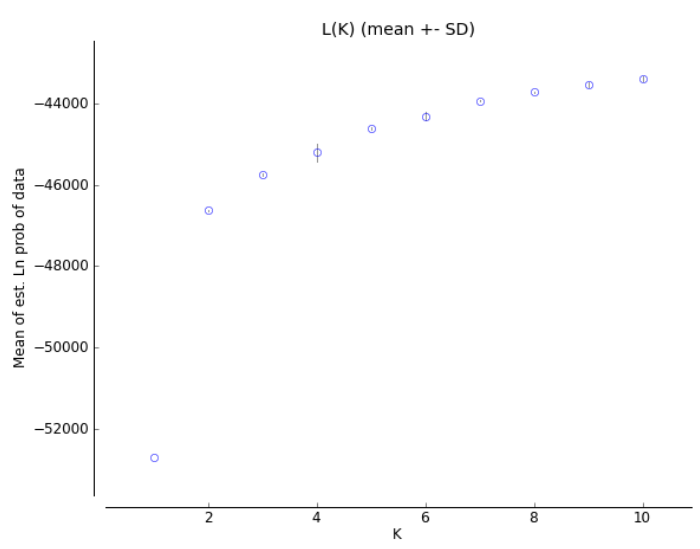

(A)

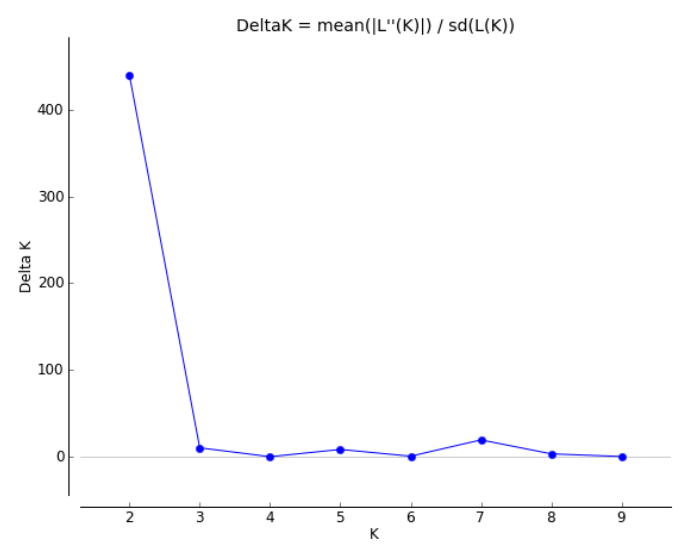

(B)

Fig. 17 Population structure of 34 T. grandis populations at SSRs. Detection of the true number of clusters $K$. (A) distribution of mean of estimated $L n$ probability of data based on $10 \mathrm{SSR}$ loci for the no-admixture model (B) magnitude of $\Delta K$ as a function of $K$ (Evanno et al., 2005). 


\subsection{Genetic variation at AFLPs}

\subsubsection{Genetic diversity within populations}

AFLPs revealed that genetic diversity varied among populations (Table 10). The percent of polymorphic loci and Nei's gene diversity was lowest in PMSR $\left(P P L=36.6 \%, H_{\mathrm{j}}=0.151\right)$ and highest in ISR $\left(P P L=94.4 \%, H_{\mathrm{j}}=0.268\right)$ (Table 10). Meanwhile, another estimate of genetic diversity $(\mathrm{Br})$ revealed lowest in TSA $(\mathrm{Br}=0.158)$ and highest in IUA $(\mathrm{Br}=0.190)$.

Genetic diversity of $T$. grandis also varied among adult and regeneration populations (Table 10). All estimates of genetic diversity for adults was higher than for regeneration in both selectively-logged and unlogged populations in Aunglan, Mabein and Pyinmana and in unlogged populations in Bamauk, Indaw, and Pinlebu. However, genetic diversity for adults was lower than for regeneration in Tharawaddy and in selectively-logged populations in Indaw and Letpadan.

Genetic diversity of BEN1 plantation was lower than that of BEN2 plantation in Benin. The estimates of average genetic diversity of Benin plantations were lower than those of Myanmar populations (Table 10).

\subsubsection{Significant tests for genetic diversity}

ANOVA tests revealed that the estimates of genetic diversity of $T$. grandis for overall adults and regeneration were not significantly different $\left(P P L \%, H_{\mathrm{j}}, \mathrm{Br}\right.$; Table 11$)$. However, in the unlogged T. grandis populations, genetic diversity $\left(H_{\mathrm{j}}\right)$ for adults was significantly higher than for regeneration $(P<0.5)$ while the other two estimates $(P P L \%$ and $B r)$ were not significantly different. Conversely, the genetic diversity of regeneration is slightly higher in selectively-logged than in unlogged $T$. grandis populations though the estimates were not significant.

All estimates of genetic diversity of $T$. grandis for the selectively-logged and unlogged populations were not significantly different $(\mathrm{P}>0.05$; Table 11). Meanwhile, genetic diversity of the northern populations was significantly higher than that of the southern populations (Table 11). Genetic diversity of adults was significantly higher in the northern populations. 
Table 10 Genetic diversity within populations of T. grandis at AFLPs.

\begin{tabular}{|c|c|c|c|c|c|c|c|}
\hline Area & Populations & $\begin{array}{l}\text { Logging } \\
\text { types }\end{array}$ & $\begin{array}{l}\text { Sample } \\
\text { types }\end{array}$ & $n$ & $P P L$ & $H_{\mathrm{j}}$ & $\mathrm{Br}$ \\
\hline \multirow{4}{*}{ Aunglan } & ASA & SL & $\mathrm{AD}$ & 48 & 70.4 & 0.207 & 1.734 \\
\hline & ASR & SL & RE & 49 & 69.0 & 0.198 & 1.728 \\
\hline & AUA & UL & $\mathrm{AD}$ & 45 & 69.0 & 0.212 & 1.761 \\
\hline & AUR & UL & $\mathrm{RE}$ & 46 & 73.2 & 0.194 & 1.665 \\
\hline \multirow[t]{4}{*}{ Bamauk } & BSA & SL & $\mathrm{AD}$ & 48 & 73.2 & 0.201 & 1.771 \\
\hline & BSR & SL & RE & 47 & 76.1 & 0.209 & 1.773 \\
\hline & BUA & UL & $\mathrm{AD}$ & 38 & 84.5 & 0.257 & 1.861 \\
\hline & BUR & UL & $\mathrm{RE}$ & 49 & 74.6 & 0.210 & 1.774 \\
\hline \multirow[t]{4}{*}{ Indaw } & ISA & SL & $\mathrm{AD}$ & 35 & 83.1 & 0.243 & 1.831 \\
\hline & ISR & SL & $\mathrm{RE}$ & 45 & 94.4 & 0.268 & 1.882 \\
\hline & IUA & UL & $\mathrm{AD}$ & 43 & 83.1 & 0.245 & 1.901 \\
\hline & IUR & UL & RE & 45 & 71.8 & 0.179 & 1.673 \\
\hline \multirow[t]{4}{*}{ Letpadan } & LSA & SL & $\mathrm{AD}$ & 49 & 52.1 & 0.185 & 1.662 \\
\hline & LSR & SL & $\mathrm{RE}$ & 48 & 52.1 & 0.198 & 1.712 \\
\hline & LUA & UL & $\mathrm{AD}$ & 47 & 62.0 & 0.197 & 1.710 \\
\hline & LUR & UL & $\mathrm{RE}$ & 47 & 49.3 & 0.191 & 1.694 \\
\hline \multirow[t]{4}{*}{ Mabein } & MSA & SL & $\mathrm{AD}$ & 34 & 78.9 & 0.253 & 1.887 \\
\hline & MSR & SL & $\mathrm{RE}$ & 45 & 67.6 & 0.200 & 1.724 \\
\hline & MUA & UL & $\mathrm{AD}$ & 43 & 84.5 & 0.256 & 1.839 \\
\hline & MUR & UL & $\mathrm{RE}$ & 49 & 74.6 & 0.204 & 1.751 \\
\hline \multirow[t]{4}{*}{ Pinlebu } & PLSA & SL & $\mathrm{AD}$ & 43 & 60.6 & 0.182 & 1.676 \\
\hline & PLSR & SL & $\mathrm{RE}$ & 48 & 70.4 & 0.199 & 1.864 \\
\hline & PLUA & $\mathrm{UL}$ & $\mathrm{AD}$ & 45 & 74.6 & 0.222 & 1.804 \\
\hline & PLUR & UL & $\mathrm{RE}$ & 48 & 39.4 & 0.165 & 1.621 \\
\hline \multirow[t]{4}{*}{ Pyinmana } & PMSA & SL & $\mathrm{AD}$ & 49 & 69.0 & 0.219 & 1.801 \\
\hline & PMSR & SL & $\mathrm{RE}$ & 47 & 36.6 & 0.151 & 1.603 \\
\hline & PMUA & $\mathrm{UL}$ & $\mathrm{AD}$ & 47 & 67.6 & 0.199 & 1.694 \\
\hline & PMUR & UL & $\mathrm{RE}$ & 48 & 63.4 & 0.171 & 1.657 \\
\hline \multirow[t]{5}{*}{ Tharawaddy } & TSA & SL & $\mathrm{AD}$ & 47 & 42.3 & 0.155 & 1.584 \\
\hline & TSR & SL & $\mathrm{RE}$ & 49 & 70.4 & 0.202 & 1.718 \\
\hline & TUA & $\mathrm{UL}$ & $\mathrm{AD}$ & 46 & 36.6 & 0.158 & 1.625 \\
\hline & TUR & UL & $\mathrm{RE}$ & 48 & 53.5 & 0.194 & 1.738 \\
\hline & Myanmar & & & 45 & 72.2 & 0.215 & 1.767 \\
\hline \multirow[t]{3}{*}{ Benin } & BEN1 & & $\mathrm{AD}$ & 40 & 39.4 & 0.151 & 1.489 \\
\hline & BEN2 & & $\mathrm{AD}$ & 38 & 67.6 & 0.187 & 1.592 \\
\hline & Benin & & & 39 & 53.5 & 0.169 & 1.541 \\
\hline
\end{tabular}

$S L$ selectively-logged populations, $U L$ unlogged populations, $A D$ adults, $R E$ regeneration, $n$ number of samples, $H_{\mathrm{j}}$ gene diversity (Nei, 1978), $P P L$ percent of polymorphic loci, $B r$ band richness based on small sample size $(n=35)$. 
Table 11 Differences in genetic diversity within T. grandis at AFLPs.

\begin{tabular}{lcccc}
\hline & $\mathrm{N}$ & $P P L$ & $H_{\mathrm{j}}$ & $\mathrm{Br}$ \\
\hline Sample types (adults vs. regeneration) & & \\
Adults & 16 & 68.2 & 0.212 & 1.759 \\
Regeneration & 16 & 64.8 & 0.196 & 1.724
\end{tabular}

Management types (UL vs. SL)

$\begin{array}{lllll}\text { UL } & 16 & 66.4 & 0.203 & 1.736 \\ \text { SL } & 16 & 66.6 & 0.204 & 1.747\end{array}$

Regions (northern vs. southern)

$\begin{array}{lllll}\text { Northern } & 16 & 74.5^{a_{* *}} & 0.218^{a_{* *}} & 1.790^{a_{* * *}} \\ \text { Southern } & 16 & 58.5^{b_{* *}} & 0.189^{b_{* *}} & 1.693^{b_{* * *}}\end{array}$

SL (adults vs. regeneration)

$\begin{array}{lllll}\text { Adult } & 8 & 66.2 & 0.206 & 1.743 \\ \text { Regen. } & 8 & 67.1 & 0.203 & 1.751\end{array}$

UL (adults vs. regeneration)

$\begin{array}{lllll}\text { Adults } & 8 & 70.2 & 0.218^{\mathrm{a}^{*}} & 1.774 \\ \text { Regen. } & 8 & 62.5 & 0.188^{\mathrm{b}^{*}} & 1.697\end{array}$

Adults (SL vs. UL)

$\begin{array}{lllll}\text { UL } & 8 & 70.2 & 0.218 & 1.774 \\ \text { SL } & 8 & 66.2 & 0.206 & 1.743\end{array}$

Regeneration (SL vs. UL)

$\begin{array}{lllll}\text { UL } & 8 & 62.5 & 0.188 & 1.697 \\ \text { SL } & 8 & 67.1 & 0.203 & 1.751\end{array}$

Adults (northern vs. southern)

$\begin{array}{lllll}\text { Northern } & 8 & 77.8^{\mathrm{a}^{* *}} & 0.232^{\mathrm{a}^{* *}} & 1.821^{\mathrm{a}^{* *}} \\ \text { Southern } & 8 & 58.6^{\mathrm{b}^{* *}} & 0.191^{\mathrm{b}^{* *}} & 1.696^{\mathrm{b}^{* *}}\end{array}$

Regeneration (northern vs. southern)

\begin{tabular}{lllll} 
Northern & 8 & 71.1 & 0.204 & 1.758 \\
Southern & 8 & 58.4 & 0.187 & 1.689 \\
\hline
\end{tabular}

$S L$ selectively logged populations, $U L$ unlogged populations, $N$ number of populations, $H_{\mathrm{j}}$ gene diversity (Nei, 1978), PPL \% percent of polymorphic loci, $\mathrm{Br}$ band richness based on small sample size $(\mathrm{n}=35)$. Values followed by different letters with $(*)(* *)$ and $(* * *)$ are significant at $P<0.05, P<0.01$ and $P<0.001$, respectively. All other values are not significant. 


\subsubsection{Genetic distances and differentiation}

\subsubsection{Nei's genetic distances among $34 T$. grandis populations}

The largest genetic distance was observed between BEN1 and PLSA (see appendix). The largest genetic distances among T. grandis populations in Myanmar were observed between the northern and southern regions while the smallest genetic distances were observed within regions.

\subsubsection{Pairwise $F_{\text {ST }}$ among $34 T$. grandis populations}

There was significant genetic differentiation between almost all population pairs except MUA and MSA populations as indicated by pairwise $F_{\mathrm{ST}} \mathrm{S}$ (see appendix). Genetic differentiations between pairwise populations ranged from 0.004 between MUA and MSA to 0.365 between PLSA and BEN1. BEN1 and BEN2 plantations were genetically most differentiated from PLSA while they were least differentiated from TSR.

Genetic differentiation between BEN1 plantation and Myanmar T. grandis populations was mostly higher. Generally, genetic differentiation between the two regions was higher than within region, and the highest pairwise differentiation was detected between populations of the two regions $\left(F_{\mathrm{ST}}=0.288\right.$, PLUR and TSA).

\subsubsection{Nei's genetic distances among adult and among regeneration populations}

The highest genetic distances were observed between the northern and southern regions (0.063 for adults (PLS vs. LS); 0.042 for regeneration (LS vs. IS); Table 12) while the lowest genetic distances were detected within the regions, particularly in population pairs in each area (0.007 for adults (TS vs. TU); 0.005 for regeneration (PLS vs. PLU); Table 12).

\subsubsection{Pairwise $\boldsymbol{F}_{\mathrm{ST}}$ among adult and among regeneration populations}

Genetic differentiation (pairwise $F_{\mathrm{ST}}$ ) among adult populations and among regeneration populations was significant except one adult population pair (MU vs. MS) (Table 13). The highest genetic differentiations were observed between the northern and southern populations 
$\left(F_{\mathrm{ST}}=0.277\right.$ for adults (PLS vs. TS); $F_{\mathrm{ST}}=0.207$ for regeneration (PLU vs. AS); Table 13). Meanwhile, the lowest genetic differentiations were observed within the regions $\left(F_{\mathrm{ST}}=0.004\right.$ for adults (MU vs. MS); $F_{\mathrm{ST}}=0.014$ for regeneration (PLU vs. PLS); Table 13). 
Table 12 Nei's unbiased genetic distances (1978) for adults (below diagonal) and regeneration (above diagonal) in T. grandis populations at AFLPs.

\begin{tabular}{lcccccccccccccccc}
\hline & AS & AU & BS & BU & IS & IU & LS & LU & MS & MU & PLS & PLU & PMS & PMU & TS & TU \\
\hline AS & & 0.010 & 0.035 & 0.040 & 0.045 & 0.027 & 0.015 & 0.016 & 0.043 & 0.039 & 0.034 & 0.038 & 0.012 & 0.016 & 0.017 & 0.019 \\
AU & 0.007 & & 0.032 & 0.032 & 0.038 & 0.017 & 0.018 & 0.012 & 0.039 & 0.032 & 0.032 & 0.030 & 0.011 & 0.019 & 0.015 & 0.018 \\
BS & 0.039 & 0.032 & & 0.009 & 0.019 & 0.013 & 0.030 & 0.031 & 0.016 & 0.009 & 0.010 & 0.014 & 0.029 & 0.025 & 0.034 & 0.033 \\
BU & 0.025 & 0.026 & 0.017 & & 0.016 & 0.010 & 0.035 & 0.034 & 0.012 & 0.009 & 0.011 & 0.017 & 0.030 & 0.026 & 0.037 & 0.035 \\
IS & 0.050 & 0.040 & 0.020 & 0.013 & & 0.026 & 0.042 & 0.039 & 0.018 & 0.022 & 0.028 & 0.039 & 0.035 & 0.033 & 0.039 & 0.036 \\
IU & 0.035 & 0.028 & 0.022 & 0.008 & 0.009 & & 0.025 & 0.022 & 0.021 & 0.013 & 0.013 & 0.016 & 0.022 & 0.026 & 0.024 & 0.031 \\
LS & 0.025 & 0.023 & 0.056 & 0.035 & 0.059 & 0.037 & & 0.006 & 0.044 & 0.032 & 0.025 & 0.030 & 0.017 & 0.024 & 0.015 & 0.014 \\
LU & 0.029 & 0.019 & 0.038 & 0.025 & 0.033 & 0.021 & 0.023 & & 0.039 & 0.026 & 0.024 & 0.024 & 0.013 & 0.022 & 0.008 & 0.010 \\
MS & 0.030 & 0.028 & 0.024 & 0.017 & 0.029 & 0.027 & 0.036 & 0.039 & & 0.010 & 0.020 & 0.027 & 0.037 & 0.029 & 0.041 & 0.039 \\
MU & 0.034 & 0.037 & 0.031 & 0.019 & 0.028 & 0.021 & 0.035 & 0.034 & 0.009 & & 0.011 & 0.017 & 0.033 & 0.028 & 0.032 & 0.033 \\
PLS & 0.059 & 0.049 & 0.031 & 0.026 & 0.018 & 0.018 & 0.063 & 0.030 & 0.050 & 0.045 & & 0.005 & 0.032 & 0.030 & 0.030 & 0.031 \\
PLU & 0.039 & 0.031 & 0.013 & 0.014 & 0.011 & 0.012 & 0.045 & 0.027 & 0.032 & 0.030 & 0.014 & & 0.032 & 0.034 & 0.030 & 0.029 \\
PMS & 0.013 & 0.016 & 0.051 & 0.026 & 0.049 & 0.030 & 0.017 & 0.026 & 0.038 & 0.039 & 0.059 & 0.039 & & 0.009 & 0.013 & 0.011 \\
PMU & 0.010 & 0.009 & 0.029 & 0.018 & 0.037 & 0.022 & 0.021 & 0.023 & 0.024 & 0.029 & 0.041 & 0.024 & 0.008 & & 0.019 & 0.016 \\
TS & 0.025 & 0.023 & 0.049 & 0.041 & 0.059 & 0.044 & 0.019 & 0.031 & 0.045 & 0.044 & 0.067 & 0.048 & 0.024 & 0.024 & \\
TU & 0.019 & 0.016 & 0.041 & 0.030 & 0.047 & 0.033 & 0.020 & 0.022 & 0.041 & 0.040 & 0.050 & 0.036 & 0.021 & 0.017 & 0.007 & \\
\hline
\end{tabular}

Populations: the last letter; $S$ selectively-logged $T$. grandis population and $U$ unlogged $T$. grandis population, the first letters; $A$ Aunglan, $B$ Bamauk, I Indaw, $L$ Letpadan, $M$ Mabein, $P L$ Pinlebu, $P M$ Pyinmana and $T$ Tharawaddy. 
Table 13 Pairwise $F_{\mathrm{ST}}$ for adults (below diagonal) and regeneration (above diagonal) in T. grandis populations at AFLPs.

\begin{tabular}{lcccccccccccccccc}
\hline & AS & AU & BS & BU & IS & IU & LS & LU & MS & MU & PLS & PLU & PMS & PMU & TS & TU \\
\hline AS & & 0.023 & 0.151 & 0.161 & 0.117 & 0.109 & 0.080 & 0.056 & 0.141 & 0.141 & 0.169 & 0.207 & 0.068 & 0.099 & 0.045 & 0.064 \\
AU & 0.021 & & 0.134 & 0.140 & 0.086 & 0.093 & 0.095 & 0.069 & 0.139 & 0.138 & 0.152 & 0.200 & 0.090 & 0.106 & 0.068 & 0.094 \\
BS & 0.211 & 0.176 & & 0.018 & 0.063 & 0.046 & 0.163 & 0.145 & 0.032 & 0.034 & 0.038 & 0.051 & 0.157 & 0.114 & 0.143 & 0.147 \\
BU & 0.097 & 0.094 & 0.082 & & 0.059 & 0.046 & 0.169 & 0.161 & 0.037 & 0.039 & 0.036 & 0.068 & 0.161 & 0.121 & 0.165 & 0.163 \\
IS & 0.148 & 0.115 & 0.071 & 0.029 & & 0.058 & 0.157 & 0.147 & 0.068 & 0.081 & 0.101 & 0.143 & 0.126 & 0.096 & 0.139 & 0.145 \\
IU & 0.111 & 0.079 & 0.090 & 0.029 & 0.018 & & 0.129 & 0.116 & 0.048 & 0.056 & 0.052 & 0.089 & 0.121 & 0.108 & 0.100 & 0.138 \\
LS & 0.112 & 0.080 & 0.234 & 0.131 & 0.179 & 0.116 & & 0.017 & 0.159 & 0.143 & 0.159 & 0.199 & 0.110 & 0.139 & 0.057 & 0.062 \\
LU & 0.116 & 0.063 & 0.203 & 0.115 & 0.119 & 0.082 & 0.079 & & 0.143 & 0.127 & 0.151 & 0.183 & 0.096 & 0.127 & 0.042 & 0.041 \\
MS & 0.123 & 0.106 & 0.117 & 0.055 & 0.081 & 0.075 & 0.130 & 0.135 & & 0.037 & 0.057 & 0.091 & 0.139 & 0.098 & 0.141 & 0.141 \\
MU & 0.119 & 0.111 & 0.130 & 0.059 & 0.074 & 0.069 & 0.130 & 0.131 & 0.004 & & 0.069 & 0.101 & 0.159 & 0.116 & 0.132 & 0.130 \\
PLS & 0.244 & 0.202 & 0.143 & 0.109 & 0.064 & 0.061 & 0.245 & 0.176 & 0.181 & 0.170 & & 0.014 & 0.190 & 0.145 & 0.147 & 0.157 \\
PLU & 0.159 & 0.124 & 0.040 & 0.041 & 0.024 & 0.037 & 0.171 & 0.141 & 0.094 & 0.092 & 0.059 & & 0.237 & 0.188 & 0.178 & 0.191 \\
PMS & 0.034 & 0.036 & 0.232 & 0.099 & 0.148 & 0.100 & 0.088 & 0.093 & 0.134 & 0.126 & 0.236 & 0.158 & & 0.035 & 0.075 & 0.058 \\
PMU & 0.029 & 0.028 & 0.183 & 0.084 & 0.135 & 0.078 & 0.102 & 0.102 & 0.116 & 0.116 & 0.207 & 0.127 & 0.020 & & 0.094 & 0.073 \\
TS & 0.127 & 0.108 & 0.266 & 0.169 & 0.191 & 0.139 & 0.104 & 0.102 & 0.185 & 0.174 & 0.277 & 0.199 & 0.108 & 0.116 & \\
TU & 0.100 & 0.092 & 0.255 & 0.144 & 0.175 & 0.123 & 0.109 & 0.106 & 0.181 & 0.176 & 0.256 & 0.182 & 0.080 & 0.089 & 0.031 & 0.045 \\
\hline
\end{tabular}

Populations: the last letter; $S$ selectively-logged T. grandis population and $U$ unlogged $T$. grandis population; the first letters; $A$ Aunglan, $B$ Bamauk, $I$ Indaw, $L$ Letpadan, $M$ Mabein, $P L$ Pinlebu, $P M$ Pyinmana and $T$ Tharawaddy, $n s$ not significant and all others are significant at $P<$ 0.05 . 


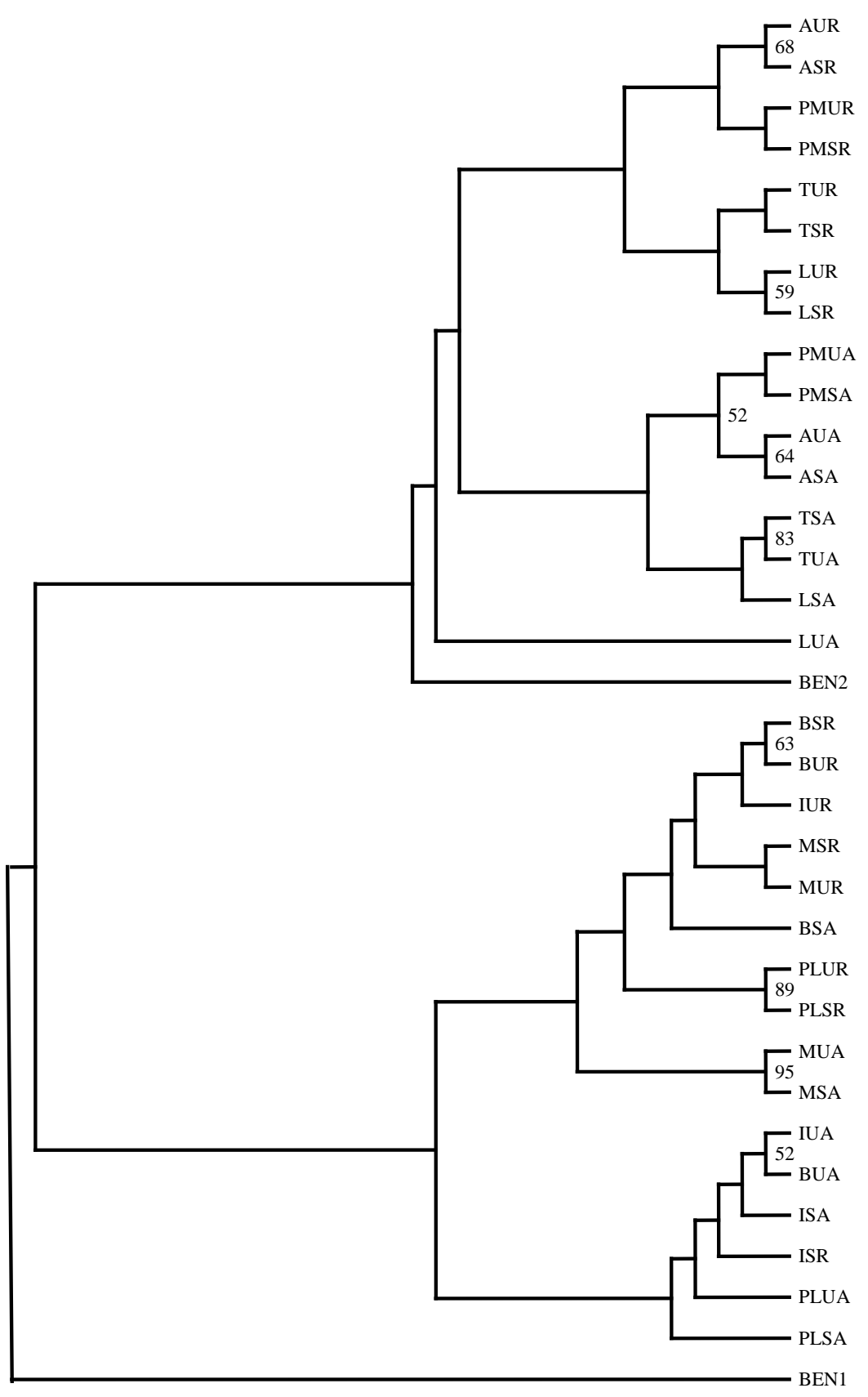

Fig. 18 UPGMA dendrogram based on Nei's genetic distances (1978) at AFLPs. The robustness of the tree was supported by bootstrapping values based on 1000 replications.

\subsubsection{Cluster analysis}

UPGMA dendrogram revealed two major clusters: one for the northern T. grandis populations and another one for the southern T. grandis populations and BEN2 plantation (Fig. 18). The BEN1 plantation behaved as outlier. In general, grouping among T. grandis populations was not strong as explained by low bootstrapping values. In the northern $T$. 
grandis populations, grouping was strong only between MSA and MUA. Meanwhile, in the southern T. grandis populations, grouping was strong only between TUA and TSA, and between AUR and ASR. Within each cluster, adult populations were mostly clustered together with adjacent adult populations while regeneration populations were also clustered together with adjacent regeneration populations.

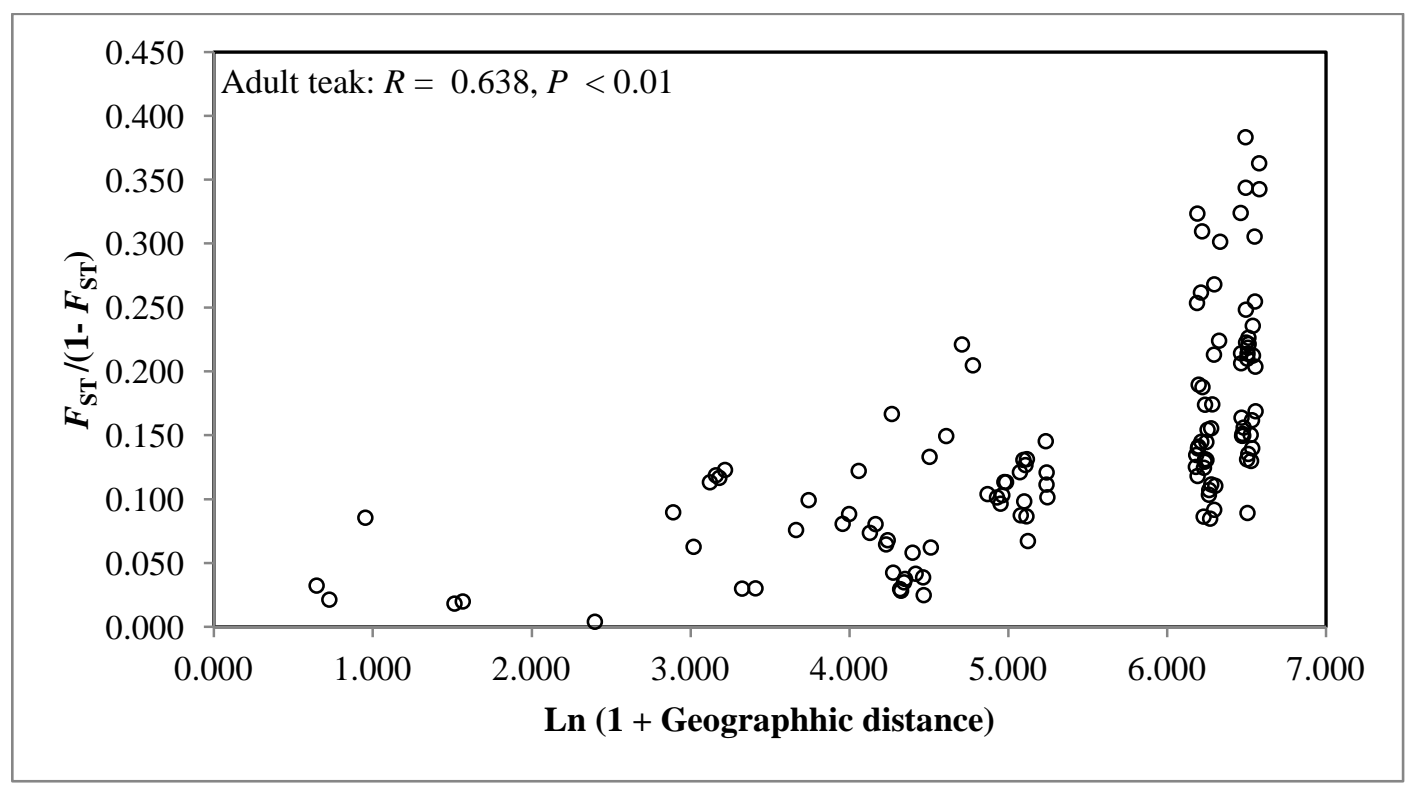

(A)

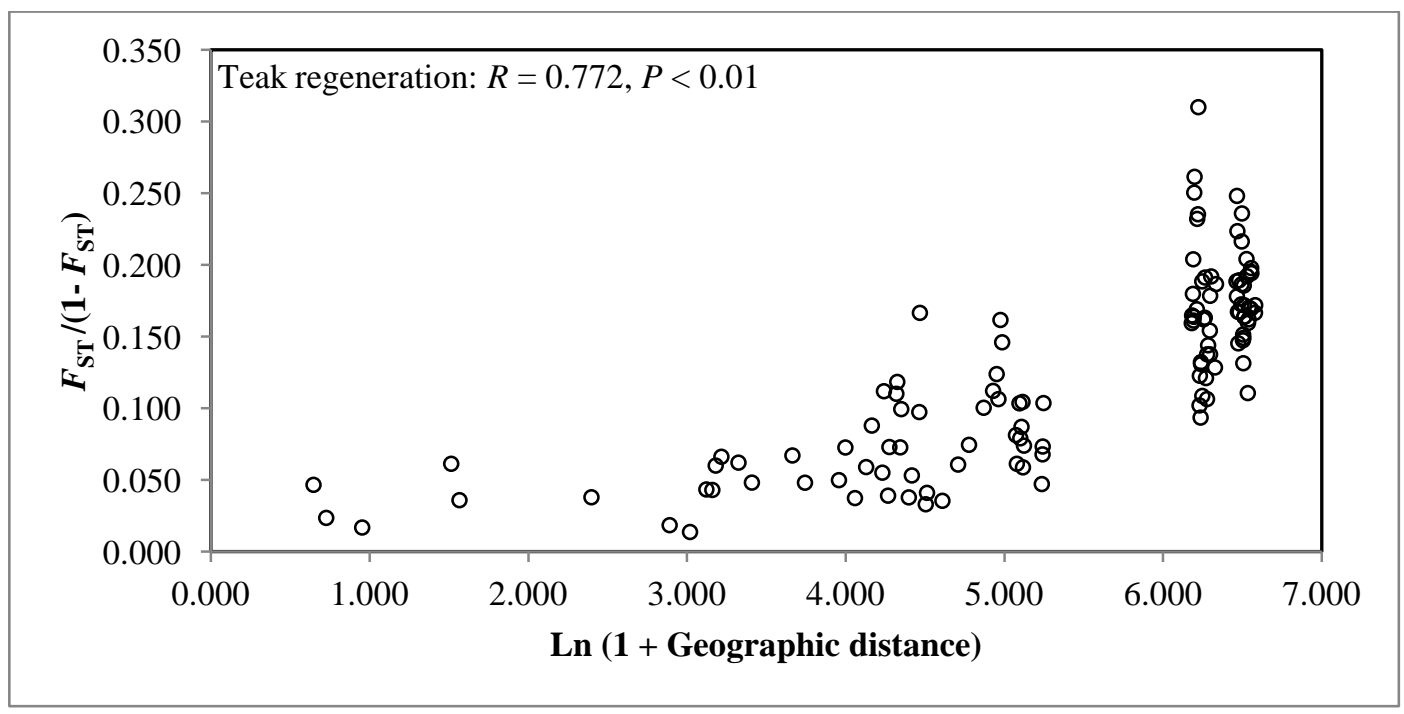

(B)

Fig. 19 Relationship between geographic and genetic distances among populations of $T$. grandis at AFLPs. (A) adults (B) regeneration. 


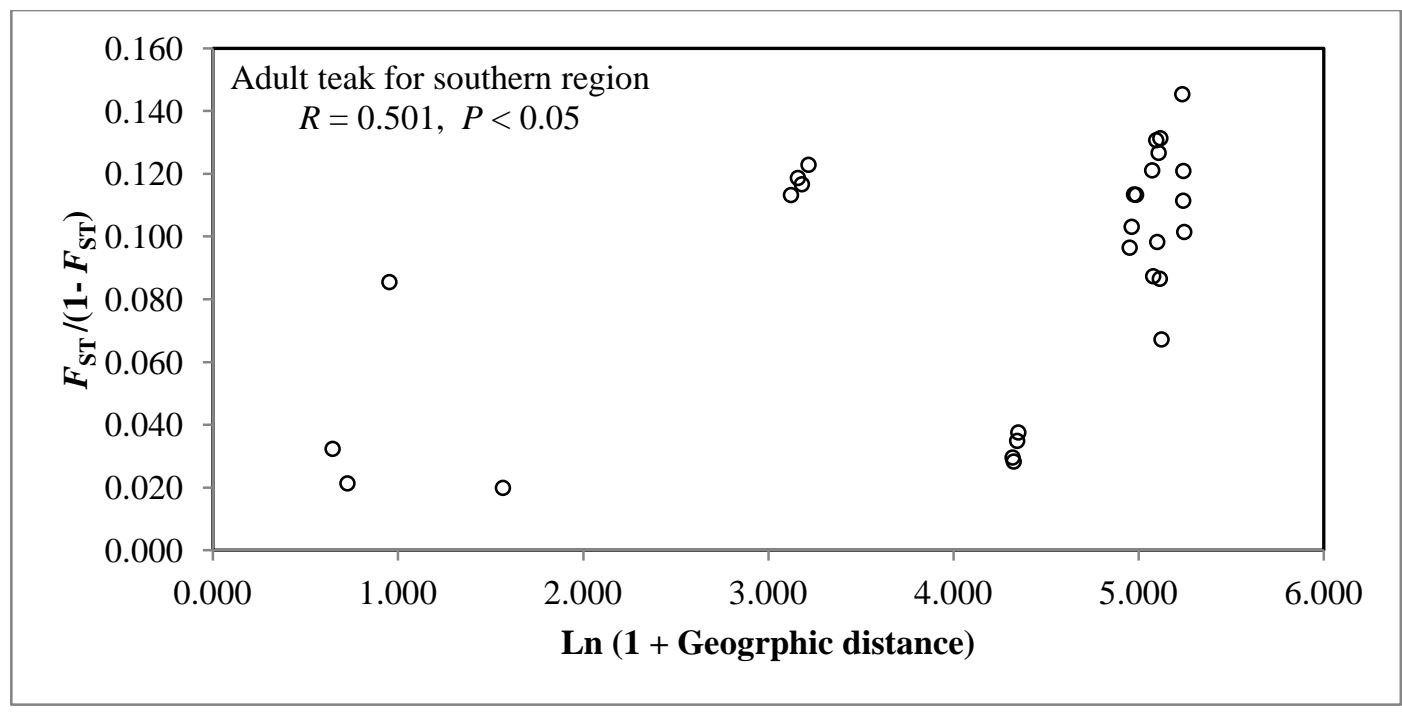

(A)

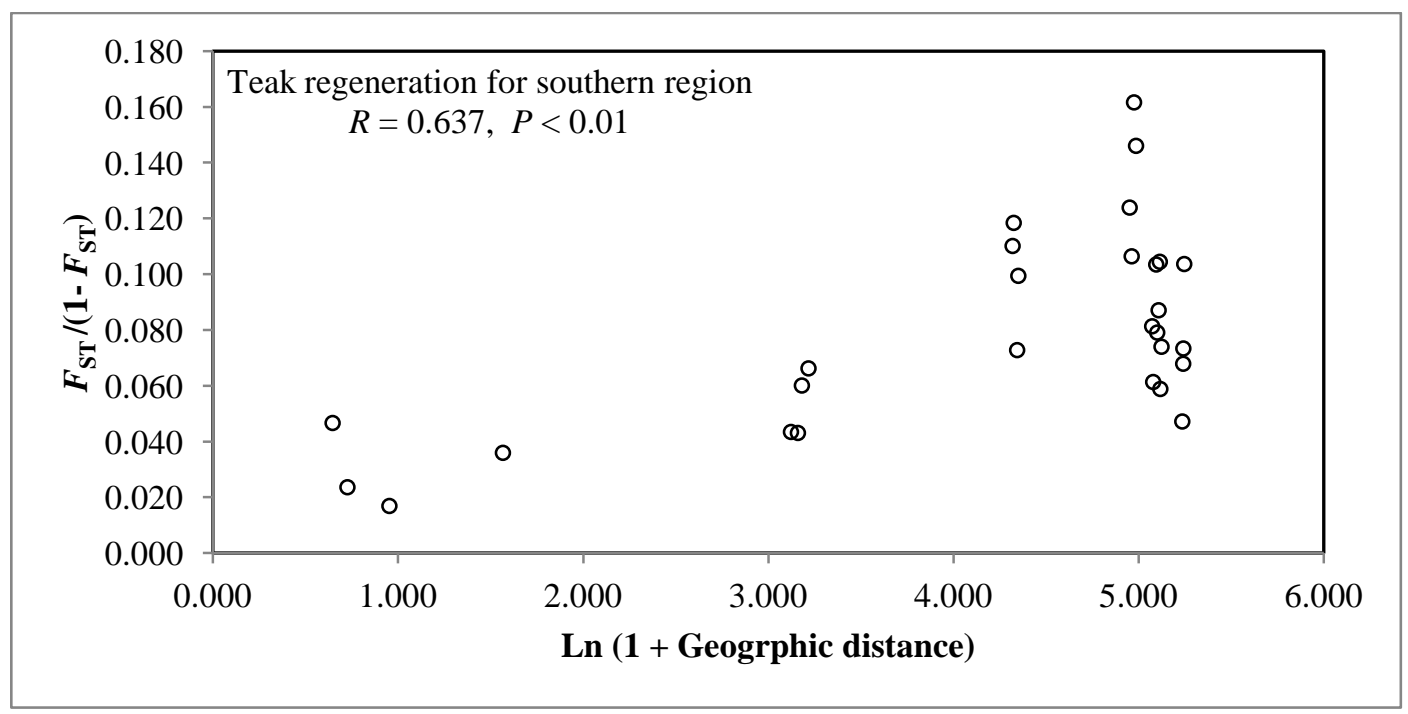

(B)

Fig. 20 Relationship between geographic and genetic distances among populations of $T$. grandis in the southern region of Myanmar at AFLPs. (A) adults (B) regeneration. 


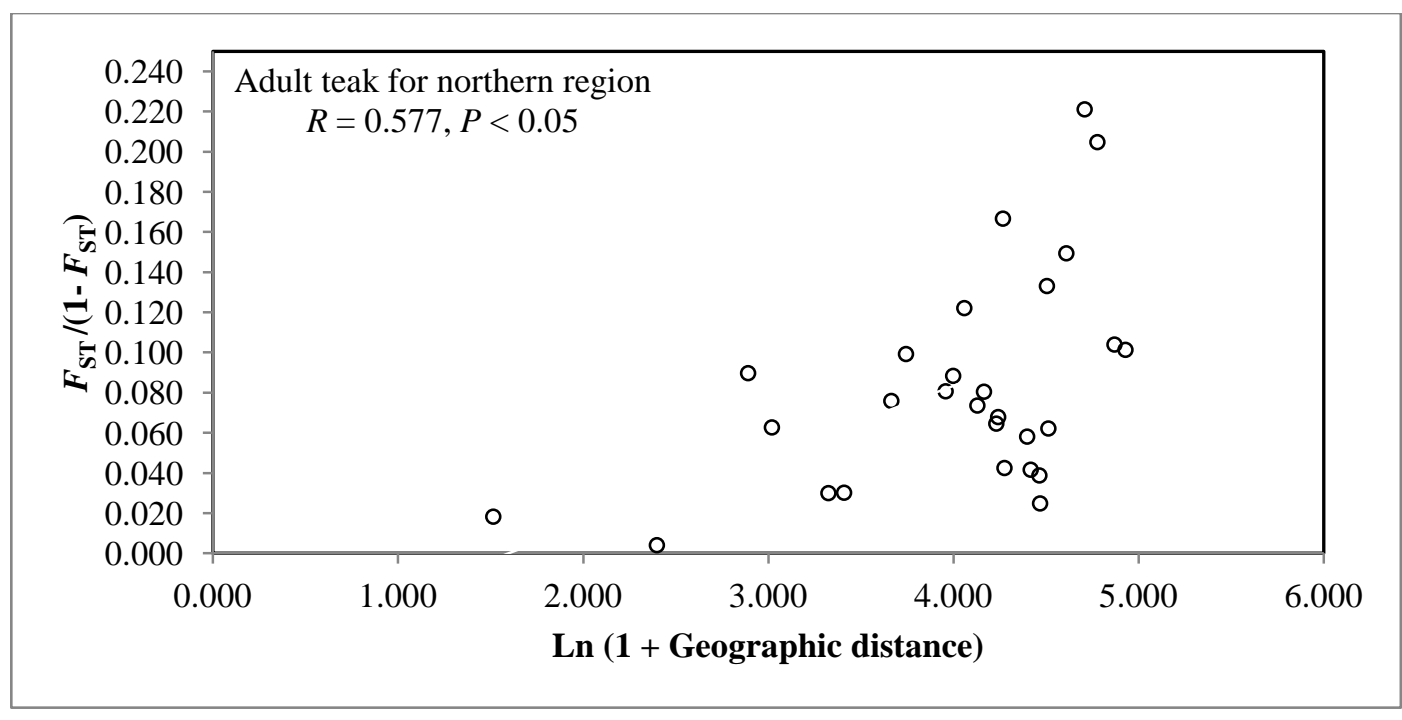

(A)

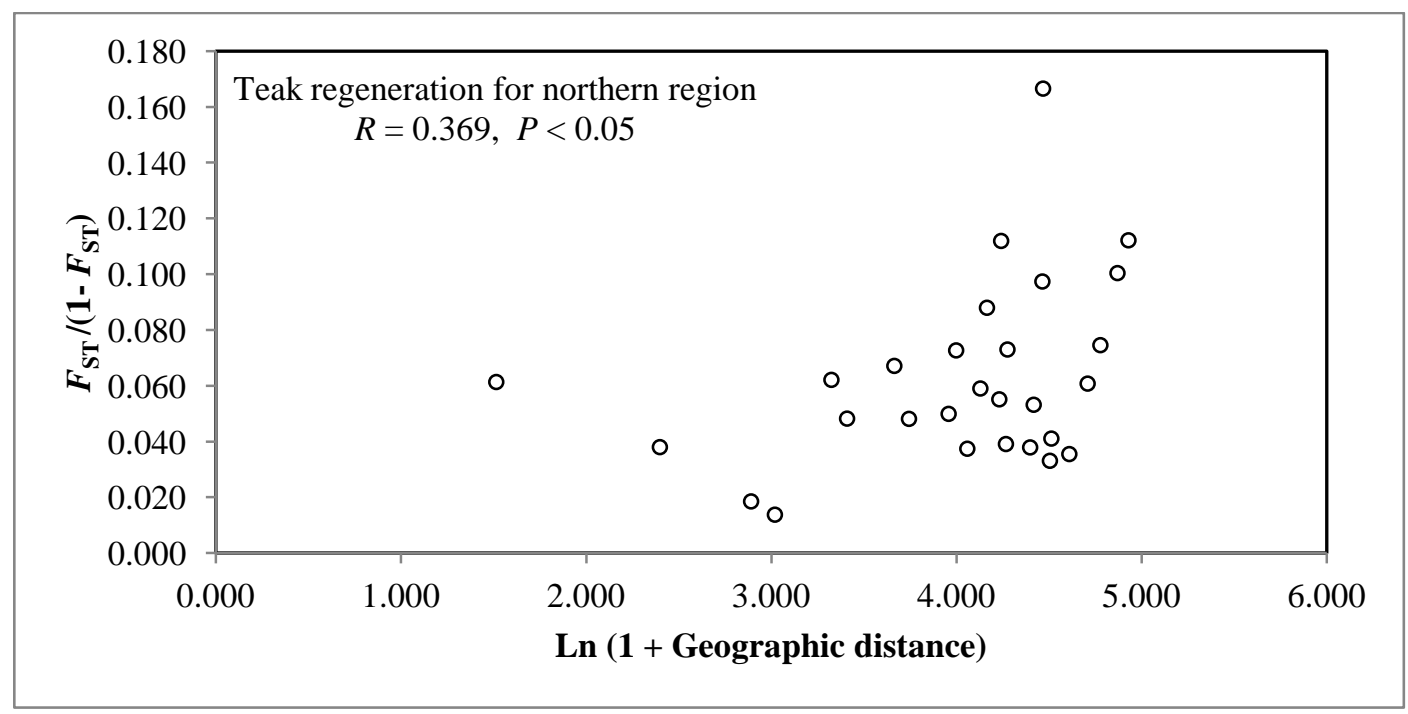

(B)

Fig. 21 Relationship between geographic and genetic distances among populations of $T$. grandis in the northern region of Myanmar at AFLPs. (A) adults (B) regeneration. 


\subsubsection{Mantel tests}

Mantel tests revealed significant and positive correlations between geographic and genetic distances among $T$. grandis populations for adults $(R=0.638, P<0.01$; Fig. 19) and regeneration $(R=0.772, P<0.01$; Fig. 19). Simiarly, significant and positive correlations were detected for adults and regeration in populations within the southern (Fig. 20) and northern (Fig. 21) regions. Regeneration in the southern region showed a slightly higher level of correlation compared to the adults in the same region $(R=0.637, P<0.01$ for regeneration; $R=0.501, P<0.05$ for adults; Fig. 20) while a relatively high level of correlation was observed for adults than regeneration in the northern region $(R=0.577, P<$ 0.05 for adults, $R=0.369, P<0.05$ for regeneration, Fig. 21).

\subsubsection{Principle Coordinate Analysis (PCA)}

The two axes explained $64.08 \%$ of the overall genetic variability (Fig. 22). The first axis $(40.81 \%)$ separated two groups: the northern populations and the southern populations including Benin plantations (Fig. 22). The second axis (23.27\%) illustrated that the northern T. grandis populations were genetically more differentiated than the southern populations. Benin T. grandis plantations stood outside of the southern T. grandis populations.

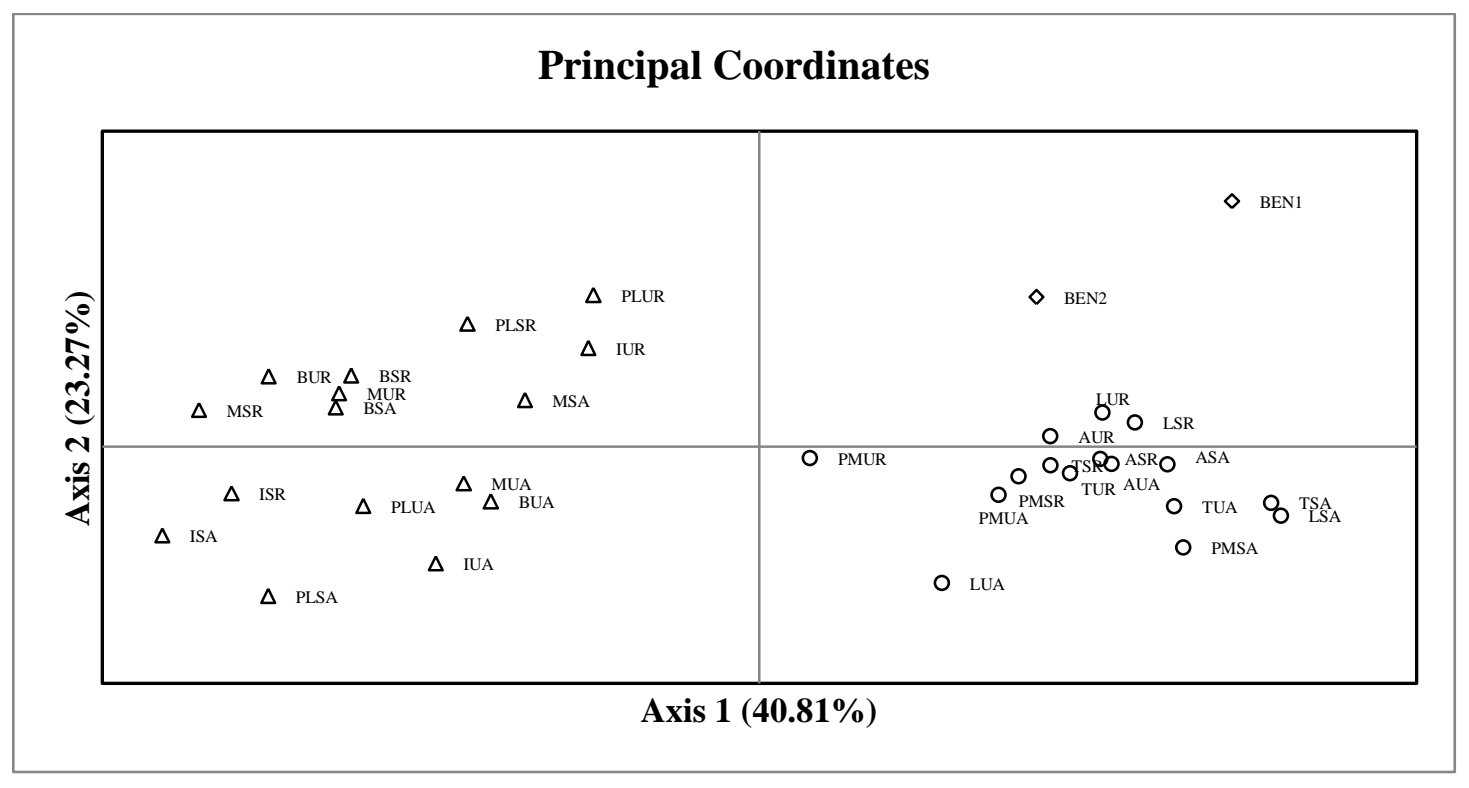

$\Delta$ northern populations, O southern populations, $\diamond$ Benin plantations

Fig. 22 Principal Coordinate Analysis (PCA) of T. grandis populations at AFLPs. 
Table 14 Analyses of Molecular Variance (AMOVA) for each group of T. grandis at AFLPs.

\begin{tabular}{lrrrrrr}
\hline \multicolumn{1}{l}{ Source of variation } & d.f. & S.S. & V.C. & $\%$ V & $\Phi_{\text {ST }}$ & $P$ value \\
\hline All Myanmar populations & & & & & & \\
Among populations & 31 & 1541.54 & 0.93 & 12.3 & 0.123 & $<0.001$ \\
Within populations & 1462 & 9603.81 & 6.57 & 87.7 & & \\
& & & & & & \\
Adult populations & & & & & & \\
Among populations & 15 & 741.46 & 0.95 & 12.27 & 0.123 & $<0.001$ \\
Within populations & 705 & 4776.11 & 6.78 & 87.73 & & \\
& & & & & & \\
Regeneration populations & & & & & & \\
Among populations & 15 & 669.21 & 0.80 & 11.04 & 0.110 & $<0.001$ \\
Within populations & 757 & 4827.70 & 6.38 & 88.96 & & \\
& & & & & & \\
Unlogged populations & & & & & & \\
Among populations & 15 & 688.06 & 0.84 & 11.31 & 0.113 & $<0.001$ \\
Within populations & 734 & 4824.87 & 6.57 & 88.69 & &
\end{tabular}

Selectively-logged populations

$\begin{array}{lrrrrrr}\text { Among populations } & 15 & 842.43 & 1.07 & 13.99 & 0.140 & <0.001 \\ \text { Within populations } & 728 & 4778.94 & 6.56 & 86.01 & & \end{array}$

Unlogged populations (adults)

$\begin{array}{lrrrrrr}\text { Among populations } & 7 & 331.24 & 0.90 & 11.23 & 0.112 & <0.001 \\ \text { Within populations } & 350 & 2488.31 & 7.11 & 88.77 & & \end{array}$

Selectively-logged populations (adults)

$\begin{array}{lrrrrrr}\text { Among populations } & 7 & 440.07 & 1.26 & 16.29 & 0.163 & <0.001 \\ \text { Within populations } & 351 & 2272.86 & 6.48 & 83.71 & & \end{array}$

Unlogged populations (regeneration)

$\begin{array}{lrrrrrr}\text { Among populations } & 7 & 316.02 & 0.80 & 11.64 & 0.116 & <0.001 \\ \text { Within populations } & 380 & 2321.62 & 6.11 & 88.36 & & \end{array}$

Selectively-logged (regeneration)

\begin{tabular}{lrrrrrr} 
Among populations & 7 & 339.10 & 0.87 & 11.56 & 0.116 & $<0.001$ \\
Within populations & 377 & 2506.08 & 6.65 & 88.44 & & \\
\hline
\end{tabular}

$S L$ selectively-logged populations, $U L$ unlogged populations, d.f. degree of freedom, S.S. sum of square, V.C. variance components, $\% V$ percentage of variation. $P$-values were obtained after 1000 permutations. 
Table 15 Analyses of Molecular Variance (AMOVA) for different groups of $T$. grandis at AFLPs.

\begin{tabular}{|c|c|c|c|c|c|c|}
\hline Source of variation & d.f. & S.S. & V.C. & $\% \mathrm{~V}$ & $\Phi$ statistics & $P$ value \\
\hline \multicolumn{7}{|c|}{ Adults and regeneration } \\
\hline Among groups & 1 & 130.88 & 0.112 & 1.5 & $\Phi_{\mathrm{CT}}=0.015$ & $<0.05$ \\
\hline \multicolumn{7}{|l|}{ Among populations } \\
\hline within groups & 30 & 1410.67 & 0.867 & 11.5 & $\Phi_{\mathrm{SC}}=0.117$ & $<0.001$ \\
\hline Within populations & 1462 & 9603.81 & 6.569 & 87.0 & $\Phi_{\mathrm{ST}}=0.130$ & $<0.001$ \\
\hline \multicolumn{7}{|c|}{ Unlogged and selectively-logged populations } \\
\hline Among groups & 1 & 11.05 & -0.054 & -0.72 & $\Phi_{\mathrm{CT}}=-0.007$ & $>0.5$ \\
\hline \multicolumn{7}{|l|}{ Among populations } \\
\hline within groups & 30 & 1530.49 & 0.952 & 12.8 & $\Phi_{\mathrm{SC}}=0.127$ & $<0.001$ \\
\hline Within populations & 1462 & 9603.81 & 6.569 & 88.0 & $\Phi_{\mathrm{ST}}=0.120$ & $<0.001$ \\
\hline \multicolumn{7}{|c|}{ Northern and southern regions } \\
\hline Among groups & 1 & 497.15 & 0.620 & 8.0 & $\Phi_{\mathrm{CT}}=0.080$ & $<0.001$ \\
\hline \multicolumn{7}{|l|}{ Among populations } \\
\hline within groups & 30 & 1044.39 & 0.605 & 7.8 & $\Phi_{\mathrm{SC}}=0.084$ & $<0.001$ \\
\hline Within populations & 1462 & 9603.81 & 6.569 & 84.3 & $\Phi_{\mathrm{ST}}=0.157$ & $<0.001$ \\
\hline \multicolumn{7}{|c|}{ Northern, southern regions and Benin } \\
\hline Among groups & 2 & 619.60 & 0.644 & 8.3 & $\Phi_{\mathrm{CT}}=0.083$ & $<0.001$ \\
\hline \multicolumn{7}{|l|}{ Among populations } \\
\hline within groups & 31 & 1085.41 & 0.614 & 7.9 & $\Phi_{\mathrm{SC}}=0.086$ & $<0.001$ \\
\hline Within populations & 1539 & 10036.42 & 6.521 & 83.8 & $\Phi_{\mathrm{ST}}=0.162$ & $<0.001$ \\
\hline
\end{tabular}

d.f. degree of freedom, S.S. sum of square, V.C. variance components, $\% V$ percentage of variation. $P$-values were obtained after 1000 permutations. 


\subsubsection{Analyses of Molecular Variance (AMOVA)}

Genetic variation mostly resided within populations (87\%; Table 14). The genetic variation among all populations in Myanmar was highly significant $\left(\Phi_{\mathrm{ST}}=0.123, P<0.001\right.$; Table 14). More than $80 \%$ of genetic variation was observed within populations for each stage and management types while genetic differentiation among populations was also significant. Noticeably, the genetic differentiation among adult $T$. grandis in selectively-logged populations $\left(\Phi_{\mathrm{ST}}=0.163\right)$ was considerably higher than in unlogged populations $\left(\Phi_{\mathrm{ST}}=\right.$ 0.112) (Table 14).

Genetic variation partitioned between unlogged and selectively-logged $T$. grandis populations was not significantly different $\left(-0.72 \%, \Phi_{\mathrm{CT}}=-0.007, P>0.05\right.$; Table 15). Meanwhile, genetic differentiation between adults and regeneration were low but significant $\left(1.5 \%, \Phi_{\mathrm{CT}}\right.$ $=0.015, P<0.05$; Table 15). The genetic differentiation of $T$. grandis between the two regions, and between the two regions and Benin plantations was highly significant $(P<$ 0.001; Table 15).

\subsubsection{Genetic structure based on Bayesian analysis}

The Bayesian analysis of population structure revealed two groups $(K=2)$ : one group for the northern T. grandis populations and another group for the southern populations and Benin $T$. grandis plantations (Fig 23). The number of populations was determined by the highest absolute probability value $L n P(D)$ (Fig. 24A) and was also determined by Evanno et al. method using the highest $\Delta K$ values. The optimal number of $K$ was observed at $K=2$ (Fig. 24B). Assignment of individual genotypes did not fully follow the prior defined subpopulations as many individual genotypes were not correctly assigned to the prior cluster. 

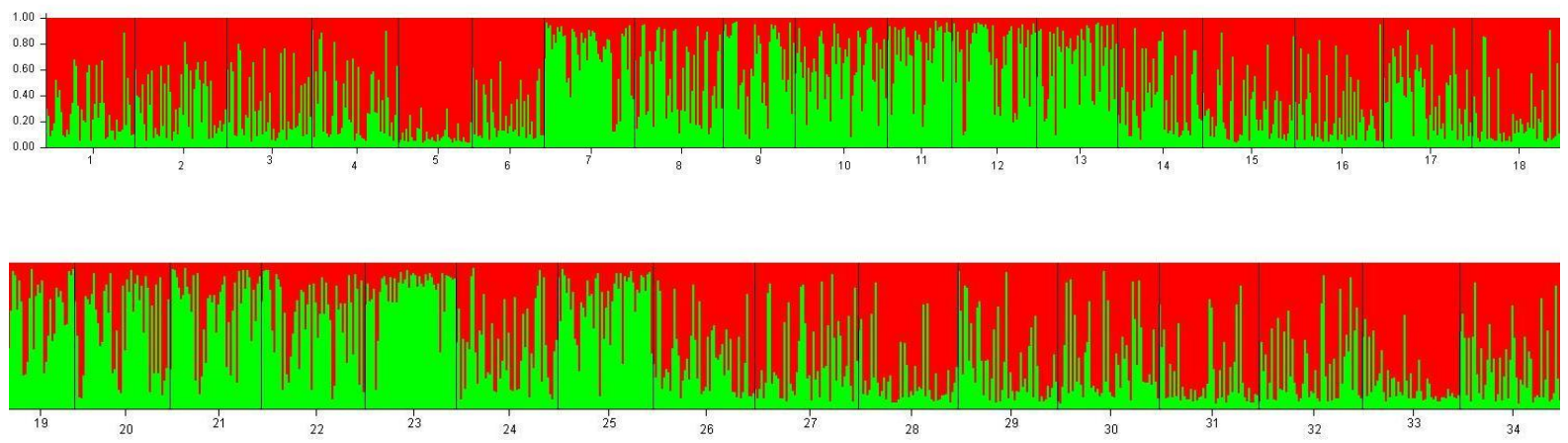

Fig. 23 Clusters of 34 T. grandis populations based on the admixture model at AFLPs. The southern populations (No.1 to No. 4; No. 15 to No. 18; No. 27 to No. 34) and two Benin plantations (No. 5 and 6), and the northern populations (No. 7 to No. 14; No.19 to No. 26).

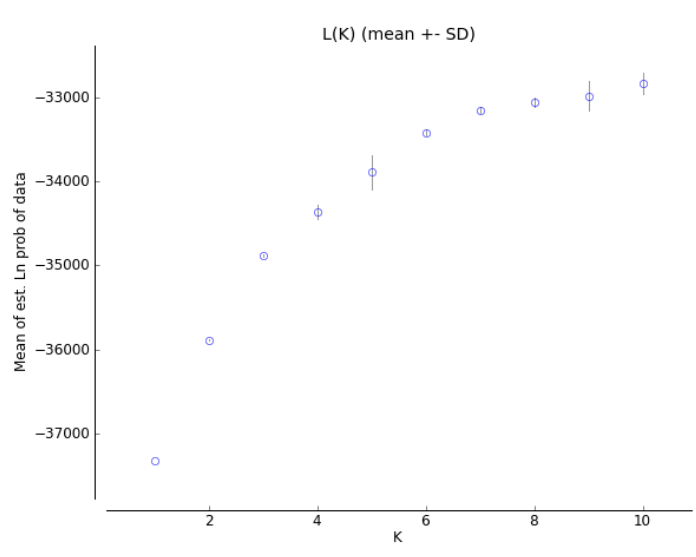

(A)

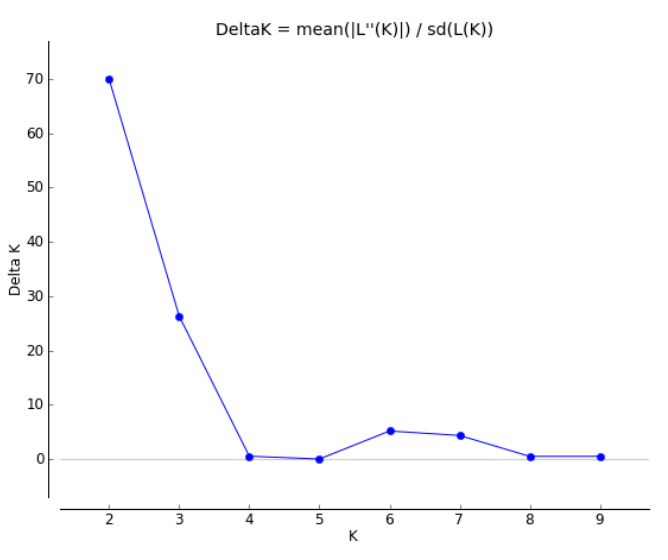

(B)

Fig. 24 Population structure of 34 T. grandis populations at AFLPs. Detection of the true number of clusters $K$. (A) distribution of mean of estimated $L n$ probability of data based on 71 AFLP loci for the admixture model. (B) magnitude of $\Delta K$ as a function of $K$ (Evanno et al., 2005).

\subsubsection{Genetic differentiation between adults and regeneration}

There was a marked difference in the band frequency of AFLP markers between adults and regeneration in the southern and northern regions (Fig. 25). Similarly, there was a strong locus-wise genetic differentiation $\left(G_{\mathrm{ST}}\right)$ between adults and regeneration in each region (Fig. 26). 


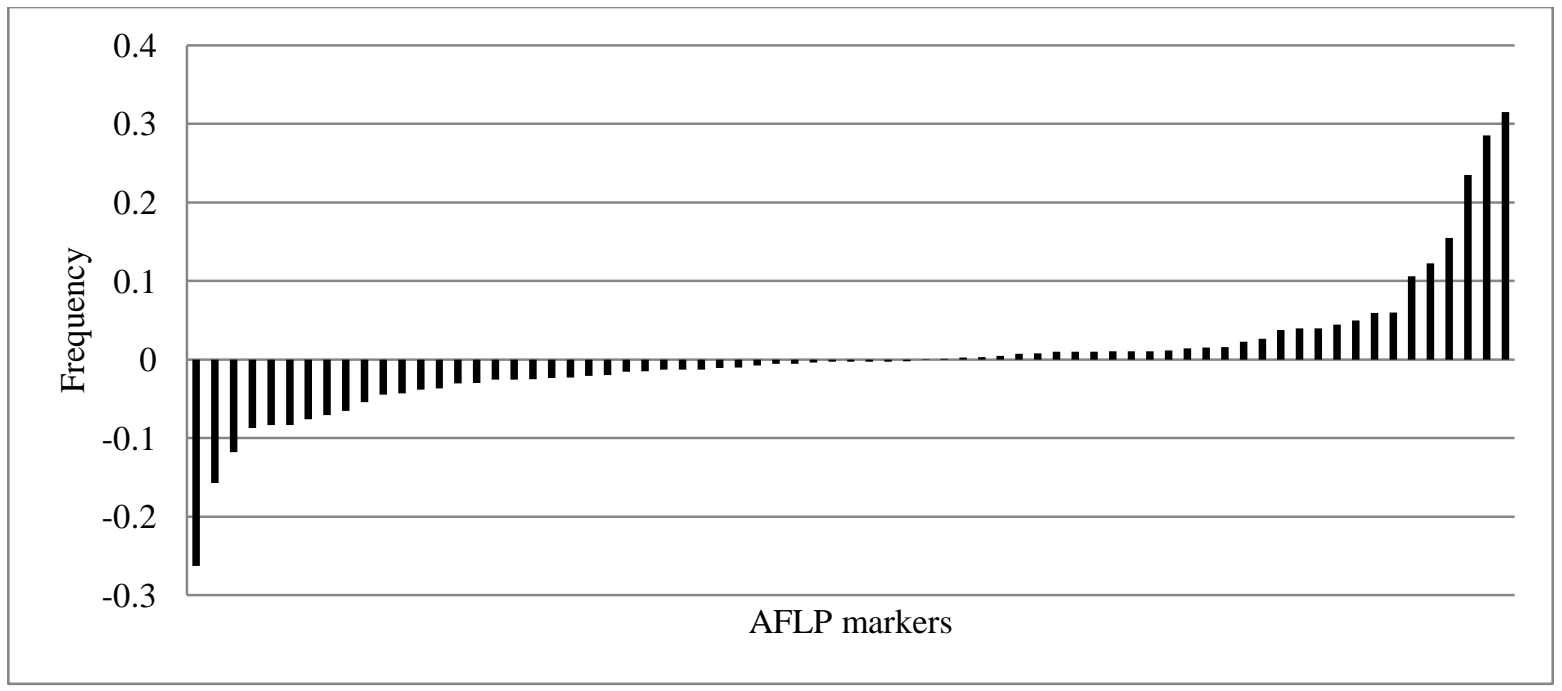

(A)

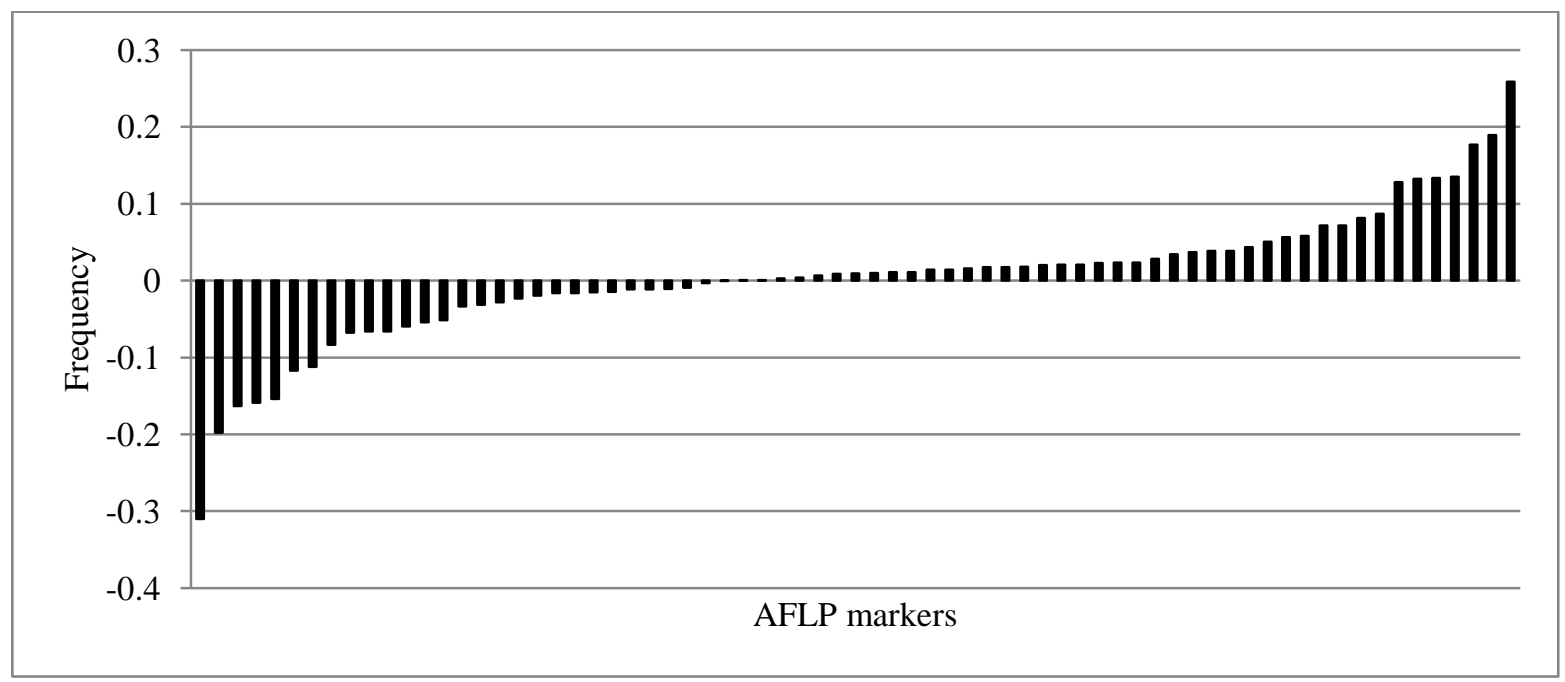

(B)

Fig. 25 Difference in AFLP band frequency between adults and regeneration in T. grandis populations in the southern region (A) and in the northern region (B) of Myanmar. 


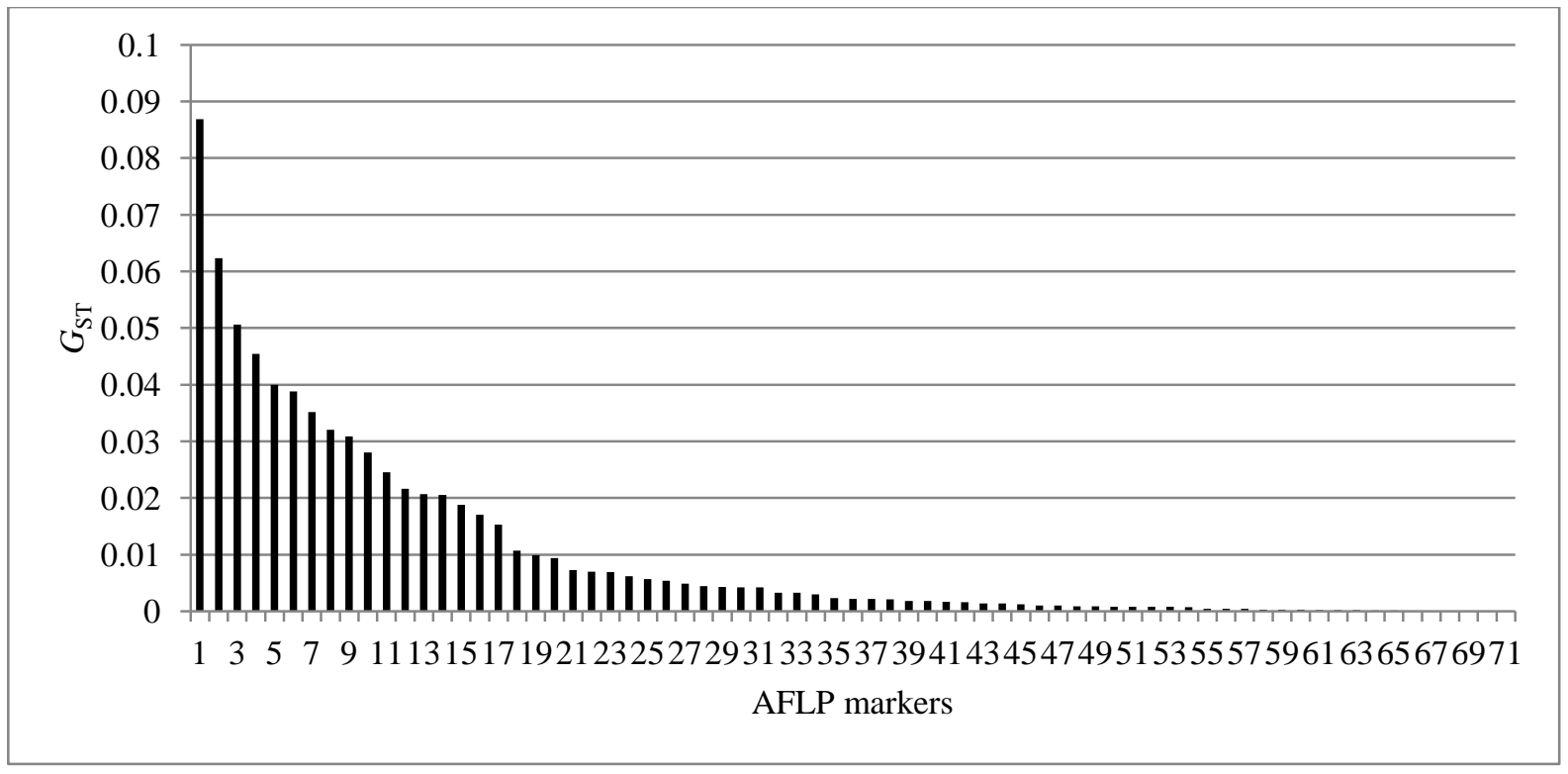

(A)

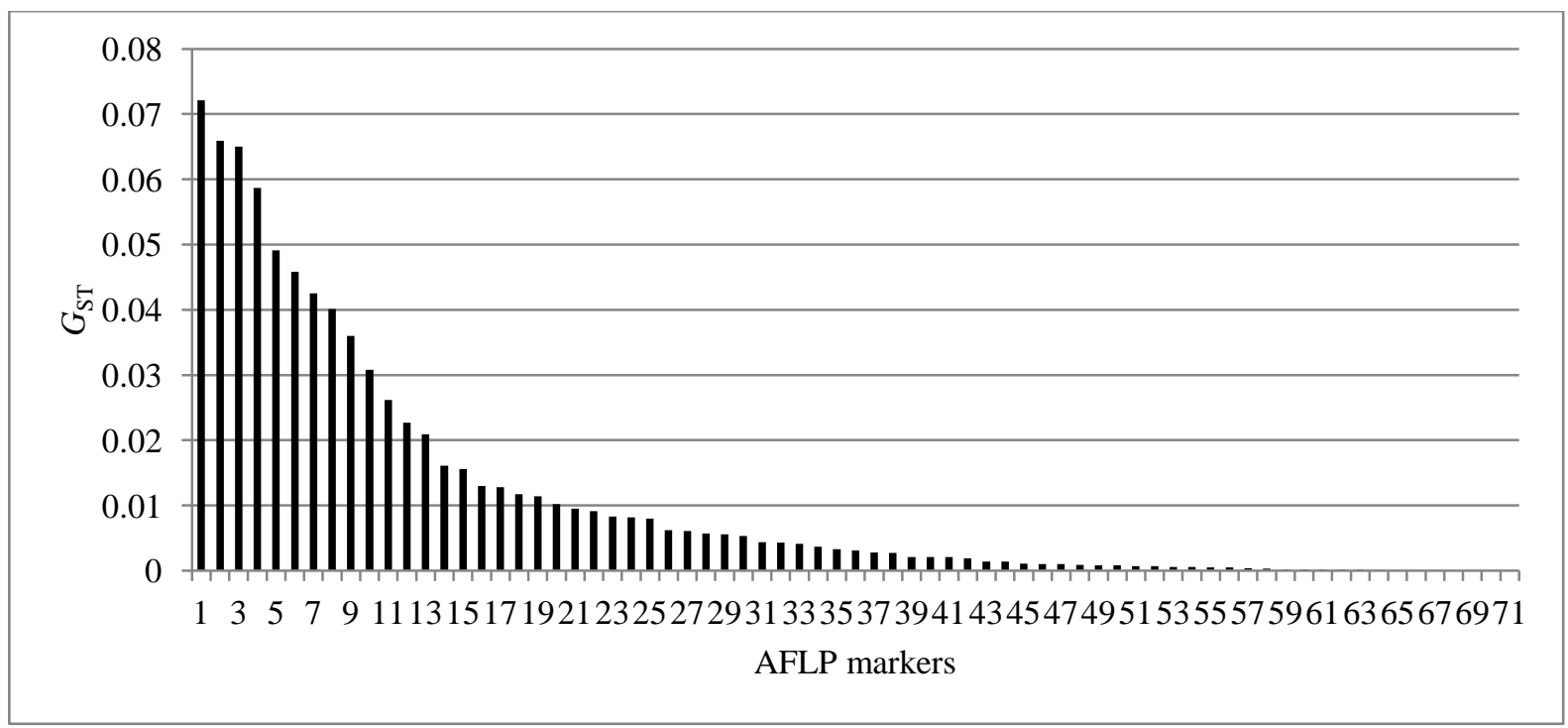

(B)

Fig. 26 Genetic differentiation between adults and regeneration at 71 AFLP markers in $T$. grandis populations in the southern region (A) and in the northern region (B) of Myanmar. 


\subsection{Correlation between SSRs and AFLPs}

The correlation between the estimates of gene diversity and genetic differentiation for the two markers was assessed using the Spearman's rank correlation coefficient. The estimates of genetic diversity $\left(H_{\mathrm{E}}\right)$ obtained from SSRs and of genetic diversity $\left(H_{\mathrm{j}}\right)$ from AFLPs were negatively correlated but not statistically significant $(R=-0.16, P>0.05$; Fig. 27). Moreover, no significant correlations were observed for adults $(R=0.05, P>0.05$; Fig. 28A) and for regeneration $(R=-0.226, P>0.05$; Fig. 28B). Similarly, there was no significant correlation between $H_{\mathrm{E}}$ from SSRs and $B r$ from AFLPs $(R=-0.174, P>0.05$; Fig. 29).

Nonetheless, there was a significant and positive correlation between genetic differentiation (Pairwise $F_{\mathrm{ST}}$ ) of SSRs and AFLPs (adults: $R=0.631, P<0.01$; Fig. 30A) (regeneration: $R=$ 0.77, $P<0.01$; Fig. 30B).

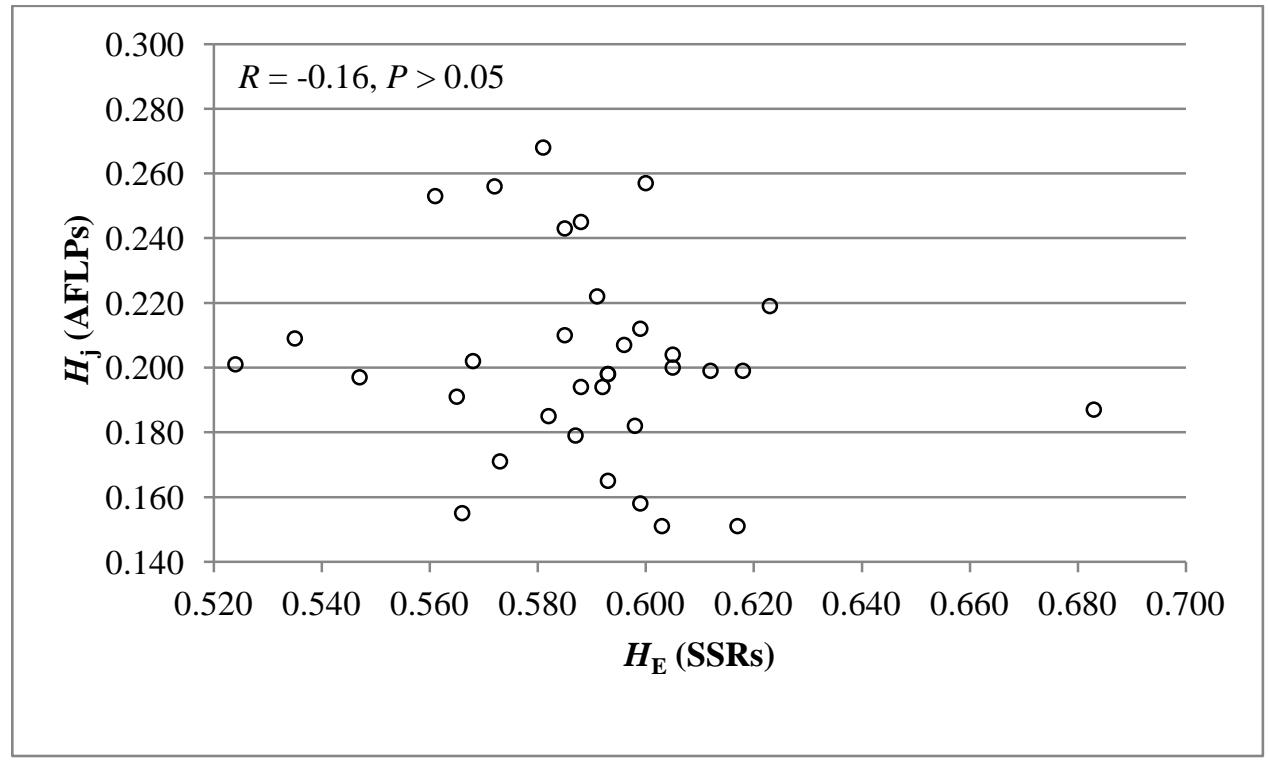

Fig. 27 Spearman's correlation between $H_{\mathrm{E}}$ from SSRs and $H_{\mathrm{j}}$ from AFLPs for $T$. grandis populations. 


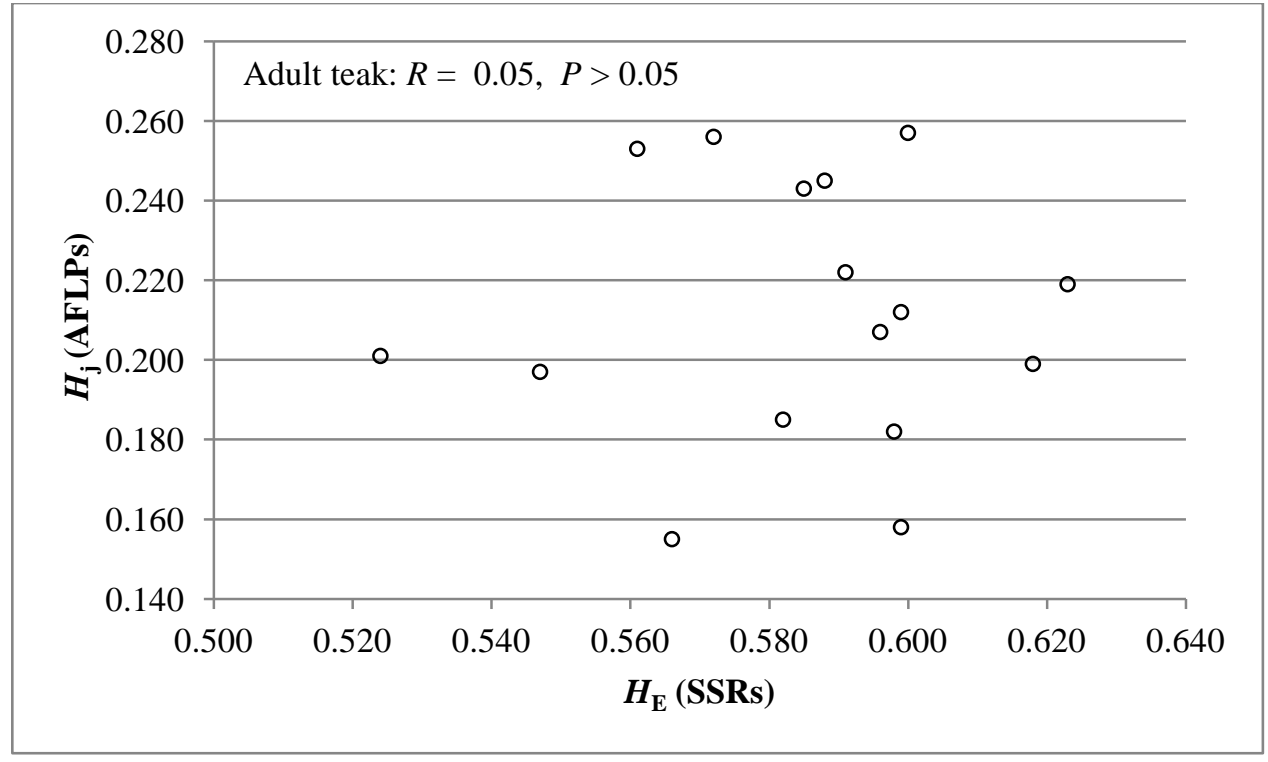

(A)

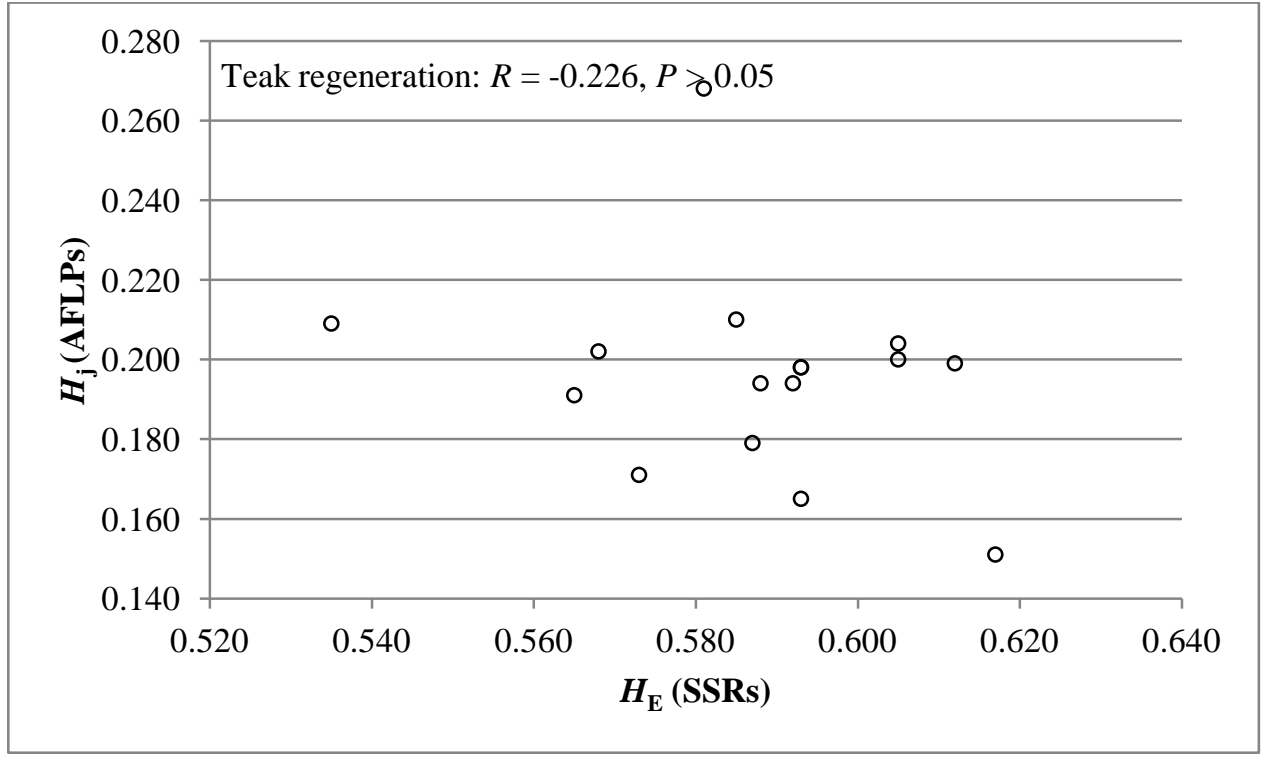

(B)

Fig. 28 Spearman's correlation between $H_{\mathrm{E}}$ from SSRs and $H_{\mathrm{j}}$ from AFLPs for $T$. grandis populations. (A) adults (B) regeneration. 


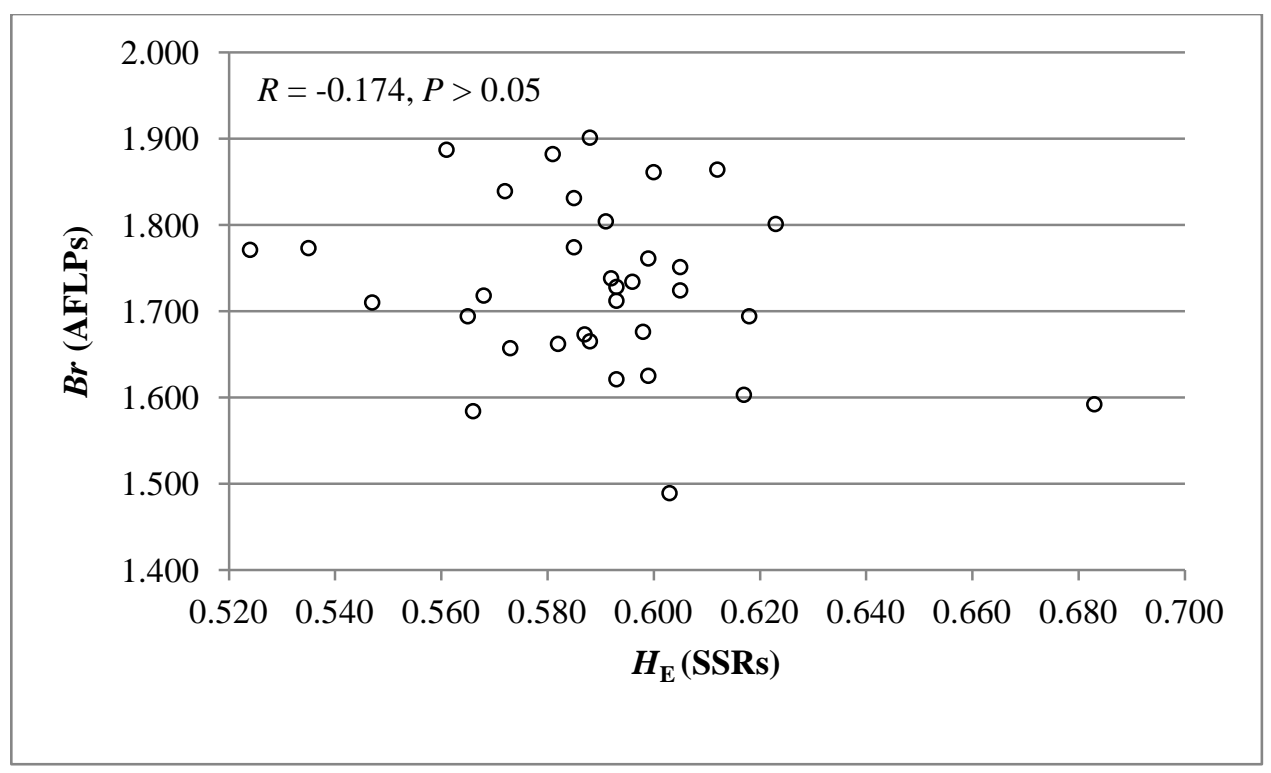

Fig. 29 Spearman's correlation between $H_{\mathrm{E}}$ from SSRs and $\mathrm{Br}$ from AFLPs for $T$. grandis populations. 


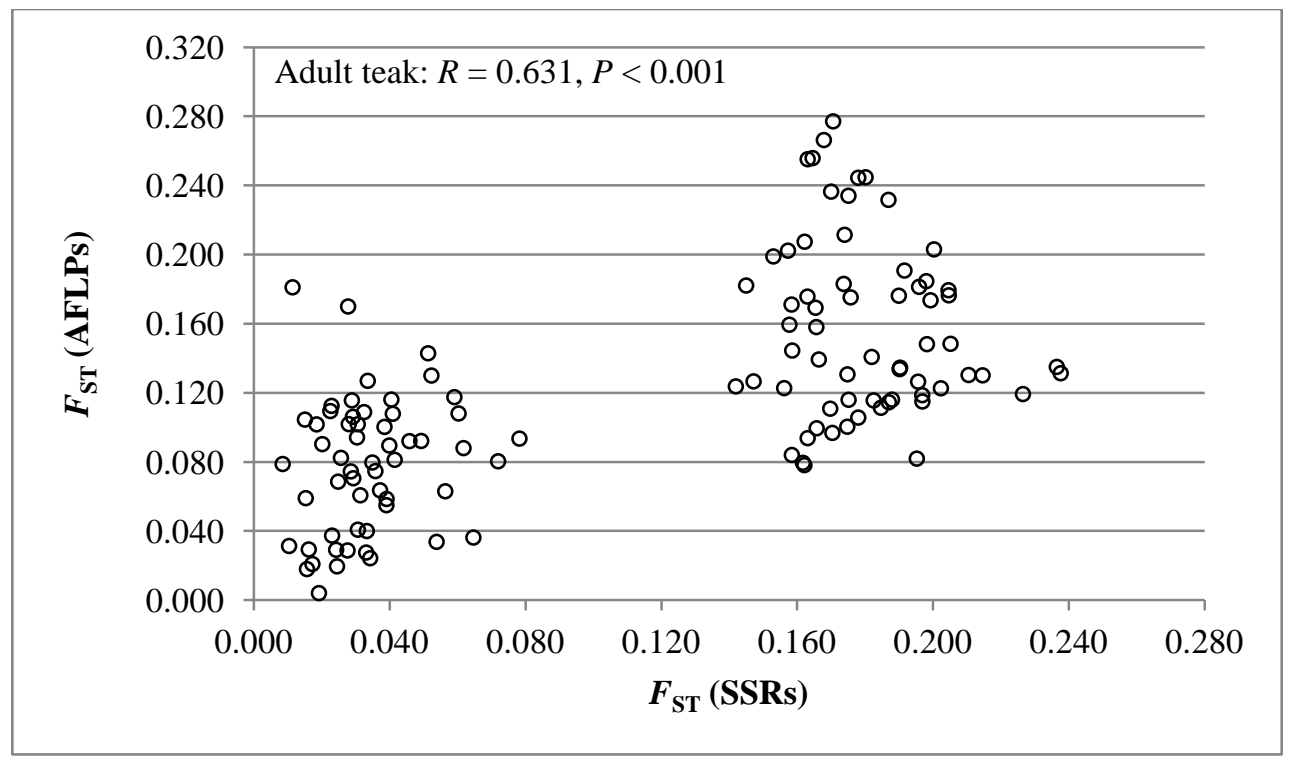

(A)

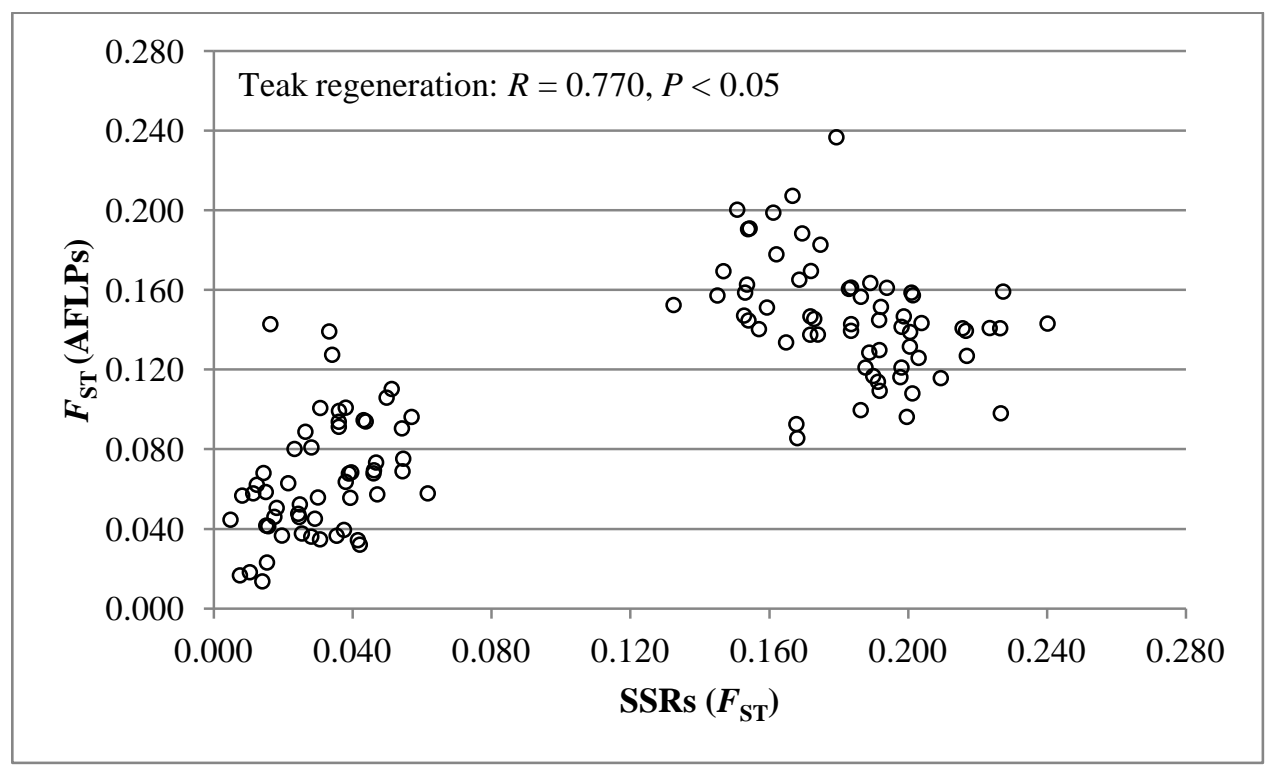

(B)

Fig. 30 Spearman's correlation between $F_{\mathrm{ST}}$ from SSRs and $F_{\mathrm{ST}}$ from AFLPs for $T$. grandis populations. (A) adults (B) regeneration. 


\section{Discussion}

\subsection{Genetic diversity within populations}

All 10 SSR loci showed heterozygote deficit (Table 3). Verhaegen et al. (2005) reported heterozygote deficit in six out of fifteen SSR loci. The presence of null alleles could also induce heterozygote deficit at SSR loci (Pemberton et al., 1995). The heterozygote deficit in this study may be explained as Wahlund effect because the total population is structured in several subpopulations (Hartl and Clark, 1989).

The SSR markers revealed a high level of genetic diversity in all $T$. grandis populations regardless of sample stages, logging types or regions (Table 4). This supports our prediction that genetic diversity of $T$. grandis in Myanmar is still high. The estimates $\left(n=1655.4, H_{\mathrm{E}}=\right.$ $0.586, A_{\mathrm{R}}=6.5$ ) are comparable to the study conducted for $T$. grandis populations from North India, South India, North Thailand and Laos using 15 SSR loci (Fofana et al., 2009). The expected heterozygosity of $T$. grandis in Myanmar was lower than in South India $\left(n=71, H_{\mathrm{E}}\right.$ $=0.76)$ and North India $\left(n=10, H_{\mathrm{E}}=0.64\right)$, but higher than in North Thailand $\left(\mathrm{n}=64, H_{\mathrm{E}}=\right.$ 0.41) and Central Laos $\left(n=21, H_{\mathrm{E}}=0.22\right)$ (Fofana et al., 2009). Allelic richness of $T$. grandis in Myanmar $\left(A_{\mathrm{R}}=6.50\right)$ was similar to South India $\left(A_{\mathrm{R}}=6.63\right)$ but higher than in North India $\left(A_{\mathrm{R}}=3.85\right)$, North Thailand $\left(A_{\mathrm{R}}=3.24\right)$ and Central Laos $\left(A_{\mathrm{R}}=3.06\right)$ (Fofana et al., 2009). Nonetheless, all these comparative assessments should be cautiously taken as these two studies were independently conducted with different number of markers and sample sizes.

SSR markers showed that genetic diversity of T. grandis in Myanmar was lower than in Benin $\left(H_{\mathrm{E}}=0.643\right.$; Table 3$)$ which is similar to $T$. grandis in North India (Fofana et al., 2009). Nearly $97 \%$ of land races in Benin, Cameron, Cote d'Ivoire, Tanzania, Togo and Senegal came from North India (Verhaegen et al., 2010). The origin of BEN1 was reported as India and the seed source of BEN2 was from Tanzania and from the former T. grandis plantations in Benin (Ganglo and Lejoly, 1999). It correspondingly suggests that North India could be the origin of seed sources for the two T. grandis plantations in Benin.

Genetic diversity of $T$. grandis is comparable to other tree species investigated by SSR makers. The estimate of $T$. grandis is slightly lower than long-lived perennial ( $\mathrm{n}=59, H_{\mathrm{E}}=$ $0.68)$, widespread species $\left(\mathrm{n}=31, H_{\mathrm{E}}=0.62\right)$, outcrossing $\left(\mathrm{n}=71, H_{\mathrm{E}}=0.65\right)$ and late successional species $\left(\mathrm{n}=34, H_{\mathrm{E}}=0.70\right)($ Nybom, 2004). 
Seventy-one AFLP markers revealed that the estimates of genetic diversity of $T$. grandis varied among populations (Table 10). A relatively high level of genetic diversity $(n=1667$, $\left.H_{\mathrm{E}}=0.215, \mathrm{PPL}=72.7, \mathrm{Br}=1.767\right)$ was observed (Table 10$)$. This result confirms the high level of genetic diversity of $T$. grandis revealed by SSR markers of this study. However, the current estimates of AFLPs are lower than the previous investigation of four adult T. grandis populations in Myanmar investigated with 69 AFLP loci from the same primer combination $\left(\mathrm{n}=85, H_{\mathrm{E}}=0.315, \mathrm{PPL}=94.23\right)(\mathrm{Minn}, 2007)$. The difference in the estimates of genetic diversity could be largely due to the different selected loci, different number of samples, sample stages and populations.

The results are comparable to other tropical tree species investigated by AFLP markers and our estimates of $T$. grandis are quite similar to Diperocarpus cf. condorensis $\left(H_{\mathrm{E}}=0.215\right.$, $P P L=71.20)\left(\right.$ Luu, 2005) but lower than in Tectona hamiltoniana $\left(H_{\mathrm{E}}=0.305, P P L=90.23\right)$ (Minn, 2007) and higher than estimates of Shorea leprosula $\left(H_{\mathrm{E}}=0.161, P P L=53.23\right)$ and Shorea parvifolia $\left(H_{\mathrm{E}}=0.138, P P L=51.79\right)\left(\mathrm{Cao}\right.$ et al., 2006) and nine Dipterocarps $\left(H_{\mathrm{E}}=\right.$ 0.100 to $\left.H_{\mathrm{E}}=0.165\right)$ (Cao et al., 2009).

\subsection{Genetic structure of $T$. grandis plantations and linkage disequilibrium}

The high levels of genetic diversity in T. grandis plantations in Benin at SSRs reflect that artificial regeneration was unlikely to induce a severe impact on their genetic diversity (Table 4). This result is comparable to Pinus roxburghii Sarg. plantations which show genetic similarity between plantations and natural populations (Gauli et al., 2009). Nonetheless, the estimates are different to the artificial regeneration in Piceae glauca which induces a decrease in genetic diversity compared to its old growth forests (Rajora, 1999).

Significant amount of associated loci observed in the $T$. grandis plantations in Benin demonstrates that human interference influences the genetic structure of T. grandis (Table 4), though T. grandis can still maintain high level of genetic diversity. Founder effects, small populations size and migration can create and maintain linkage disequilibria (Lynch and Walsh, 1998). The significant amount of associated loci may be explained by the establishment of plantations using seeds collected from a few numbers of founder trees (Stefenon et al., 2008). Introducing tree species from such a small number of founder trees could decrease genetic diversity of tree species (Finkeldey and Hattemer, 2007). 
Contrastingly, the SSR analysis detected high level of genetic diversity of $T$. grandis. Nevertheless, AFLPs of the current study detected low genetic diversity in those plantations compared to T. grandis in Myanmar, possibly due to founder effects.

Significant amount of associated loci was also observed in six adult $T$. grandis populations (TUA, TSA, MUA and MSA, PMUA) and one regeneration population (LSR) (Table 4) in Myanmar. This elevated linkage disequilibrium among pairs of polymorphic loci could also be an indication of recent population bottlenecks or admixture at the subpopulation level and high population turnover at a metapopulation level (Tero et al., 2003).

\subsection{Genetic structure of adults and regeneration}

The level of inbreeding varied among adult and regeneration populations (Table 4). Some $T$. grandis populations did not show significant inbreeding in regeneration but in adults of the same stand. Meanwhile, some T. grandis populations showed significant inbreeding only in regeneration. Moreover, some adult T. grandis populations with significant levels of inbreeding can also induce regeneration populations with non-significant levels of inbreeding. This significant inbreeding for regeneration and adult stages could be due to the current and historical genetic bottlenecks and reproductive isolation.

Generally, high levels of inbreeding were observed in regeneration, indicating frequent mating among related trees including selfing. T. grandis is reported to be partially selfincompatible species (Tangmitcharoen and Owens, 1997). But this high level of inbreeding in regeneration demonstrates that $T$. grandis is a mixed mating species (Finkeldey and Hattemer, 2007). Interestingly, inbreeding was significantly higher in the unlogged T. grandis populations than in the logged stands (Table 5). This may be explained by stronger selection against inbred individuals in logged stands.

Genetic diversity of tropical and subtropical forest trees are not greatly different among different temporal stages (Hall et al., 1994; Spain and Lowe, 2011) and this was observed for adults and regeneration at SSRs (Table 5). Nonetheless, the results of SSRs are not congruent to adults and regeneration of Prunus africana which shows significantly higher level of genetic diversity in adults ( $H_{\mathrm{E}}$ : adults: mean 0.80, seedlings: mean 0.75$)$ (Farwig et al., 2008). These differences could be largely due to different population history and different mating system of the species. 
Significant positive $F_{\mathrm{ST}}$ setween parental trees (adults) and young cohorts (regeneration) would be expected if many genes come from differentiated populations and young cohorts showing reduction in genetic diversity relative to parental population (Spain and Lowe, 2011). For SSRs, twelve out of sixteen pairwise $F_{\text {ST }}$ values between adult and regeneration in each stand was low and not significant (see appendix). Moreover, adults and regeneration in the remaining four stands having significant pairwise $F_{\mathrm{ST}}$ was also low (> 0.018). This reflects our expectation that progenies are largely produced from adult (putatively parental) T. grandis of the same stand and gene flow among stands is low. The NJ tree and UPGMA dendrogram also supported genetic similarity between adults and regeneration by higher bootstrapping values (Fig. 8 and 9). Correspondingly, AMOVAs supported a similar genetic structure of adults and regeneration by revealing no significant genetic differentiation between them (Table 9).

For AFLPs, ANOVAs did not reveal significant differences concerning the genetic diversity $\left(H_{j}, P P L\right.$, and $\left.B r\right)$ for overall adults and regeneration (Table 11$)$, which is congruent to the result of SSRs (Table 5). Nonetheless, the genetic diversity $\left(H_{\mathrm{j}}\right)$ of adults was significantly higher than that of regeneration in the unlogged stands (Table 11). AMOVA correspondingly showed that there was significant genetic differentiation between adults and regeneration at AFLPs $(1.5 \%, P<0.05$; Table 15). Such difference between adults and regeneration was due to the small effects of many different AFLP loci (Fig. 26) and some of them might be under selection.

Contrary to our expectation, AFLPs showed that genetic differentiation was significant between adults and regeneration in each stand revealed by the pairwise $F_{\mathrm{ST}} \mathrm{S}$ (see appendix), in contrast to the result of SSRs. The UPGMA analysis interestingly showed that adults and regeneration in each stand did not group together, but they rather grouped with the sample stages of adjacent populations (Fig. 18). This genetic similarity of the same sample stages could be explained by natural selection in young regeneration stages. The example of intense natural selection has been reported for tree species. For example, 52,000 seedlings are required to reach to one 450 year-old adult Pseudotsuga menziesii tree (Campbell and Sugano, 1979) and 20,000 seedlings are required to reach a 400 year-old adult Eucalyptus regnans tree (Barber, 1965). Thus, all representing genotypes of regeneration revealed by AFLPs are not likely to reach adult stages due to natural selection. 
In addition, the contrasting results between SSRs and AFLPs could be due to the nature of different markers (Nybom, 2004). Moreover, the different quality of DNA in regeneration and adults might influence differentiation patterns at AFLP markers which generally need relatively high quality DNA. Different types of $T$. grandis samples (tree leaf, seedling leaf, graft leaf and seed), and different extraction methods influence the amplification pattern of dominant Inter-Simple Sequence Repeat (ISSR) marker (Narayanan et al., 2006). Nevertheless, in order to improve accuracy and precision, AFLP probes with ambiguous patterns were carefully removed from the analysis, and only reliable and reproducible fragments were carefully screened and chosen for the analysis. The marked difference in marker frequencies and locus-wise $G_{\mathrm{ST}}$ for each AFLP locus between adults and regeneration within the northern and southern region (Fig. 26) suggests that many loci are responsible for genetic difference between adults and regeneration.

Additionally, the level of genetic diversity in a population can be affected by genetic, life history and ecological characteristics of tree species which collectively define their genetic structure (Yeh, 2000). Generally, teak regeneration is abundant in logged stands since teak needs full light for its survival and growth. The genetic structure of (offspring) regeneration and (parental) adults will differ if the number of offsprings are small (White et al., 2007). Thus, restricted abundance of regeneration in unlogged stands might also influence genetic diversity of teak regeneration. As a rule, genetic diversity for the adults and regeneration in the same stand are expected to be similar. However, the unintentional change of genetic structure of natural regeneration can not be ruled out, even though the transmission of genes from the parent generation to the progenies implies a limited potential for drastic changes in their genetic structures (Finkeldey and Ziehe, 2004).

\subsection{The impacts of selective logging on genetic variation of $T$. grandis}

Following intensive logging, it is expected to have an increased level of inbreeding in the stand due to the increased reproductive isolation. In case of selective logging where only a small number of trees are selectively removed, reproductive isolation is expected to be small, and minimum or no inbreeding would be expected. In consonance with our expectation, the present study indicates no significant impact of selective logging on inbreeding (Table. 5). This is comparable to other studies which shows no impact of selective logging on breeding system (Kitamura et al., 1994; Chaisurisri et al., 1997; Takahashi et al., 2000; Cloutier et al., 
2007). Meanwhile, increased level of inbreeding has been reported for Shorea megistophylla (Murawski et al., 1994). In our study, selective logging $\left(F_{\text {IS }}=0.037\right)$ induced a slightly higher level of inbreeding in adult $T$. grandis populations compared to unlogged stands $\left(F_{\text {IS }}=0.013\right)$ (Table 5). This indicates that reproductive isolation become stronger after removal of target diameter trees in selectively-logged stands.

We assumed that selective logging could not strongly affect genetic diversity of $T$. grandis due to the selective removal of a few $T$. grandis trees. The SSR results support our expectation as the genetic diversity $\left(H_{\mathrm{E}}, H_{\mathrm{E}}, A_{\mathrm{R}}\right)$ of selectively-logged and unlogged $T$. grandis populations were not significantly different (Table 5). Correspondingly, no significant impact of logging on genetic diversity $\left(H_{\mathrm{j}}, P P L, B r\right)$ of $T$. grandis was detected at AFLPs (Table 11). AMOVAs of both markers also supported no significant impact of logging (Table 9 and 15). This could be largely due to the existence of a high level of genetic diversity of $T$. grandis which has sufficient capacity to resist and recover from the humaninduced genetic effects (Reusch et al., 2005). Life history traits of tree species such as mating system and pollen and seed dispersal mechanism also plays a role in mitigating loss of genetic diversity in the remnant forests following disturbances and logging (Dick, 2001; White et al., 2002). Our result is comparable to studies with no significant impact of logging on genetic diversity of forest trees species: Fagus sylvatica (Buiteveld et al., 2007; Rajendra, 2011), Quercus tiaoloshanica (Zheng et al., 2005), and Mansonia altissima (Akinnagbe et al., 2010).

SSRs revealed a slightly higher level of $F_{\mathrm{ST}}$ values in the selectively-logged population $\left(\Phi_{\mathrm{ST}}\right.$ $=0.134)$ than in the unlogged adult $T$. grandis populations $\left(\Phi_{\mathrm{ST}}=0.119\right)$. AFLPs also showed a similar trend of slightly higher level of genetic differentiation among adult $T$. grandis populations followed by selective logging $\left(\Phi_{\mathrm{ST}}=0.163\right)$ compared to unlogged adult stands $\left(\Phi_{\mathrm{ST}}=0.112\right)$. Though the estimates were not significant, there was a trend of increasing genetic differentiation among populations and decreasing genetic variation within populations due to the impact of logging (Slatkin, 1995; Young et al., 1996; Hartl and Clark, 2007). Apart from this trend, selective logging did not produce significant impacts on genetic structure of $T$. grandis forests, and thus, the selection felling is still considered to be a sustainable forest management system for $T$. grandis forests. However, care should be taken for this assessment because selectively neutral genetic markers like SSRs and AFLPs may not be relevant to adaptive and quantitative traits like diameter of $T$. grandis trees. Thus, the 
application of adaptive markers is strongly recommended to further investigate the impact of selective logging on adaptive genetic structure of $T$. grandis forests.

\subsection{Genetic variation and structure of $T$. grandis among populations and regions}

The SSRs revealed that the estimates of genetic diversity $\left(H_{\mathrm{S}}\right.$ and $\left.H_{\mathrm{O}}\right)$ within populations were not significantly different for the northern and southern $T$. grandis populations but allelic richness $\left(A_{\mathrm{R}}\right)$ was significantly higher in the $T$. grandis populations in the southern region (Table 5). Contrary to SSRs, AFLPs revealed that the estimates ( $\mathrm{Hj}, \mathrm{PPL}$ and $\mathrm{Br}$ ) were significantly higher in the northern $T$. grandis populations, and this significant estimate was mostly attributed by adult $T$. grandis populations (Table 11). This differences in genetic diversity between the two regions revealed by the two markers could be due to the nature of applied markers (Nybom, 2004). However, in this study, different historical evolutionary factors like genetic drift and gene flow could be responsible for different level of genetic diversity in two regions.

Both markers revealed that genetic variation mainly resided within populations of $T$. grandis (> $80 \%$; Table 8 and Table 14), which agrees the observation because woody species with large geographic ranges and outcrossing breeding maintains more genetic diversity within species and populations but less variation among populations (Hamrick et al., 1992). The result is comparable to the genetic variation within populations of $T$. grandis: $57 \%$ variation for 28 genotypes in T. grandis originating from India, Indonesia and Thailand (Shrestha et al., 2005), 79\% variation in 15 T. grandis populations in Thailand (Changtragoon and Szmidt, 2000), $78 \%$ variation in 10 T. grandis populations in India (Nicodemus et al., 2003).

The $\Phi_{\mathrm{ST}}$ values (analogous to $F_{\mathrm{ST}}$ ) for both markers suggests $T$. grandis possessed moderate level of genetic differentiation $\left(\Phi_{\mathrm{ST}}=0.116\right.$ (SSRs) and $\Phi_{\mathrm{ST}}=0.123$ (AFLPs)). This differentiation is comparable to the majority of tree species: (Table 16).

Both markers revealed positive and significant correlations between geographic and genetic distances among populations (Fig. 10 and 19) and among adult and among regeneration populations within southern and northern regions (Fig. 11, 12, 20, and 21), indicating an existence of isolation by distance (IBD). IBD is a phenomenon characterized by increasing genetic divergence and decreasing gene flow within increasing geographical distances 
(Crispo and Hendry, 2005). Due to the presence of IBD, multiple T. grandis populations should be included for conservation programs to maintain high level of genetic diversity.

All clustering analyses support two distinct genetic structures for the northern and the southern regions (Fig.8, 9, 13, 14 and 16 for SSRs; Fig.18, 22, and 23 for AFLPs), revealing two centers of genetic diversity for T. grandis in Myanmar. Accordingly, genetic distances (Nei, 1978) between the two regions were higher than within each region (Table 6 and 12). The values of pairwise $F_{\mathrm{ST}}$ s between the two regions $(<0.20)$ were also significantly higher (Table 7 and 13). AMOVA of both markers also demonstrated significant genetic differentiation between the two regions (Table 9 and 15). This significantly higher level of genetic differentiation among populations in the two regions could be attributed to differential selection due to different environmental conditions and reduction of population size (genetic drift) in either population and no migration between populations and elevated rate of mutation in populations in the two regions (White et al., 2007). In populations in equilibrium between drift and migration, genetic differentiation among populations is expected to increase with the geographic distance (Slatkin, 1994). All our findings indicate limited gene flow or migration between populations in the northern and southern regions, leading to a strong genetic differentiation. Moreover, the existence of the geographic barrier could also be responsible for this strong genetic differentiation as the large dry area without natural T. grandis forests between the two regions might avoid effective gene flow and migration between the regions. Thus, this stronger genetic differentiation between the two regions could be due to no migration for many generations.

Contrary to our expectation, the Bayesian analyses of both markers showed that the southern T. grandis populations in Myanmar and the T. grandis plantations in Benin grouped together, indicating genetic similarity between them. NJ of SSRs also supports this result. For AFLPs, the UPGMA dendrograms did not consistently show clustering between the two groups. However, PCA of both markers were able to differentiate between the two groups as Benin $T$. grandis plantations stood separately, indicating PCA as a useful tool to differentiate among them.

Low levels of $F_{\mathrm{ST}}$ values within each northern and southern region indicate higher gene exchanges within the regions than between the regions. There are significant correlations between gene flow and mode of reproduction, resulting higher levels of gene flow for 
outcrossing or mixed mating species than for selfing species (Morjan and Rieseberg, 2004). This is mainly true for the populations within the regions in this study. 
Table 16 Comparison of SSRs and AFLPs for genetic diversity and differentiation of natural populations of different tree species.

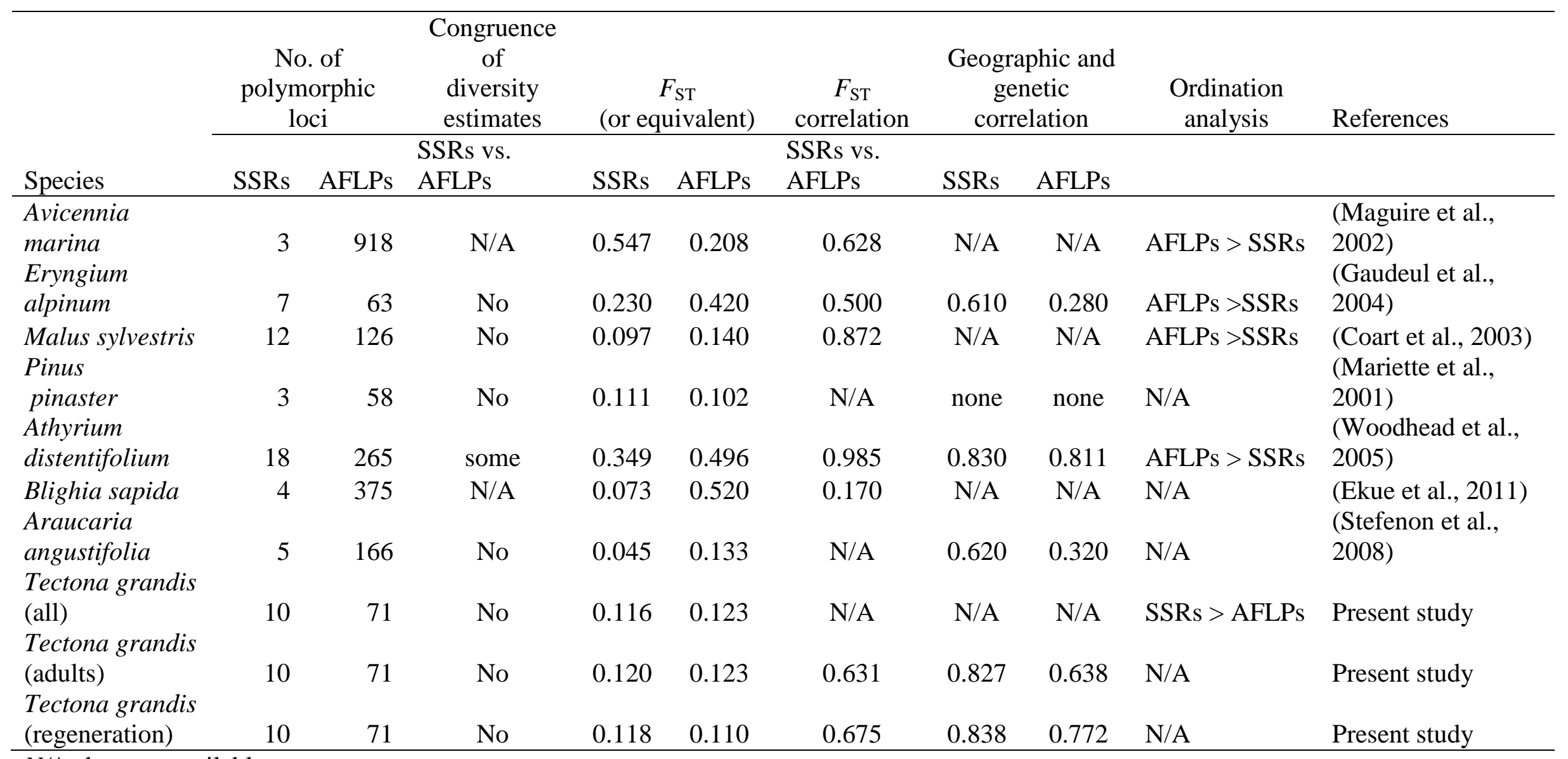

N/A data not available. 


\subsection{Congruency and discrepancy between SSRs and AFLPs}

The ranking of populations based on the diversity estimates from the two markers in this study were not congruent (Fig 27, 28 and 29). These estimates of genetic diversity between SSRs $\left(H_{\mathrm{E}}\right)$ and AFLPs $\left(H_{\mathrm{j}}\right)$ were negatively but not significantly correlated (Fig. 27 and 28). This result is comparable to other studies (Table 16) and it could also be possibly due to the different nature of the markers. SSRs are highly polymorphic and co-dominant markers which can produce any numbers of alleles at each locus, and thus, expected heterozygosity can reach up to 1 . On the other hand, AFLPs are biallelic markers which can produce a maximum of two alleles at each locus, and thus, the gene diversity can reach up to a maximum of 0.5 only.

Moreover, the correlation between the two markers also depends on the numbers of loci used since the correlation between the two markers should increase when sufficient numbers of loci are used (Mariette et al., 2002). One possible explanation for conflicting diversity estimates between the two markers will be the result of random variation in the data with populations of broadly equivalent levels of diversity having different rank order levels of variation attributable to minor differences in diversity estimates (Mariette et al., 2002). Additionally, it could be explained that both markers may selectively screen complementary, rather than overlapping, regions of genome (Crouch et al., 1999). This discrepancy explains a better coverage of the genome with numerous AFLP markers, higher mutation rates of microsatellites or the absence of significant differences among within-population diversity estimates (Gaudeul et al., 2004).

Despite the discrepancy in the estimates of genetic diversity, the patterns of genetic differentiation (pairwise $F_{\mathrm{ST}}$ ) between the two markers were congruent, showing a positive and significant correlation (Fig. 30). All these results explain different segregation of the markers within the population level but evolutionary groups show similar patterns (Maguire et al., 2002). Due to the discrepant and congruent estimates, the combined application of both markers provides more accurate and comprehensive information for T. grandis.

SSR markers are more effective to differentiate not only at the population level but also at the regional level, which is contrasting to other studies (Table 16). Thus, SSRs could be better marker system to differentiate the origins of $T$. grandis in this study. Meanwhile, genomic AFLPs contributed more variable estimates of genetic diversity among the populations, suggesting that AFLPs could be still effectively applied to assess comprehensive patterns of genetic variation of $T$. grandis. 


\section{Conclusion}

Teak (T. grandis) is one of the most valuable tropical timber species being well-known for its timber strength and beauty. T. grandis naturally occurs in India, Laos, Myanmar and Thailand. Myanmar has the largest area of T. grandis forests among these four countries. Nevertheless, genetic resources of T. grandis in Myanmar are increasingly threatened due to high deforestation rate, and consequently, conservation and sustainable utilization are urgently needed to safeguard its genetic resources.

T. grandis still has a high level of genetic diversity in Myanmar. Thus, in situ and ex situ conservation should be effectively implemented to maintain these genetic resources. This study indicates two centers of genetic diversity of T. grandis in Myanmar: one for the northern and another for the southern regions. Moreover, due to strong genetic differentiation between the northern and southern regions, the two regions should be regarded as two different conservation units. Furthermore, many spatially-isolated populations should be included in the conservation programs due to the presence of IBD and significant genetic differentiation among $T$. grandis populations.

Information on genetic variation of tree species alone will never be complete for gene conservation, and thus, other factors like geographical, ecological, and political criteria need to be considered when deciding the number of populations (White et al., 2007). At least one or more populations from the center of the species' origin, where high level of genetic diversity exist, should be given priority for gene conservation (Yanchuk and Lester, 1996). Moreover, $T$. grandis populations with the highest number of alleles $(A)$, allelic richness $\left(A_{\mathrm{R}}\right)$ and percent of polymorphic loci $(P P L)$ should also be given priority to maintain the genetic multiplicity of populations. T. grandis populations with significantly high levels of inbreeding (e.g., TSA) should be considered for ex situ conservation which may particularly be important for populations that suffer from inbreeding and as an indicator for high rates of allelic loss and genetic erosion (van Zonneveld et al., 2012).

Seeds or planting materials for plantation programs should be carefully collected from a large number of T. grandis trees situated in areas with high genetic diversity. Moreover, seeds or reproductive materials should be collected from many different populations for gene bank storage, provenance trials and other ex-situ plantations. Furthermore, provenances for transfer of seeds or seedlings should be delineated based on the significant genetic differentiation among populations. Multiple breeding strategies (Namkoong, 1989), which are well-suited 
approaches for allogamous tree species like teak with large distribution range, should be implemented in order to conserve and utilize all broad bases of genetic resources sustainably.

Forest management practices can alter genetic structure of forest trees (Finkeldey and Ziehe, 2004). However, selective logging did not significantly affect genetic structure of $T$. grandis populations in this study. Thus, Myanmar Selection System (MSS) can still be considered as a sustainable management practice for $T$. grandis forests. Nonetheless, care should be taken as excessive and intensive logging may lead to genetic erosion (Ledig, 1992). Furthermore, adaptive genetic markers are recommended to further confirm the impacts of logging on genetic structure of $T$. grandis forests since neutral genetic markers like SSRs and AFLPs may not able to detect the impacts on adaptive and quantitative traits like diameters of the trees.

In this study, SSRs and AFLPs provide us comprehensive and complementary information on the patterns of genetic variation of $T$. grandis forests. Therefore, the combined application of these two markers is considered to be the best approach to assess the patterns of genetic variation of T. grandis in Myanmar for the conservation and sustainable utilization of genetic resources. 


\section{Summary}

Teak (Tectona grandis Linn. f.) is a valuable tropical tree species which naturally occurs in India, Laos, Myanmar and Thailand. The total area of $T$. grandis forests was reported to be about 28 million ha, and 60 percent of $T$. grandis forests (about 16.5 million ha) was known to be in Myanmar. However, natural T. grandis forests in Myanmar are nowadays under enormous threats due to high deforestation rates, and thus, genetic resources of $T$. grandis are increasingly at risk. Consequently, the conservation and sustainable utilization of the genetic resources of teak forests are urgently needed.

Nonetheless, information on the patterns of genetic variation of T. grandis is still lacking. In addition, there is no information about the impact of selective logging on the genetic structure of teak forests which have been managed by the Myanmar Selection System for more than one century. Similarly, no investigation has ever been carried out for the genetic structure of natural regeneration which plays an important role for future teak forests.

Thus, the presented study was conducted with three major objectives: 1) to investigate the genetic variation of $T$. grandis; 2) to assess the genetic differentiation between adults and regeneration; 3) to examine the impact of selective logging on the genetic structure of teak forests.

Leaf samples from adult trees $(n=50)$ and natural regeneration $(n=50)$ were collected in unlogged and its adjacent selectively-logged $T$. grandis stands. The sampling included eight population pairs in Myanmar $(n=1600)$ : four population pairs (unlogged and selectivelylogged populations) each in the northern and in the southern regions. Additionally, leaf samples from two plantations in Benin $(\mathrm{n}=80)$ were collected. The patterns of genetic variation of $T$. grandis were assessed using ten Simple Sequence Repeats (SSRs) and 71 Amplified Fragment Length Polymorphisms (AFLPs).

For SSRs, genetic diversity within T. grandis populations in Myanmar was relatively high (A $\left.=6.8, H_{\mathrm{E}}=0.586, H_{\mathrm{O}}=0.564\right) . T$. grandis in Myanmar had still higher genetic diversity than in Laos and Thailand but the genetic diversity was lower than in India. T. grandis populations in Myanmar had a lower diversity than the plantations in Benin $\left(A=7.9, H_{\mathrm{E}}=0.643, H_{\mathrm{O}}=\right.$ 0.642) revealing that artificial regeneration did not affect the genetic diversity of teak. Nonetheless, extensive associations of loci in these plantations indicate human interferences 
on genetic structure of $T$. grandis plantations. This suggests founder effects caused by an origin from a few seed trees.

For SSRs, the genetic diversity $\left(H_{\mathrm{E}}\right)$ was not significantly different between adults and regeneration, between selectively-logged and unlogged populations and between the northern and southern regions. However, the allelic richness was significantly higher in populations in the southern region $\left(A_{\mathrm{R}}=7.0\right)$ than in the northern region $\left(A_{\mathrm{R}}=6.1\right)$. Inbreeding was also not significantly different between the logging types and between the regions. Similarly, there were no significant differences with regard to inbreeding for all adults and the regeneration. However, a significant difference between inbreeding coefficients was observed for the adults $\left(F_{\mathrm{IS}}=0.013\right)$ and the regeneration $\left(F_{\mathrm{IS}}=0.061\right)$ in unlogged $T$. grandis stands.

Not only SSRs but also AFLPs revealed high genetic diversity within T. grandis populations $\left(P P L=72.2 \%, H_{\mathrm{j}}=0.216, \mathrm{Br}=1.767\right)$. In contrast to SSRs, AFLPs revealed higher genetic diversity in Myanmar than in Benin $\left(P P L=53.5 \%, H_{\mathrm{j}}=0.169, \mathrm{Br}=1.541\right)$, which could be explained by the different nature of markers. On the whole, AFLPs revealed that the genetic diversity was not significantly different between unlogged and selectively-logged populations and between regeneration and adults. However, in unlogged populations, the estimate of genetic diversity $\left(H_{\mathrm{j}}\right)$ was significantly higher in adults $\left(H_{\mathrm{j}}=0.218\right)$ than in the regeneration $\left(H_{\mathrm{j}}=0.188\right)$. This reduced level of genetic diversity in the regeneration could be largely due to the mating system and limited abundance of natural regeneration in unlogged stands. The genetic diversity of the northern populations $\left(P P L=74.5 \%, H_{\mathrm{j}}=0.218, \mathrm{Br}=1.790\right)$ was also significantly higher than that of southern populations $\left(P P L=58.5 \%, H_{\mathrm{j}}=0.189, \mathrm{Br}=1.693\right)$, which is contrasting to the result of SSRs.

For SSRs, there was no significant genetic differentiation (pairwise $F_{\mathrm{ST}}$ ) and low genetic distances between adults and regeneration in the same stand. In addition, UPGMA and NJ revealed a strong grouping of adults and regeneration. This confirms the genetic similarity between adults and regeneration in the same stand.

For AFLPs, there was a significant genetic differentiation between adults and regeneration and low genetic distances between the same age types in most stands. An UPGMA dendrogram revealed genetic similarity between the same age type of adjacent populations, rather than between adults and regeneration of the same stand. This result is not congruent with the result of SSRs. This genetic similarity between the similar age classes could be explained as a selection process taking place in the early temporal stages of $T$. grandis. This 
strong difference between adults and regeneration was attributed by many AFLP loci with small effects.

An Analysis of Molecular Variance (AMOVA) showed that the genetic variation between adults and regeneration was significantly different at AFLPs $(1.5 \%, P<0.05)$. This result is in contrast to the result of SSRs which showed no significant difference between them $(-0.71$ $\%, P>0.05)$.

Both markers consistently revealed that selective logging did not significantly affect the genetic structure of $T$. grandis forests, indicating a resilient capacity of teak forests against genetic effects followed by silvicultural regimes. Nonetheless, both markers constantly showed a slight decrease in genetic variation and subsequently slight increase in genetic differentiation among selectively-logged adult populations.

There were significant and positive correlations between the genetic and geographical distances among all adult and regeneration populations (SSRs: $R=0.827$ for adults, $R=$ 0.838 for regeneration; AFLPs: $R=0.638$ for adults, $R=0.772$ for regeneration) and among the populations within the northern and the southern regions, suggesting the existence of a strong isolation-by-distance.

AMOVAs detected the highest genetic variation within populations (> 80\%) at both markers, which is congruent with genetic patterns of other tropical tree species. Moreover, both markers showed a significant genetic differentiation among all $32 \mathrm{~T}$. grandis populations in Myanmar $\left(\Phi_{\mathrm{ST}}=0.120\right.$ for SSRs, $\Phi_{\mathrm{ST}}=0.123$ for AFLPs, $\left.P<0.001\right)$, confirming the importance of inclusion of a number of different populations for conservation programs.

For both markers, all analyses consistently revealed an obvious split between the northern and the southern populations. The highest genetic differentiation between the two regions was consistently confirmed by pairwise $F_{\mathrm{ST}}$ s and Nei's genetic distances, suggesting little or limited gene flow and migration between the two regions. Due to the high genetic diversity and genetic differentiation between the two regions, two centers of genetic diversity of $T$. grandis were suggested. In this study, Bayesian analyses consistently showed genetic similarity of $T$. grandis plantations in Benin and the populations in the southern regions of Myanmar at both markers. NJ and UPGMA showed the same clustering at SSRs while the UPGMA dendrogram revealed no consistent clustering between these two groups. However, a PCA was successfully able to differentiate between them at both markers. 
The correlation between the estimates of genetic diversity from both markers was negative but not significant $(R=-0.16, P>0.05)$. Nonetheless, genetic differentiation $\left(F_{\mathrm{ST}}\right)$ calculated by both markers were positively and significantly correlated $(R=0.631, P<0.001$ for adults; $R=0.770, P<0.05$ for regeneration). This result is explained by a similar evolutionary history of the $T$. grandis populations but there may be non-random associations of markers within populations.

In this study, the combined application of SSRs and AFLPs is considered to be the best approach to assess the patterns of genetic variation of $T$. grandis, accordingly providing comprehensive and complementary information for the conservation and sustainable utilization of genetic resources of T. grandis in Myanmar. 


\section{Zusammenfassung}

Teak (Tectona grandis Linn. f.) ist eine wertvolle tropische Baumart, deren natürliche Verbreitung Indien, Laos, Myanmar und Thailand umfasst. Das gesamte Areal von T. grandis entspricht etwa 28 Mio. ha; $60 \%$ davon liegen in Myanmar. Die natürlichen T. grandisWälder in Myanmar und damit die genetischen Ressourcen dieser Art sind heute stark durch hohe Abholzungsraten gefährdet. Daher ist es dringend notwendig, Teakwälder zu erhalten und nachhaltig zu nutzen. Gleichwohl fehlen Informationen zur Verteilung der genetischen Variation der Art sowie zum Einfluss selektiver Abholzung auf die genetische Struktur von Teak, deren Wälder seit mehr als einem Jahrhundert durch das „Myanmar Selection System“ bewirtschaftet werden. Zudem gibt es bislang keine Erfassung der genetischen Struktur der natürlichen Verjüngung, der eine wichtige Rolle in Teakwäldern zukommt.

Die hier präsentierte Studie verfolgte drei Hauptziele: 1) die Erfassung der genetischen Variation von $T$. grandis, 2) die Abschätzung der genetischen Differenzierung zwischen Adulten und Verjüngung, 3) die Beurteilung des Bewirtschaftungseinflusses auf die genetische Struktur von Teak.

Es wurden Blattproben von adulten Bäumen $(\mathrm{n}=50)$ und der natürlichen Verjüngung $(\mathrm{n}=$ 50) in unbewirtschafteten und bewirtschafteten $T$. grandis-Beständen gesammelt. Die Probenahme erfolgte in acht Populationspaaren $(n=1600)$ : jeweils vier Populationspaare (unbewirtschaftet und bewirtschaftet) im nördlichen und im südlichen Myanmar. Zudem wurden Blattproben in zwei Plantagen in Benin $(n=80)$ gesammelt. Die genetische Variation wurde mit 10 SSR- (Simple Sequence Repeats) und 71 AFLP-Loci (Amplified Fragment Length Polymorphisms) untersucht.

Die mit den SSR-Markern ermittelte genetische Diversität der T. grandis-Populationen in Myanmar war relativ hoch $\left(A=6,8 ; H_{\mathrm{E}}=0,586 ; H_{\mathrm{O}}=0,564\right)$. Die Diversität war im Vergleich zu Laos und Thailand etwas höher, im Vergleich zu Indien etwas niedriger. Die $T$. grandis-Populationen in Myanmar wiesen eine niedrigere genetische Diversität auf als die Plantagen in Benin $\left(A=7,9 ; H_{\mathrm{E}}=0,643 ; H_{\mathrm{O}}=0,642\right)$. Die künstliche Verjüngung hat die genetische Diversität von Teak somit nicht beeinflusst. Dennoch wurde eine erhöhte Anzahl stochastisch assoziierter Loci in diesen Plantagen gefunden. Dies verweist auf einen anthropogenen Einfluss auf die genetische Struktur der T. grandis-Populationen. So können Gründereffekte angenommen werden, da die Verjüngung von nur wenigen Bäumen ausgegangen ist. Die genetische Diversität an den SSR-Loci $\left(H_{\mathrm{E}}\right)$ war zwischen den Adulten 
und der Verjüngung, zwischen unbewirtschafteten und bewirtschafteten sowie zwischen den nördlichen und südlichen Regionen nicht signifikant verschieden. Allerdings war die „allelic richness“ in den südlichen Populationen $\left(A_{\mathrm{R}}=7,0\right)$ signifikant höher als in den nördlichen $\left(A_{\mathrm{R}}=6,1\right)$. Es wurden ebenfalls keine signifikanten Unterschiede von Inzuchteffekten zwischen den Bewirtschaftungstypen und den Regionen gefunden. Für alle Adulten und die gesamte Verjüngung wurden keine signifikanten Unterschiede bezüglich der Inzucht beobachtet, allerdings waren die Unterschiede zwischen den Adulten $\left(F_{\mathrm{IS}}=0.013\right)$ und der Verjüngung $\left(F_{\mathrm{IS}}=0,061\right)$ in den unbewirtschafteten Beständen signifikant.

Die AFLP-Untersuchungen ergaben ebenfalls eine hohe genetische Diversität in den $T$. grandis-Populationen $\left(P P L=72,2 \% ; H_{\mathrm{j}}=0,216 ; \mathrm{Br}=1,767\right)$, die zwischen den Populationen variiert. Im Gegensatz $\mathrm{zu}$ den SSR-Untersuchungen ergaben die AFLPs eine höhere genetische Diversität in Myanmar als in Benin ( $\left.P P L=53,5 \% ; H_{\mathrm{j}}=0,169 ; \mathrm{Br}=1,541\right)$. Dieser Widerspruch kann durch die unterschiedlichen Eigenschaften der Marker erklärt werden. Die mit den AFLPs ermittelte genetische Diversität war zwischen den unbewirtschafteten und den bewirtschafteten Populationen sowie zwischen der Verjüngung und den Adulten nicht signifikant verschieden. In den unbewirtschafteten Populationen wurde jedoch eine signifikant höhere genetische Diversität $\left(H_{\mathrm{j}}\right)$ für die Adulten $\left(H_{\mathrm{j}}=0,218\right)$ als für die Verjüngung $\left(H_{\mathrm{j}}=0,188\right)$ ermittelt. Die reduzierte Diversität in der Verjüngung ist vermutlich eine Folge des Reproduktionssystems und dem begrenzten Auftreten natürlicher Verjüngung in den unbewirtschafteten Beständen. Die genetische Diversität der nördlichen Populationen $\left(P P L=74,5 \% ; H_{\mathrm{j}}=0,218 ; B r=1,790\right)$ war signifikant höher als in den südlichen Populationen $\left(P P L=58,5 \% ; H_{\mathrm{j}}=0,189 ; \mathrm{Br}=1,693\right)$. Das ist zu den SSR-Untersuchungen ein ebenfalls gegensätzliches Ergebnis.

Mit den SSR-Markern wurden keine signifikante Differenzierung (pairwise $F_{\mathrm{ST}}$ ) und niedrige genetischen Distanzen zwischen den Adulten und der Verjüngung in den einzelnen Beständen gefunden. Das unterstreicht die genetische Ähnlichkeit der Adulten und der Verjüngung im entsprechenden Bestand.

Mit den AFLPs wurden eine signifikante Differenzierung, aber niedrige genetische Distanzen zwischen den Adulten und der Verjüngung in den meisten Beständen gefunden. Ein UPGMA-Dendrogramm zeigte eine höhere genetische Ähnlichkeit zwischen gleichen Altersgruppen benachbarter Populationen als zwischen den Adulten und der Verjüngung des gleichen Bestandes. Dieses Ergebnis entspricht nicht den SSR-Untersuchungen. Die 
genetische Ähnlichkeit innerhalb der gleichen Altersstufen kann durch einen Selektionsprozess in den frühen Entwicklungsstadien von T. grandis erklärt werden. Dieser deutliche Unterschied zwischen den Adulten und der Verjüngung fand sich an vielen AFLPLoci mit jeweils schwachen Effekten.

Eine molekulare Varianzanalyse (AMOVA) ergab, dass die genetische Variation für die AFLPs zwischen den Adulten und der Verjüngung signifikant verschieden war $(1,5 \% ; P<$ 0,05). Die SSR-Marker hingegen fanden keinen signifikanten Unterschied $(-0,71 \% ; P>$ $0,05)$.

Beide Marker zeigten, dass die Bewirtschaftung die genetische Struktur von T. grandis nicht signifikant beeinflusst und unterstreicht damit die Widerstandsfähigkeit der Teakwälder gegenüber genetischen Effekten durch waldbauliche Maßnahmen. Dennoch ergaben beide Marker eine leichte Abnahme der genetischen Variation in den bewirtschafteten adulten Populationen sowie eine leichte Zunahme der genetischen Differenzierung zwischen diesen.

Es wurde eine signifikante und positive Korrelation der genetischen und geografischen Distanzen zwischen allen 16 adulten Populationen und der Verjüngung (SSRs: $R=0,827$ für Adulte, $R=0,838$ für die Verjüngung; AFLPs: $R=0,638$ für Adulte, $R=0,772$ für die Verjüngung) sowie zwischen den nördlichen und südlichen Populationen gefunden. Das zeigt einen starken ,,isolation-by-distance“-Effekt.

Molekulare Varianzanalysen für beide Markersysteme fanden die höchste genetische Variation innerhalb von Populationen (> $80 \%$ ). Das entspricht den genetischen Mustern tropischer Baumarten. Darüber hinaus zeigten beide Marker signifikante genetische Differenzierungen zwischen allen 32 T. grandis-Populationen in Myanmar $\left(\Phi_{\mathrm{ST}}=0,120\right.$ für SSRs; $\Phi_{\mathrm{ST}}=0,123$ für AFLPs; $\left.P<0.001\right)$. Dieses Ergebnis unterstreicht die Bedeutung der Berücksichtigung vieler Populationen für Erhaltungsprogramme.

Alle Analysen für beide Marker ergaben eine deutliche Trennung zwischen den nördlichen und südlichen Populationen. Die hohe genetische Differenzierung zwischen den Regionen wurde durch die paarweisen $F_{\mathrm{ST}} \mathrm{S}$ und Nei's genetische Distanzen bestätigt. Diese Ergebnisse verweisen auf geringen Genfluss und Migration zwischen den beiden Regionen. Aufgrund der hohen genetischen Diversität und Differenzierung zwischen den Regionen werden zwei Diversitätszentren von $T$. grandis vermutet. Die Bayesschen Analysen ergaben für beide Marker außerdem genetische Ähnlichkeiten der T. grandis-Plantagen in Benin und den 
Populationen im Süden Myanmars. Diese Gruppierung zeigten auch die NJ- und UPGMAAnalysen der SSR-Daten, obwohl die Gruppierung in den UPGMA-Dendrogrammen nicht konsistent war. In den PCAs der beiden Marker waren die beiden Gruppen jedoch deutlich voneinander getrennt.

Die mit den beiden Markern ermittelten genetischen Diversitäten zeigten eine negative, aber nichtsignifikante Korrelation $(R=-0,16 ; P>0.05)$. Die genetischen Differenzierungen $\left(F_{\mathrm{ST}}\right)$ hingegen korrelierten positiv und signifikant $(R=0,631, P<0.001$ für Adulte; $R=0,770, P<$ 0,05 für die Verjüngung). Das wird erklärt durch eine vergleichbare Evolution der T. grandisPopulationen, obwohl es nichtzufällige Assoziationen zwischen einzelnen Markern in den Populationen geben könnte.

Diese Studie zeigt, dass die kombinierte Anwendung von SSR- und AFLP-Markern als beste Methode angesehen werden kann, mit der man die Verteilung der genetischen Variation von T. grandis analysieren kann. Der hier gewählte Ansatz erbrachte umfassende Informationen für die Erhaltung der genetischen Ressourcen und die nachhaltige Nutzung von T. grandis in Myanmar. 


\section{References}

Akinnagbe, A., Gailing, O., Finkeldey, R., 2010. Genetic diversity of Mansonia altissima A. Chev. under different regimes of human impact in the Akure Forest Reserve, Nigeria. Forestry Studies in China 12, 193-200.

Anon., 2012. Germplasm Resources Information Network (GRIN). In. USDA, ARS, National Genetic Resources Program, National Germplasm Resources Laboratory, Beltsville, Maryland, http://www.ars-grin.gov/cgi-bin/npgs/html/genus.pl?11908.

Ball, J.B., Pandey, D., Hirai, S., 1999. Global overview of teak plantations. In, Proceedings of the Regional Seminar: Site, Technology and Productivity of Teak Plantation, Chiang Mai, Thailand.

Barber, H.N., 1965. Selection in natural populations. Heredity 20, 551-572.

Bawa, K.S., Seidler, R., 1998. Natural forest management and conservation of biodiversity in tropical forests. Conservation Biology 12, 46-55.

Bedell, P.E., 1989. Preliminary observations on variability of teak in India. Indian Forestry $115,72-81$.

Bhat, K.M., Priya, P.B., 2004. Influence of provenance variation on wood properties of teak from the Western Ghat region in India. Iawa Journal 25, 273-282.

Boshier, D., Amaral, W., 2004 Threats to forest ecosystems and challenges for the conservation and sustainable use of forest genetic resources In: B., V., Amaral W., B., M. (Eds.), Challenges in managing forest genetic resources for livelihoods. IP-GRI Rome.

Bryndum, B., Hedegart, T., 1969. Pollination of teak (Tectona grandis Linn. f.). Silvae. Genetica. 18, 77-80.

Buchert, G.P., Rajora, O.P., Hood, J.V., Dancik, B.P., 1997. Effects of harvesting on genetic diversity in old growth eastern white pine in Ontario, Canada. Conservation Biology $11,747-758$.

Buiteveld, J., Vendramin, G.G., Leonardi, S., Kamer, K., Geburek, T., 2007. Genetic diversity and differentiation in European beech (Fagus sylvatica L.) stands varying in management history. Forest Ecology and Management 247, 98-106.

Campbell, R.K., Sugano, A.I., 1979. Genecology of bud-burst phenology in Douglas-fir : response to flushing temperature and chilling. Botanical Gazette 140, 223-31.

Cantino, P.D.e.a., 1992 Genera of Labiatae: status and classification. In: Harley, R. M. \& T. Reynolds, eds., Advances in labiate science. Adv Lab Sci, 511-522. 
Cao, C.-P., Gailing, O., Siregar, I., Siregar, U., Finkeldey, R., 2009. Genetic variation in nine Shorea species (Dipterocarpaceae) in Indonesia revealed by AFLPs. Tree Genetics and Genomes 5, 407-420.

Cao, C.P., Finkeldey, R., Siregar, I.Z., Siregar, U.J., Gailing, O., 2006. Genetic diversity within and among populations of Shorea leprosula Miq. and Shorea parvifolia Dyer (Dipterocarpaceae) in Indonesia detected by AFLPs. Tree Genetics and Genomes 2, 225-239.

Cavalli-Sforza, L.L., Edwards, A.W.F., 1967. Phylogenetic analysis: Models and estimation procedures. American Journal of Human Genetics 19, 233-257.

Chaisurisri, K., Wungplong, P., Liewlaksaneeyanawin, C., Boyle, T.J.B., 1997. Impacts of disturbance on genetic diversity of some forest species in Thailand. In, Wrap- up Workshop of the CIFOR-IPGRI: Impact of Disturbance Project, Bangalore, India.

Changtragoon, S., Szmidt, A.E., 2000. Genetic diversity of teak (Tectona grandis Linn. F.) in Thailand revealed by Random Amplified Polymorphic DNA (RAPD). In, IUFRO Working Party: Tropical species breeding and genetic resources: Forest genetics for the next millennium, Durban, South Africa, pp. 82-83.

Cloutier, D., Kanashiro, M., Ciampi, A.Y., Schoen, D.J., 2007. Impact of selective logging on inbreeding and gene dispersal in an Amazonian tree population of Carapa guianensis Aubl. Molecular Ecology 16, 797-809.

Coart, E., Glabeke, S.V., Petit, R.J., Bockstaele, E.V., Roldán-Ruiz, I., 2005. Range wide versus local patterns of genetic diversity in hornbeam (Carpinus betulus L.). Conservation Genetics 6, 259-273.

Coart, E., Vekemans, X., Smulders, M.J.M., Wagner, I., Van Huylenbroeck, J., Van Bockstaele, E., Roldán-Ruiz, I., 2003. Genetic variation in the endangered wild apple (Malus sylvestris (L.) Mill.) in Belgium as revealed by amplified fragment length polymorphism and microsatellite markers. Molecular Ecology 12, 845-857.

Crispo, E., Hendry, A.P., 2005. Does time since colonization influence isolation by distance? A meta-analysis. Conservation Genetics 6, 665-682.

Crouch, J.H., Crouch, H.K., Constandt, H., Van Gysel, A., Breyne, P., Van Montagu, M., Jarret, R.L., Ortiz, R., 1999. Comparison of PCR-based molecular marker analyses of Musa breeding populations. Molecular Breeding 5, 233-244.

Dah, S.E., 2004. Teak and forest management in Myanmar. In, ITTO Tropical Forest Update, pp. 12-13. 
Dick, C.W., 2001. Genetic rescue of remnant tropical trees by an alien pollinator. In, Proceedings of the Royal Society of London Series B-Biological Sciences, pp. 23912396.

Earl, D.A., vonHoldt, B.M., 2011. STRUCTURE HARVESTER: a website and program for visualizing STRUCTURE output and implementing the Evanno method. Conservation Genetics Resources 4, 359-361.

Ekue, M.R.M., Vornam, B., Finkeldey, R., Gailing, O., 2011. Assessment of the domestication state of ackee (Blighia sapida K.D. Koenig) in Benin based on AFLP and microsatellite markers. Conservation Genetics 12, 475-489.

Evanno, G., Regnaut, S., Goudet, J., 2005. Detecting the number of clusters of individuals using the software structure: a simulation study. Molecular Ecology 14, 2611-2620.

Excoffier, L., Lischer, H.E.L., 2010. Arlequin suite ver 3.5: a new series of programs to perform population genetics analyses under Linux and Windows. Molecular Ecology Resources 10, 564-567.

FAO, 2011. State of World Forests.

Farwig, N., Braun, C., Böhning-Gaese, K., 2008. Human disturbance reduces genetic diversity of an endangered tropical tree, Prunus africana (Rosaceae). Conservation Genetics 9, 317-326.

Felsenstein, J., 1989. PHYLIP: phylogeny inference package (version 3.2). Cladistics 5, 164166.

Finkeldey, R., Hattemer, H.H., 2007. Tropical Forest Genetics. Springer-Verlag.

Finkeldey, R., Ziehe, M., 2004. Genetic implications of silvicultural regimes. Forest Ecology and Management 197, 231-244.

Fofana, I., Ofori, D., Poitel, M., Verhaegen, D., 2009. Diversity and genetic structure of teak (Tectona grandis Linn. f) in its natural range using DNA microsatellite markers. New Forests 37, 175-195.

FRA, 2010. Country Report: Myanmar, Forest Resources Assessment.

Freeland, J., 2005. Molecular ecology. John Wiley \& Sons, Chichester, West Sussex, England; Hoboken, NJ.

Ganglo, C.J., Lejoly, J., 1999. LE TECK AU BÉNIN: Gestion et perspectives. Bois Et Forets Des Tropiques 261.

Gaudeul, M., Till-Bottraud, I., Barjon, F., Manel, S., 2004. Genetic diversity and differentiation in Eryngium alpinum L. (Apiaceae): comparison of AFLP and microsatellite markers. Heredity 92, 508-518. 
Gauli, A., Gailing, O., Stefenon, V.M., Finkeldey, R., 2009. Genetic similarity of natural populations and plantations of Pinus roxburghii Sarg. in Nepal. Annals of Forest Science 66.

Gill, B.S., Bedi, Y.S., S.S., B., 1983. Cytopalynological studies in woody members of family Verbenaceae from north-west and central India. Journal of Indian Botanical Society 62, 235-244.

Goudet, J., 2001. FSTAT: a program to estimate and test gene diversities and fixation indices (version 2.9.3). In. http://www.unil.ch/izea/softwares/fstat.html.

Gunaga, R.P., Vasudeva, R., 2002. Genetic variation for fruiting phenology among teak clones of different provenances of Karnataka. Indian Journal of Forestry 25, 215-220.

Gyi, K.K., 1972. An investigation of factors relevant to development of teak plantation in South East Asia with particular reference to Burma. In. Australian National University, Canberra Australia.

Gyi, K.K., Tint, K., 1998. Management status of natural teak forests. In, Teak for the Future: Proceedings of the second regional seminar on teak, pp. 27-48.

Hall, P., Chase, M.R., Bawa, K.S., 1994. Low genetic-Variation but high population differentiation in a common tropical forest tree species. Conservation Biology 8, 471482.

Hamrick, J.L., Godt, M.J.W., Sherman-Broyles, S.L., 1992. Factors influencing levels of genetic diversity in woody plant species. New Forests 6, 95-124.

Hartl, D.L., Clark, A.G., 1989. Principles of population genetics. Second Edition, Sinauer Associates, Sunderland, Mass.

Hartl, D.L., Clark, A.G., 2007. Principles of population genetics. Fourth Edition, Sinauer Associates, Sunderland.

Hedegart, T., 1973. Pollination of teak (Tectona grandis L.). Silvae Genetica 22, 124-128.

Hedegart, T., 1976. Breeding system, variation and genetic improvement of teak (Tectona grandis Linn. f.). In: J., B., B.T., S. (Eds.), Tropical Trees. Academic Press, London, pp. 109-123.

Indira, E.P., 2003. Why teak seed orchards are low productive? In, Proceedings of the international conference on quality timber products of teak from sustainable forest management Peechi, India, pp. 347-351.

Kadambi, K., 1972. Silviculture and management of teak. Stephen F. Austin State University, School of Forestry, Nacogdoches, Tex. 
Kaosa-ard, A., 1977. Physiological studies on sprouting of teak (Tectona grandis Linn. f.) planting stumps. In, Ph.D. Thesis. Australian National University, Canberra Australia, p. 370 .

Kaosa-ard, A., 1981. Teak: its natural distribution and related factors. Nat. His. Bull. Siam. Soc. $29,55-74$.

Kaosa-ard, A., 1986. Teak (Tectona grandis Linn. f.) in ASEAN: A survey report. ASEAN/Canada Forest Seed Centre.

Kaosa-ard, A., 1991. Teak in Thailand. In, Regional Seminar on Teak Guangzhou, China.

Kaosa-ard, A., 1998. Overview of problems in teak plantation establishment. In: Kashio, M., White, K. (Eds.), Teak for the future: Proceedings of the second regional seminar on teak, Yangon, pp. 49-59.

Kaosa-ard, A., 1999. Gains from provenance selection. In, Proceedings of international seminar on site, technology and productivity of teak plantations, Chiang Mai, Thailand, pp. 191-207.

Kermode, C.W.D., 1964. Some aspects of silviculture in Burma forests. Superintendent, Central Press, Bangoon.

Kitamura, K., Rahman, M.Y.B.A., Ochiai, Y., Yoshimaru, H., 1994. Estimation of the outcrossing rate on Dryobalanops aromatica Gaertn. f. in primary and secondary forests in Brunei, Borneo, Southeast Asia. Plant Species Biology 9, 37-41.

Kjaer, E.D., Kajornsrichon, S., Lauridsen, E.B., 1999. Heartwood, calcium and silica content in five provenances of teak (Tectona grandis L.). Silvae Genetica 48, 1-3.

Kjaer, E.D., Siegismund, H.R., Suangtho, V., 1996. A multivariate study on genetic variation in teak (Tectona grandis Linn. f.). Silvae Genetica 45, 361-368.

Koski, V., Stahl, P., 2000. Impacts of silviculture and forest management on genetic diversity of trees. In, Proceedings of the XXI IUFRO world congress 2000: Forests and society The role of research, Kuala Lumpur, Malaysia, pp. 110-119.

Kulkarni, D.H., 1951. Distribution of teak on the northern slopes of Satpura with special reference to geology. In, Proceedings of eighth silvicultural conference, Dehradun, pp. $154-163$.

Kumaravelu, G., 1991. Status of research and development of teak in India.

Kyaw, N.N., 2003. Site influence on growth and phenotype of teak (Tectona grandis Linn. f.) in natural forests of Myanmar.In Ph.D. thesis, Cuvillier Verlag, Göttingen.

Langella, O., 2002. Populations (Version 1.2.31) Centre National de la Recherche Scientifique, France. 
Ledig, F.T., 1992. Human impacts on genetic diversity in forest ecosystems. Oikos 63, 87108.

Lee, C.-T., Wickneswari, R., Mahani, M.C., Zakri, A.H., 2002. Effect of selective logging on the genetic diversity of Scaphium macropodum. Biological Conservation 104, 107-118.

Liengsiri, C., Boyle, T.J.B., Yeh, F.C., 1998. Mating system in Pterocarpus macrocarpus Kurz in Thailand. Heredity 89, 216-221.

Lundqvist, A.-C., Andersson, S., Lönn, M., 2008. Genetic variation in wild plants and animals in Sweden: a review of case studies from the perspective of conservation genetics. In. Swedish Environmental Protection Agency.

Luu, H.-T., 2005. Genetic variation and the reproductive system of Dipterocarpus cf. condorensis Pierre in Vietnam. In. Cuvillier, Göttingen.

Lwin, K., 2001. Natural regeneration of teak in moist deciduous forests on eastern and western exposures of the Bago Yama in Myanmar. In, Forest Sciences and Forest Ecology. Göttingen, Göttingen.

Lwin, O., Hyun, J.O., Yahya, A.F., 2010. Assessment of teak (Tectona grandis Linn. F.) provenance tests in the Bago Yoma Region, Myanmar. Journal of Korean Forestry Society 99, 686-692.

Lynch, M., Milligan, B.G., 1994. Analysis of population genetic structure with RAPD markers. Molecular Ecology 3, 91-99.

Lynch, M., Walsh, B., 1998. Genetics and analysis of quantitative traits. Sinauer, Sunderland, Mass.

Maguire, T.L., Peakall, R., Saenger, P., 2002. Comparative analysis of genetic diversity in the mangrove species Avicennia marina (Forsk.) Vierh. (Avicenniaceae) detected by AFLPs and SSRs. Theoretical and Applied Genetics 104, 388-398.

Mantel, N., 1967. The detection of disease clustering and a generalized regression approach. Cancer Research 27, 209-220.

Mariette, S., Chagné, D., Lézier, C., Pastuszka, P., Raffin, A., Plomion, C., Kremer, A., 2001. Genetic diversity within and among Pinus pinaster populations: comparison between AFLP and microsatellite markers. Heredity 86, 469-479.

Mariette, S., Le Corre, V., Austerlitz, F., Kremer, A., 2002. Sampling within the genome for measuring within-population diversity: trade-offs between markers. Molecular Ecology $11,1145-1156$. 
Medri, C., Ruas, P.M., Higa, A.R., Murakami, M., Ruas, C.D., 2003. Effects of forest management on the genetic diversity in a population of Araucaria angustifolia (bert.) O. Kuntze. Silvae Genetica 52, 202-205.

Minn, Y., 2007. Genetic diversity within and among populations of Teak (Tectona grandis Linn. f.) and Dahat (Tectona hamiltoniana Wall.) in Myanmar detected by AFLPs and cpSSRs. In, Forest Genetics and Forest Tree Breeding, Faculty of Forest Sciences and Forest Ecology. Goettingen University, Goettingen, p. 70.

Morjan, C.L., Rieseberg, L.H., 2004. INVITED REVIEW: How species evolve collectively: implications of gene flow and selection for the spread of advantageous alleles. Molecular Ecology 13, 1341-1356.

Murawski, D.A., Gunatilleke, I.A.U.N., Bawa, K.S., 1994. The effects of selective logging on Inbreeding in Shorea megistophylla (Dipterocarpaceae) from Sri-Lanka. Conservation Biology 8, 997-1002.

Namkoong, G., 1989. Population genetics and dynamics of conservation. In: Stoner, A.K., Knutson, L.V., Beltsville Symposia in Agricultural, R. (Eds.), Biotic diversity and germplasm preservation, global imperatives Kluwer Academic Publishers, Dordrecht [etc.], pp. 161-181.

Narayanan, C., Dubey, S., Wali, S.A., Shukla, N., Kumar, R., Mandal, A.K., Ansari, S.A., 2006. Optimization of DNA extraction for ISSR studies in Tectona grandis L.f. - an important forest tree species. African Journal of Biotechnology 5, 1220-1223.

Nei, M., 1973. Analysis of gene diversity in subdivided populations. Proceedings of the National Academy of Sciences of the United States of America 70, 3321-3323.

Nei, M., 1978. Estimation of average heterozygosity and genetic distance from a small number of individuals. Genetics 89, 583-590.

Nicodemus, A., Nagarajan, B., Narayanan, C., 2003. RAPD variation in Indian teak populations and its implications for breeding and conservation. In, Proceedings of the international conference on quality timber products of teak from sustainable forest management., Peechi, India, pp. 321-330.

Nybom, H., 2004. Comparison of different nuclear DNA markers for estimating intraspecific genetic diversity in plants. Molecular Ecology 13, 1143-1155.

Page, R.D.M., 1996. TreeView: An application to display phylogenetic trees on personal computers. Computer Applied Biosciences 12, 357-358.

Palupi, E.R., Owens, J.N., 1998. Reproductive phenology and reproductive success of teak (Tectona grandis L. F.). International Journal of Plant Sciences 159, 833-842. 
Parthiban, K.T., Surendran, C., Paramathma, M., 2003. Molecular characterization of teak seed sources using RAPD's. In, Proceedings of the international conference on quality timber products of teak from sustainable forest management, Peechi, India, pp. 331337.

Peakall, R., Smouse, P.E., 2006. GENALEX 6: genetic analysis in Excel. Population genetic software for teaching and research. Molecular Ecology Notes 6, 288-295.

Pemberton, J.M., Slate, J., Bancroft, D.R., Barrett, J.A., 1995. Nonamplifying alleles at microsatellite Loci - a caution for parentage and population studies. Molecular Ecology 4, 249-252.

Pengduoang, V., 1991. Teak in Laos. In, Paper presented at China/ESCAP/FAO Regional Seminar on Teak Guangzhou, China.

Petit, R.J., 2007. AFLPDiv Ver. 1.1. Free software. In, http://www.pierroton.inra.fr/genetics/labo/Software/Aflpdiv/index.html.

Pritchard, J.K., Stephens, M., Donnelly, P., 2000. Inference of population structure using multilocus genotype data. Genetics 155, 945-959.

Rajendra, K.C., 2011. Spatial dynamics of intraspecific genetic variation in European beech (Fagus sylvatica L.). In Ph.D. thesis, Cuvillier Verlag, Göttingen.

Rajora, O.P., 1999. Genetic biodiversity impacts of silvicultural practices and phenotypic selection in white spruce. Theoretical and Applied Genetics 99, 954-961.

Reusch, T.B.H., Ehlers, A., Hämmerli, A., Worm, B., 2005. Ecosystem recovery after climatic extremes enhanced by genotypic diversity. Proceedings of the National Academy of Sciences of the United States of America 102, 2826-2831.

Rousset, F., 2008. genepop'007: a complete re-implementation of the genepop software for Windows and Linux. Molecular Ecology Resources 8, 103-106.

Shrestha, M.K., Volkaert, H., Straeten, D.V.D., 2005. Assessment of genetic diversity in Tectona grandis using Amplified Fragment Length Polymorphism markers. Canadian Journal of Forest Research 35, 1017-1022.

Slatkin, M., 1994. Gene flow and population structure. Princeton University Press., NJ.

Slatkin, M., 1995. A measure of population subdivision based on microsatellite allele frequencies. Genetics 139, 457-462.

Sneath, P.H.A., Sokal, R.R., 1973. Numerical taxonomy : the principles and practice of numerical classification. W.H. Freeman, San Francisco.

Sokal, R.A., Rohlf, T.J., 1994. Biometry. W.H. Freeman, London. 
Spain, C.S., Lowe, A.J., 2011. Genetic consequences of subtropical rainforest fragmentation on Macadamia tetraphylla (Proteaceae). Silvae Genetica 60, 241-249.

Stefenon, V.M., Gailing, O., Finkeldey, R., 2007. Genetic structure of Araucaria angustifolia (Araucariaceae) populations in Brazil: Implications for the in situ conservation of genetic resources. Plant Biology 9, 516-525.

Stefenon, V.M., Gailing, O., Finkeldey, R., 2008. Genetic structure of plantations and the conservation of genetic resources of Brazilian pine (Araucaria angustifolia). Forest Ecology and Management 255, 2718-2725.

Takahashi, M., Mukouda, M., Koono, K., 2000. Differences in genetic structure between two Japanese beech (Fagus crenata Blume) stands. Heredity 84, 103-115.

Tangmitcharoen, S., Owens, J.N., 1997. Floral biology, pollination, pistil receptivity, and pollen tube growth of teak (Tectona grandis Linn f). Annals of Botany-London 79, 227-241.

Tero, N., Aspi, J., Siikamäki, P., Jäkäläniemi, A., Tuomi, J., 2003. Genetic structure and gene flow in a metapopulation of an endangered plant species, Silene tatarica. Molecular Ecology 12, 2073-2085.

Tewari, D.N., 1992. A monograph on teak (Tectona grandis L. f.). International Book Distributors, Dehra Dun, India.

Thein, H.M., Mamoru, K., Fukushima, M., Minn, Y., 2007. Structure and composition of a teak-bearing forest under the Myanmar selection system: impacts of logging and bamboo flowering. Southeast Asian Studies 45, 303-316.

Troup, R.S., 1921. The silviculture of Indian trees. The Clarendon Press, Oxford.

Van Oosterhout, C., Hutchinson, W.F., Wills, D.P.M., Shipley, P., 2004. Micro-Checker: software for identifying and correcting genotyping errors in microsatellite data. Molecular Ecology Notes 4, 535-538.

van Zonneveld, M., Scheldeman, X., Escribano, P., Viruel, M.A., Van Damme, P., Garcia, W., Tapia, C., Romero, J., Sigueñas, M., Hormaza, J.I., 2012. Mapping genetic diversity of Cherimoya (Annona cherimola Mill.): Application of spatial analysis for conservation and use of plant genetic resources. PLoS ONE 7, e29845.

Varghese, M., Nicodemus, A., Ramteke, P.K., Anbazhagi, G., Bennet, S.S.R., Subramanian, K., 2000. Variation in growth and wood traits among nine populations of teak in Peninsular India. Silvae Genetica 49, 201-205. 
Vasudeva, R., Hanumantha, M., Gunaga, R.P., 2004 Genetic variation for floral traits among teak (Tectona grandis Linn. f.) clones: implications to seed orchard fertility. Current Sciences 87, 358-362.

Vekemans, X., 2002. AFLP-SURV version 1.0. Laboratoire de Génétique et Ecologie Végétale. In. Université Libre de Bruxelles, Belgium.

Verhaegen, D., Fofana, I.J., Logossa, Z.A., Ofori, D., 2010. What is the genetic origin of teak (Tectona grandis L.) introduced in Africa and in Indonesia? Tree Genetics and Genomes 6, 717-733.

Verhaegen, D., Ofori, D., Fofana, I., Poitel, M., Vaillant, A., 2005. Development and characterization of microsatellite markers in Tectona grandis (Linn. f). Molecular Ecology Notes 5, 945-947.

Vos, P., Hogers, R., Bleeker, M., Reijans, M., Vandelee, T., Hornes, M., Frijters, A., Pot, J., Peleman, J., Kuiper, M., Zabeau, M., 1995. AFLP - a New Technique for DNAFingerprinting. Nucleic Acids Research 23, 4407-4414.

Weir, B.S., Cockerham, C.C., 1984. Estimating F-statistics for the analysis of population structure. Evolution 38, 1358-1370.

Weising, K., Nybom, H., Pfenninger, M., Kahl, G., 2005. DNA fingerprinting in plants: principles, methods, and applications. CRC Press, Boca Raton.

White, G.M., Boshier, D.H., Powell, W., 2002. Increased pollen flow counteracts fragmentation in a tropical dry forest: An example from Swietenia humilis Zuccarini. In, Proceedings of the National Academy of Sciences of the United States of America, pp. 2038-2042.

White, K.J., 1991. Teak : some aspects of research and development. FAO Regional Office for Asia and the Pacific Food and Agriculture Organization of the United Nations, Bangkok.

White, T.L., Adams, W.T., Neale, D.B., 2007. Forest Genetics. CAB International, Wallingford.

Wickneswari, R., Ho, W.S., Lee, K.S., Lee, C.T., 2004. Impact of disturbance on population and genetic structure of tropical forest trees. Forest Genetics 11, 193-201.

Woodhead, M., Russell, J., Squirrell, J., Hollingsworth, P.M., Mackenzie, K., Gibby, M., Powell, W., 2005. Comparative analysis of population genetic structure in Athyrium distentifolium (Pteridophyta) using AFLPs and SSRs from anonymous and transcribed gene regions. Molecular Ecology 14, 1681-1695. 
Yanchuk, A.D., Lester, D.T., 1996. Setting priorities for conservation of the conifer genetic resources of British Columbia. Forestry Chronicle 72, 406-415.

Yeh, F.C., 2000. Population genetics. In: Young, A.G., Boshier, D., Boyle, T.J.B. (Eds.), Forest conservation genetics: principles and practice. Collingwood, VIC, Australia: CSIRO Pub. ; Wallingford, Oxon, U.K. CABI Pub, p. 352.

Yeh, F.C., Boyle, T.J.B., 1997. Population genetic analysis of co-dominant and dominant markers and quantitative traits. Belgian Journal of Botany 129.

Young, A., Boyle, T., Brown, T., 1996. The population genetic consequences of habitat fragmentation for plants. Trends in Ecology and Evolution 11, 413-418.

Zheng, J.-W., An, S.-Q., Chen, L., Leng, X., Wang, Z.-S., Xiang, H.-J., 2005. Effects of logging on the genetic diversity of Quercus tiaoloshanica Chun et Ko in a tropical montane forest of Hainan Island, Southern China. Journal of Integrative Plant Biology 47, 1184-1192.

Zhivotovsky, L.A., 1999. Estimating population structure in diploids with multilocus dominant DNA markers. Molecular Ecology 8, 907-913. 


\section{Appendices}

Appendix 1 AFLP Protocol.

\begin{tabular}{|c|c|c|c|}
\hline \multicolumn{2}{|c|}{$\begin{array}{l}\text { Restriction - Ligation - Reaction } \mathbf{R L R} \\
(\text { for } 10 \text { probes- } 60 \mu \mathrm{l}) \text { : }\end{array}$} & \multicolumn{2}{|c|}{$\begin{array}{l}\text { Restriction - Ligation - Mix } \mathbf{R L M} \\
\text { (for } 10 \text { probes- } 20 \mu \mathrm{l}) \text { : }\end{array}$} \\
\hline $\mathrm{T}_{4}$ DNA Ligase buffer $10 \mathrm{x}$ & $10.0 \mu \mathrm{l}$ & $\mathrm{T}_{4}$ DNA Ligase buffer $10 \mathrm{x}$ & $2.0 \mu \mathrm{l}$ \\
\hline $0.5 \mathrm{M} \mathrm{NaCl}$ & $10.0 \mu \mathrm{l}$ & $0.5 \mathrm{M} \mathrm{NaCl}$ & $2.0 \mu \mathrm{l}$ \\
\hline BSA $(1 \mathrm{mg} / \mathrm{ml})$ & $5.0 \mu \mathrm{l}$ & BSA $(1 \mathrm{mg} / \mathrm{ml})$ & $1.0 \mu \mathrm{l}$ \\
\hline MseI Adaptor pair (+/-) & $6.0 \mu \mathrm{l}$ & $\operatorname{Mse} \mathrm{I}(10 \mathrm{u} / \mu \mathrm{l})$ & $0.8 \mu \mathrm{l}$ \\
\hline EcoRI Adaptor pair (+/-) & $6.0 \mu \mathrm{l}$ & $\operatorname{EcoRI}(10 \mathrm{u} / \mu \mathrm{l})$ & $4.0 \mu \mathrm{l}$ \\
\hline \multirow[t]{2}{*}{$\mathrm{HPLC} \mathrm{H}_{2} \mathrm{O}$} & $23.0 \mu 1$ & $\mathrm{~T}_{4}$ DNA Ligase $(4 \mathrm{u} / \mu \mathrm{l})$ & $3.0 \mu \mathrm{l}$ \\
\hline & & HPLC $\mathrm{H}_{2} \mathrm{O}$ & $7.2 \mu \mathrm{l}$ \\
\hline
\end{tabular}

\section{Step I: Restriction Ligation}

(Note: always hold on the top part of the tubes for $M s \mathrm{eI}, E c o \mathrm{RI}$ and $\mathrm{T}_{4} \mathrm{DNA}$ ligase to avoid reaction: always put them on ice)

\section{Step I A: Incubation}

Each probe contains:

$6 \mu \mathrm{l} L \mathrm{R}+4 \mu \mathrm{l}$ genomic DNA $+2 \mu \mathrm{l} \mathrm{RLM}$

Mix and incubate overnight (at room temperature).

(Note: thoroughly centrifuged)

\section{Step I B: Dilution of RL}

Fill to $50 \mu \mathrm{l}$ with $\mathrm{H}_{2} \mathrm{O}\left(+38 \mu \mathrm{l} \mathrm{H}_{2} \mathrm{O}\right)$ 
Step II: Pre-selective amplification

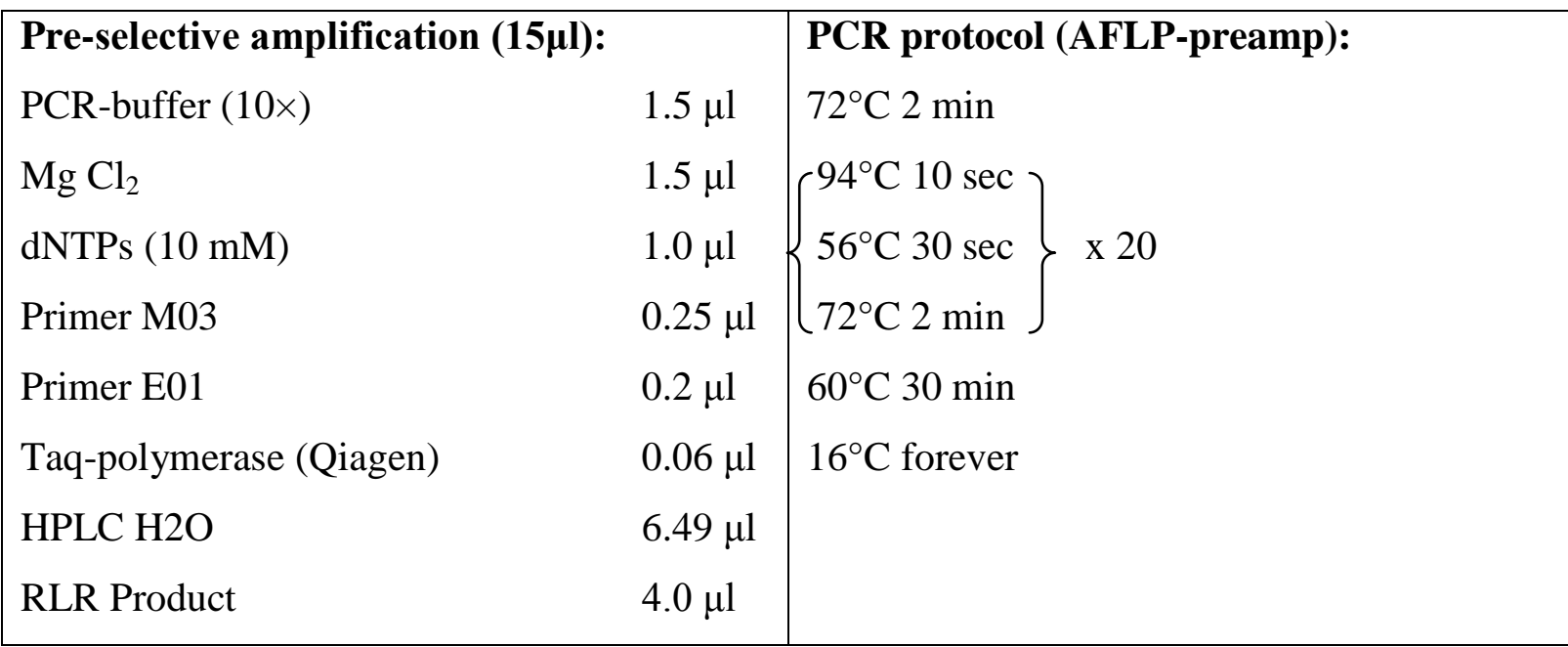

Step II A: Electrophoresis

GEL: $1.5 \%$ Agarose Gel (1.5 g Agarose $+100 \mathrm{ml}$ TAE+1.5 $\mu$ l Ethydium Bromide)

$2 \mu \mathrm{l}$ Bro-phenol $+5 \mu$ AFLP-preamp product

Run at $150 \mathrm{~V}$ for 15 minutes and photographed under UV light.

Step II B: Dilution of AFLP-preamp Product

Step III: AFLP Selective amplification

\begin{tabular}{|c|c|c|}
\hline \multicolumn{2}{|l|}{ Selective Amplification (15 $\mu \mathrm{l})$ : } & PCR protocol (AFLP-Selec): \\
\hline $\mathrm{HPLC} \mathrm{H}_{2} \mathrm{O}$ & $7.09 \mu 1$ & $94{ }^{\circ} \mathrm{C} 2 \mathrm{~min}$ \\
\hline PCR-buffer $(10 \times)$ & $1.50 \mu \mathrm{l}$ & {$\left[94^{\circ} \mathrm{C} 10 \mathrm{sec}, 65^{\circ} \mathrm{C} 30 \mathrm{sec}, 72^{\circ} \mathrm{C} 2 \mathrm{~min}\right] 1$} \\
\hline $\mathrm{MgCl}_{2}$ & $1.50 \mu 1$ & {$\left[94^{\circ} \mathrm{C} 10 \mathrm{sec}, 64^{\circ} \mathrm{C} 30 \mathrm{sec}, 72^{\circ} \mathrm{C} 2 \mathrm{~min}\right] 1$} \\
\hline dNTPs $(10 \mathrm{mM})$ & $1.00 \mu 1$ & {$\left[94^{\circ} \mathrm{C} 10 \mathrm{sec}, 63^{\circ} \mathrm{C} 30 \mathrm{sec}, 72^{\circ} \mathrm{C} 2 \mathrm{~min}\right] 1$} \\
\hline MseI primer (M74) & $0.60 \mu \mathrm{l}$ & {$\left[94^{\circ} \mathrm{C} 10 \mathrm{sec}, 62^{\circ} \mathrm{C} 30 \mathrm{sec}, 72^{\circ} \mathrm{C} 2 \mathrm{~min}\right] 1$} \\
\hline EcoRI primer $(\mathrm{E} 41)$ & $0.25 \mu \mathrm{l}$ & {$\left[94^{\circ} \mathrm{C} 10 \mathrm{sec}, 61^{\circ} \mathrm{C} 30 \mathrm{sec}, 72^{\circ} \mathrm{C} 2 \mathrm{~min}\right] 1$} \\
\hline Taq-polymerase & $0.06 \mu l$ & {$\left[94^{\circ} \mathrm{C} 10 \mathrm{sec}, 60^{\circ} \mathrm{C} 30 \mathrm{sec}, 72^{\circ} \mathrm{C} 2 \mathrm{~min}\right] 1$} \\
\hline DNA (AFLP-preamp product) & $3.0 \mu \mathrm{l}$ & {$\left[94^{\circ} \mathrm{C} 10 \mathrm{sec}, 59^{\circ} \mathrm{C} 30 \mathrm{sec}, 72^{\circ} \mathrm{C} 2 \mathrm{~min}\right] 1$} \\
\hline & & {$\left[94^{\circ} \mathrm{C} 10 \mathrm{sec}, 58^{\circ} \mathrm{C} 30 \mathrm{sec}, 72^{\circ} \mathrm{C} 2 \mathrm{~min}\right] 1$} \\
\hline & & {$\left[94^{\circ} \mathrm{C} 10 \mathrm{sec}, 57^{\circ} \mathrm{C} 30 \mathrm{sec}, 72^{\circ} \mathrm{C} 2 \mathrm{~min}\right] 1$} \\
\hline & & {$\left[94^{\circ} \mathrm{C} 10 \mathrm{sec}, 56^{\circ} \mathrm{C} 30 \mathrm{sec}, 72^{\circ} \mathrm{C} 2 \mathrm{~min}\right] 24$} \\
\hline & & $60^{\circ} \mathrm{C} 30 \mathrm{~min}$ \\
\hline & & $16^{\circ} \mathrm{C}$ forever \\
\hline
\end{tabular}




\section{Step III A: Electrophoresis}

The same protocol as mentioned above.

\section{Step III B: Dilution of AFLP-Selec products}

\section{Step IV: Gene Scan}

Each probe contains: $12 \mu \mathrm{HiDi}$ mixed $\{1270 \mu \mathrm{l}+1.6 \mu \mathrm{l}$ for 1 plate (96 probes) $+2 \mu \mathrm{l}$ dil of Sel-AFLP product

Denaturation at $90^{\circ} \mathrm{C}$ for $2 \mathrm{~min}$

Put on ice before loading into ABI 3100 Genetic Analyzer.

\section{Notes:}

\section{Preparation of Adaptors (M+/- and E+/-)}

Prepare together $\mathrm{M}+$ and $\mathrm{M}$ - in one tube and $\mathrm{E}+$ and $\mathrm{E}-$ in another tube.

Transfer to the reaction tube.

Denature at $95^{\circ} \mathrm{C}$ for $5 \mathrm{~min}$.

Check the amount.

Dilute 1:5. (e.g. $150 \mu \mathrm{l} \mathrm{M}+/$ - plus $600 \mu 1 \mathrm{H}_{2} \mathrm{O}$ ) 
Sequences of adaptors and primers used for AFLP analysis

EcoRI adapter

MseI adapter

$$
E c o \text { RI + } 0 \text { primer E00 }
$$

Eco RI + 1 primer E01

$E c o \mathrm{RI}+3$ primer $\mathrm{E} 41$

Mse I + 0 primer M00

Mse I +1 primer M03

Mse I +3 primer M74

E41-Fam (labelled)
5'-CTCGTAGACTGCGTACC-3'

$(\mathrm{E}-)$

3'-CTGACGCATGGTTAA-5'

$(\mathrm{E}+)$

5-'GACGATGAGTCCTGAG-3'

3'-TACTCAGGACTCAT-5'

5'-GACTGCGTACCAATTC-3'

5'-GACTGCGTACCAATTCA-3'

(pre-sel)

5'-GACTGCGTACCAATTCAGG-3'

5'-GATGAGTCCTGAGTAA-3'

5'-GATGAGTCCTGAGTAAG-3'

(pre-sel)

5'-GATGAGTCCTGAGTAAGGT-3' (sel) 
Appendix 2 Ln (1+ Geographical distance) among T. grandis populations.

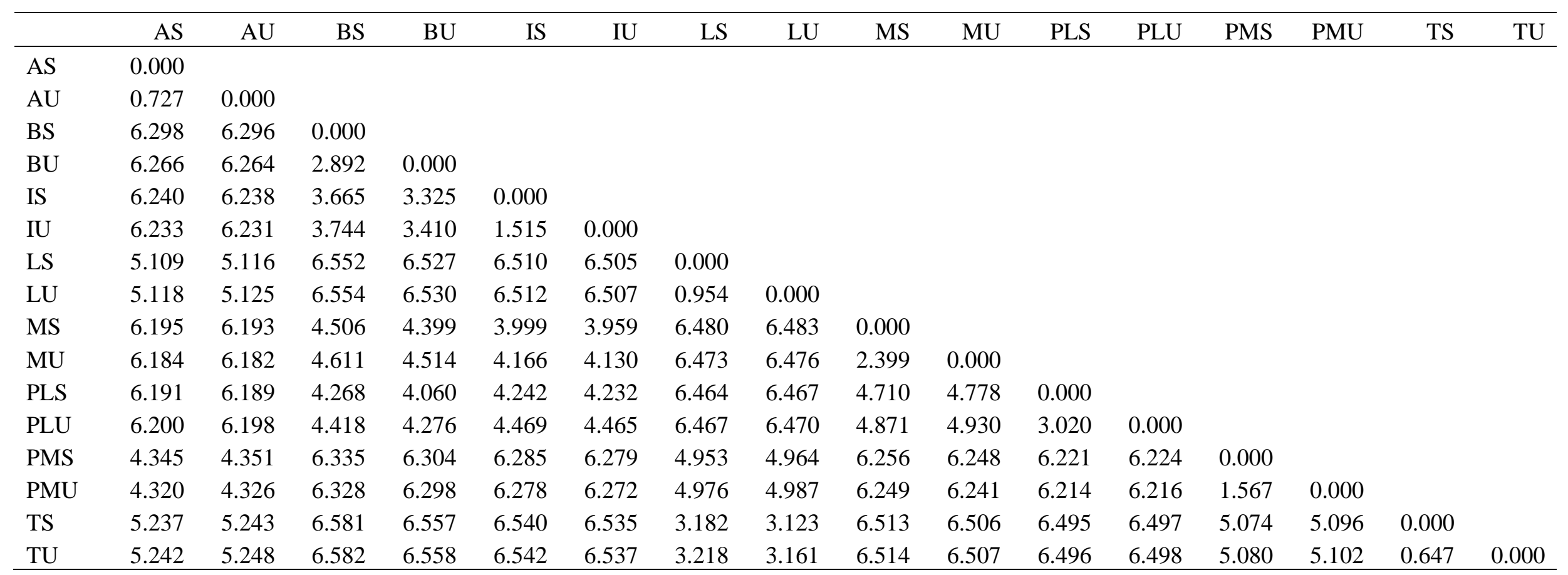

A Aunglan, $B$ Bamauk, $I$ Indaw, $L$ Letpadan, $M$ Mabein, $P L$ Pinlebu, $P M$ Pyinmana, $T$ Tharawaddy, $S$ selectively-logged teak population and $U$ unlogged teak population 
Appendix 3 Geographical distances $(\mathrm{km})$ among $T$. grandis populations.

\begin{tabular}{|c|c|c|c|c|c|c|c|c|c|c|c|c|c|c|c|c|}
\hline & $\mathrm{AS}$ & $\mathrm{AU}$ & BS & $\mathrm{BU}$ & IS & IU & LS & LU & MS & MU & PLS & PLU & PMS & PMU & TS & $\mathrm{TU}$ \\
\hline $\mathrm{AS}$ & 0.0 & & & & & & & & & & & & & & & \\
\hline $\mathrm{AU}$ & 1.1 & 0.0 & & & & & & & & & & & & & & \\
\hline BS & 542.5 & 541.4 & 0.0 & & & & & & & & & & & & & \\
\hline IS & 511.8 & 510.8 & 38.1 & 26.8 & 0.0 & & & & & & & & & & & \\
\hline IU & 508.3 & 507.3 & 41.3 & 29.3 & 3.5 & 0.0 & & & & & & & & & & \\
\hline LS & 164.5 & 165.6 & 699.5 & 682.5 & 670.7 & 667.3 & 0.0 & & & & & & & & & \\
\hline MU & 484.1 & 483.1 & 99.5 & 90.3 & 63.4 & 61.2 & 646.5 & 648.1 & 10.0 & 0.0 & & & & & & \\
\hline PLS & 487.6 & 486.6 & 70.4 & 56.9 & 68.6 & 67.9 & 640.7 & 642.3 & 110.0 & 117.9 & 0.0 & & & & & \\
\hline PLU & 491.7 & 490.7 & 81.9 & 71.0 & 86.3 & 85.9 & 642.7 & 644.3 & 129.4 & 137.4 & 19.5 & 0.0 & & & & \\
\hline PMS & 76.1 & 76.6 & 562.9 & 546.0 & 535.6 & 532.3 & 140.6 & 142.1 & 520.1 & 516.1 & 502.3 & 503.5 & 0.0 & & & \\
\hline PMU & 74.2 & 74.7 & 559.2 & 542.2 & 531.9 & 528.5 & 144.0 & 145.5 & 516.3 & 512.3 & 498.7 & 499.9 & 3.8 & 0.0 & & \\
\hline
\end{tabular}

$A$ Aunglan, $B$ Bamauk, $I$ Indaw, $L$ Letpadan, $M$ Mabein, $P L$ Pinlebu, $P M$ Pyinmana, $T$ Tharawaddy, $S$ selectively-logged teak population and $U$ unlogged teak population 
Appendix 4 Nei's 1978 unbiased genetic distances among T. grandis populations at SSRs.

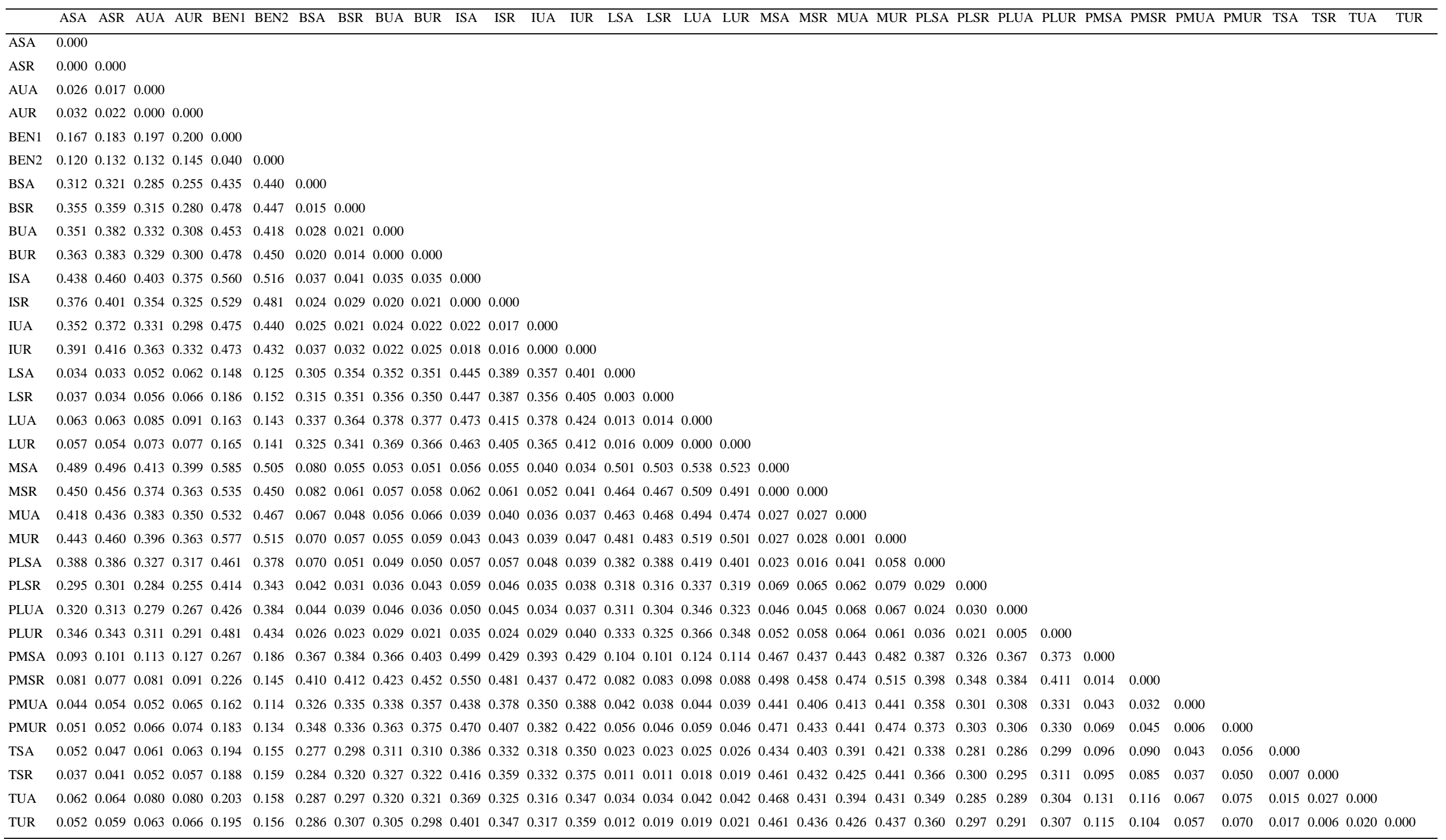


Appendix 5 Pairwise $F_{\mathrm{ST}}$ among $34 T$. grandis populations at SSRs.

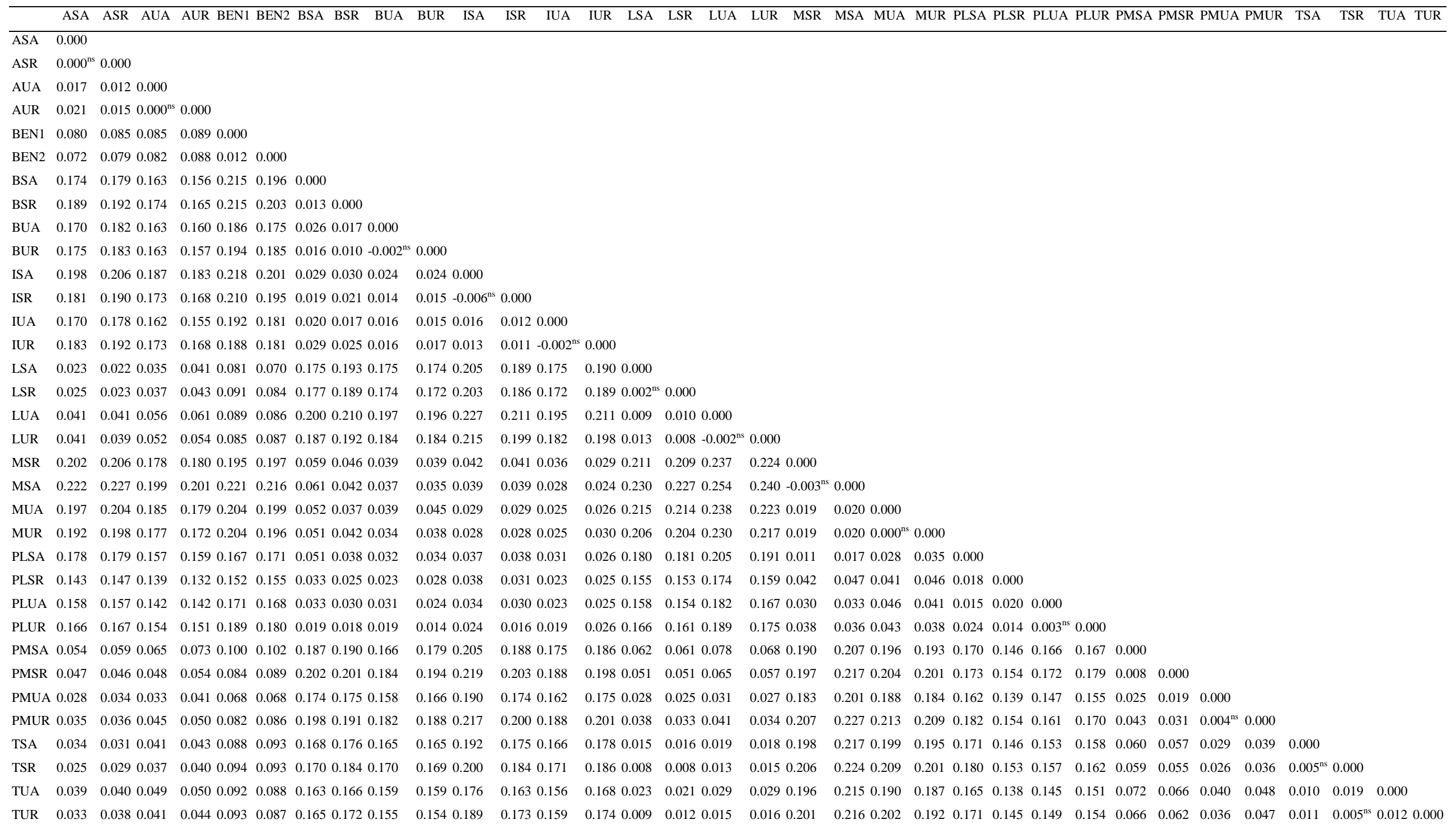

$n s$ not significant. All other values are significant at $5 \%$ probability. 
Appendix 6 Nei's 1978 unbiased genetic distances among 34 T. grandis populations at AFLPs.

ASA ASR AUA AUR BEN1 BEN2 BSA BSR BUA BUR ISA ISR IUA IUR LSA LSR LUA LUR MSA MSR MUA MUR PLSA PLSR PLUA PLUR PMSA PMSR PMUA PMUR TSA TSR TUA TUR ASA 0.000

ASR $\quad 0.022 \quad 0.000$

AUA $\quad 0.007 \quad 0.0170 .000$

$\begin{array}{llllllll}\text { AUR } & 0.021 & 0.010 & 0.014 & 0.000\end{array}$

$\begin{array}{lllllll}\text { BEN1 } & 0.051 & 0.052 & 0.044 & 0.049 & 0.000\end{array}$

$\begin{array}{llllllll}\text { BEN2 } & 0.025 & 0.031 & 0.025 & 0.031 & 0.022 & 0.000\end{array}$

$\begin{array}{lllllllll}\text { BSA } & 0.039 & 0.033 & 0.032 & 0.031 & 0.066 & 0.036 & 0.000\end{array}$

$\begin{array}{llllllllll}\text { BSR } & 0.040 & 0.035 & 0.032 & 0.032 & 0.065 & 0.037 & 0.011 & 0.000\end{array}$

$\begin{array}{llllllllll}\text { BUA } & 0.025 & 0.033 & 0.026 & 0.031 & 0.067 & 0.035 & 0.017 & 0.020 & 0.000\end{array}$

$\begin{array}{lllllllllllll}\text { BUR } & 0.041 & 0.040 & 0.038 & 0.032 & 0.061 & 0.033 & 0.012 & 0.009 & 0.015 & 0.000\end{array}$

$\begin{array}{lllllllllllll}\text { ISA } & 0.050 & 0.043 & 0.040 & 0.040 & 0.094 & 0.055 & 0.020 & 0.023 & 0.013 & 0.019 & 0.000\end{array}$

$\begin{array}{llllllllllllll}\text { ISR } & 0.051 & 0.045 & 0.045 & 0.038 & 0.085 & 0.053 & 0.025 & 0.019 & 0.015 & 0.016 & 0.011 & 0.000\end{array}$

$\begin{array}{llllllllllllll}\text { IUA } & 0.035 & 0.036 & 0.028 & 0.037 & 0.077 & 0.047 & 0.022 & 0.026 & 0.008 & 0.023 & 0.009 & 0.014 & 0.000\end{array}$

$\begin{array}{lllllllllllllll}\text { IUR } & 0.037 & 0.027 & 0.028 & 0.017 & 0.047 & 0.026 & 0.017 & 0.013 & 0.026 & 0.010 & 0.029 & 0.026 & 0.031 & 0.000\end{array}$

$\begin{array}{lllllllllllllllll}\text { LSA } & 0.025 & 0.028 & 0.023 & 0.028 & 0.063 & 0.036 & 0.056 & 0.052 & 0.035 & 0.055 & 0.059 & 0.057 & 0.037 & 0.041 & 0.000\end{array}$

$\begin{array}{lllllllllllllllll}\text { LSR } & 0.021 & 0.015 & 0.015 & 0.018 & 0.041 & 0.018 & 0.035 & 0.030 & 0.026 & 0.035 & 0.046 & 0.042 & 0.034 & 0.025 & 0.013 & 0.000\end{array}$

$\begin{array}{lllllllllllllllllll}\text { LUA } & 0.029 & 0.027 & 0.019 & 0.026 & 0.070 & 0.045 & 0.038 & 0.046 & 0.025 & 0.044 & 0.033 & 0.043 & 0.021 & 0.039 & 0.023 & 0.023 & 0.000\end{array}$

$\begin{array}{llllllllllllllllllll}\text { LUR } & 0.020 & 0.016 & 0.015 & 0.012 & 0.041 & 0.016 & 0.032 & 0.031 & 0.026 & 0.034 & 0.043 & 0.039 & 0.033 & 0.022 & 0.017 & 0.006 & 0.026 & 0.000\end{array}$

$\begin{array}{llllllllllllllllllllll}\text { MSA } & 0.030 & 0.038 & 0.028 & 0.035 & 0.064 & 0.029 & 0.024 & 0.021 & 0.017 & 0.019 & 0.029 & 0.030 & 0.027 & 0.024 & 0.036 & 0.030 & 0.039 & 0.026 & 0.000\end{array}$

$\begin{array}{lllllllllllllllllllll}\text { MSR } & 0.049 & 0.043 & 0.043 & 0.039 & 0.076 & 0.044 & 0.016 & 0.016 & 0.020 & 0.012 & 0.018 & 0.018 & 0.023 & 0.021 & 0.062 & 0.044 & 0.047 & 0.039 & 0.019 & 0.000\end{array}$

$\begin{array}{lllllllllllllllllllllllllll}\text { MUA } & 0.034 & 0.046 & 0.037 & 0.042 & 0.085 & 0.042 & 0.031 & 0.027 & 0.019 & 0.025 & 0.028 & 0.023 & 0.021 & 0.033 & 0.035 & 0.034 & 0.034 & 0.032 & 0.009 & 0.028 & 0.000\end{array}$

$\begin{array}{lllllllllllllllllllllll}\text { MUR } & 0.037 & 0.039 & 0.032 & 0.032 & 0.067 & 0.033 & 0.010 & 0.009 & 0.018 & 0.009 & 0.021 & 0.022 & 0.022 & 0.013 & 0.046 & 0.032 & 0.043 & 0.026 & 0.012 & 0.010 & 0.016 & 0.000\end{array}$

$\begin{array}{llllllllllllllllllllllll}\text { PLSA } & 0.059 & 0.051 & 0.049 & 0.052 & 0.104 & 0.066 & 0.031 & 0.043 & 0.026 & 0.033 & 0.018 & 0.034 & 0.018 & 0.047 & 0.063 & 0.058 & 0.030 & 0.054 & 0.050 & 0.040 & 0.045 & 0.038 & 0.000\end{array}$

$\begin{array}{lllllllllllllllllllllllllllll}\text { PLSR } & 0.035 & 0.034 & 0.030 & 0.032 & 0.046 & 0.020 & 0.017 & 0.010 & 0.021 & 0.011 & 0.027 & 0.028 & 0.029 & 0.013 & 0.048 & 0.025 & 0.045 & 0.024 & 0.018 & 0.020 & 0.026 & 0.011 & 0.042 & 0.000\end{array}$

$\begin{array}{llllllllllllllllllllllllllll}\text { PLUA } & 0.039 & 0.032 & 0.031 & 0.035 & 0.076 & 0.042 & 0.013 & 0.017 & 0.014 & 0.018 & 0.011 & 0.020 & 0.012 & 0.024 & 0.045 & 0.034 & 0.027 & 0.033 & 0.032 & 0.022 & 0.030 & 0.017 & 0.014 & 0.020 & 0.000\end{array}$

$\begin{array}{llllllllllllllllllllllllllllll}\text { PLUR } & 0.037 & 0.038 & 0.033 & 0.030 & 0.047 & 0.020 & 0.019 & 0.014 & 0.030 & 0.017 & 0.040 & 0.039 & 0.043 & 0.016 & 0.049 & 0.030 & 0.052 & 0.024 & 0.025 & 0.027 & 0.036 & 0.017 & 0.053 & 0.005 & 0.026 & 0.000\end{array}$

$\begin{array}{llllllllllllllllllllllllllllll}\text { PMSA } & 0.013 & 0.029 & 0.016 & 0.033 & 0.068 & 0.036 & 0.051 & 0.050 & 0.026 & 0.052 & 0.049 & 0.050 & 0.030 & 0.050 & 0.017 & 0.022 & 0.026 & 0.025 & 0.038 & 0.052 & 0.039 & 0.044 & 0.059 & 0.045 & 0.039 & 0.050 & 0.000\end{array}$

$\begin{array}{llllllllllllllllllllllllllllllllll}\text { PMSR } & 0.022 & 0.012 & 0.015 & 0.011 & 0.056 & 0.029 & 0.028 & 0.029 & 0.027 & 0.030 & 0.037 & 0.035 & 0.029 & 0.022 & 0.032 & 0.017 & 0.026 & 0.013 & 0.039 & 0.037 & 0.043 & 0.033 & 0.041 & 0.032 & 0.029 & 0.032 & 0.027 & 0.000\end{array}$

$\begin{array}{lllllllllllllllllllllllllllllllll}\text { PMUA } & 0.010 & 0.023 & 0.009 & 0.025 & 0.055 & 0.023 & 0.029 & 0.030 & 0.018 & 0.037 & 0.037 & 0.039 & 0.022 & 0.036 & 0.021 & 0.017 & 0.023 & 0.016 & 0.024 & 0.037 & 0.029 & 0.027 & 0.041 & 0.028 & 0.024 & 0.030 & 0.008 & 0.017 & 0.000\end{array}$

$\begin{array}{llllllllllllllllllllllllllllllllllllll}\text { PMUR } & 0.023 & 0.016 & 0.018 & 0.019 & 0.058 & 0.033 & 0.021 & 0.025 & 0.027 & 0.026 & 0.032 & 0.033 & 0.027 & 0.026 & 0.046 & 0.024 & 0.033 & 0.022 & 0.037 & 0.029 & 0.043 & 0.028 & 0.039 & 0.030 & 0.025 & 0.034 & 0.036 & 0.009 & 0.019 & 0.000\end{array}$

$\begin{array}{lllllllllllllllllllllllllllllllllllllllll}\text { TSA } & 0.025 & 0.020 & 0.023 & 0.016 & 0.071 & 0.040 & 0.049 & 0.046 & 0.041 & 0.049 & 0.059 & 0.050 & 0.044 & 0.031 & 0.019 & 0.021 & 0.031 & 0.018 & 0.045 & 0.056 & 0.044 & 0.044 & 0.067 & 0.049 & 0.048 & 0.045 & 0.024 & 0.014 & 0.024 & 0.032 & 0.000\end{array}$

$\begin{array}{lllllllllllllllllllllllllllllllllllllll}\text { TSR } & 0.023 & 0.017 & 0.016 & 0.015 & 0.048 & 0.024 & 0.029 & 0.034 & 0.026 & 0.037 & 0.040 & 0.039 & 0.026 & 0.024 & 0.020 & 0.015 & 0.020 & 0.008 & 0.034 & 0.041 & 0.037 & 0.032 & 0.043 & 0.030 & 0.025 & 0.030 & 0.028 & 0.013 & 0.016 & 0.019 & 0.021 & 0.000 & \end{array}$

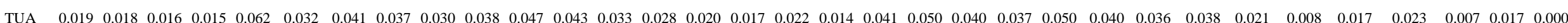

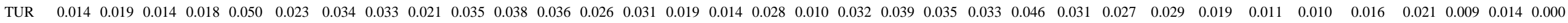


Appendix 7 Pairwise $F_{\mathrm{ST}}$ among $34 T$. grandis populations at AFLPs.

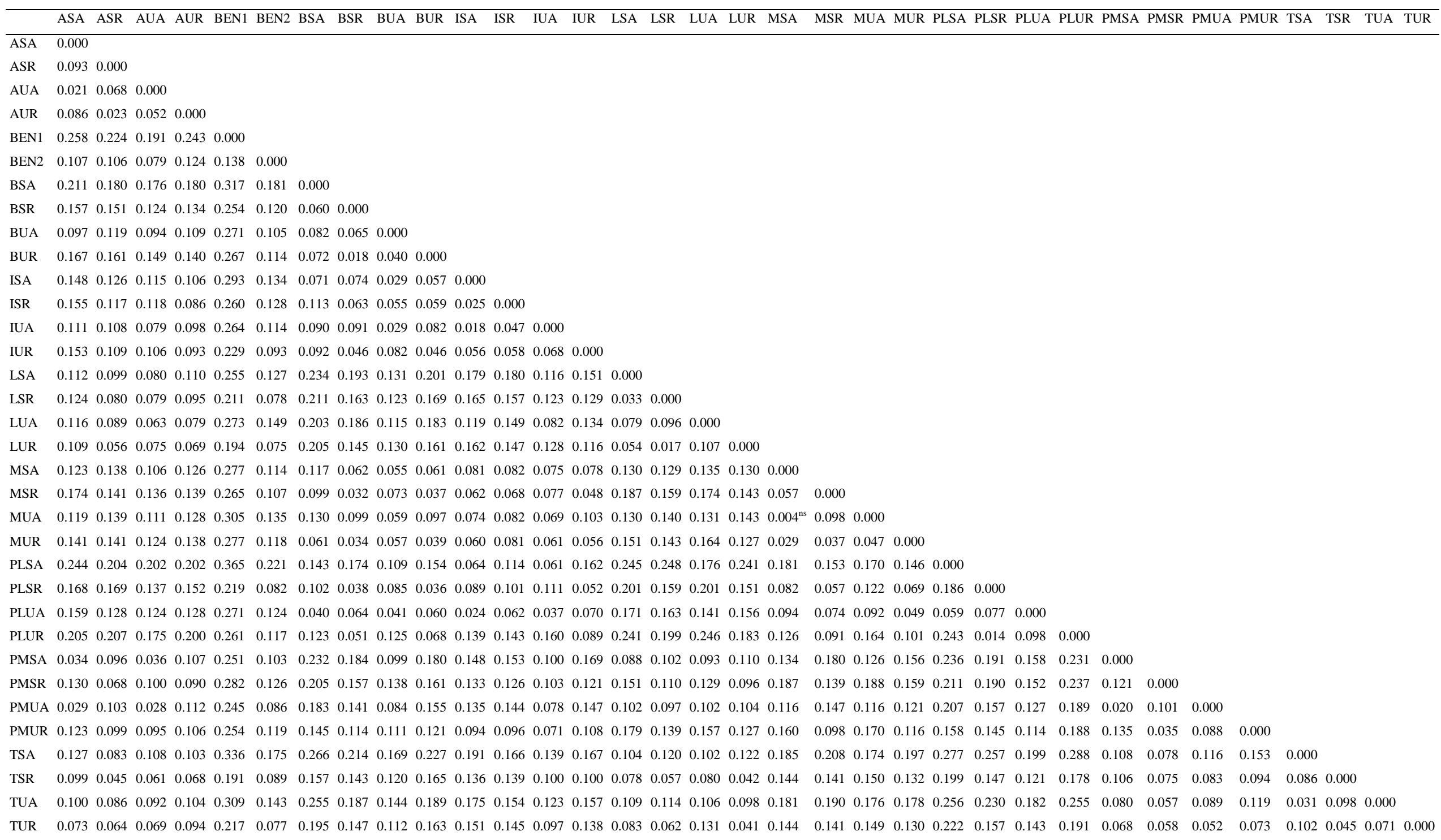

$110 n s$ not significant. All other values are significant at $5 \%$ probability. 
Appendix 8 Linkage disequilibrium in $T$. grandis populations.

\begin{tabular}{|c|c|c|c|c|c|c|c|c|}
\hline SSR Loci & TUA & TSA & MUA & MSA & PMUA & LSR & BEN1 & BEN2 \\
\hline A06 \& B02 & & & & & & & $*$ & $*$ \\
\hline A06 \& B03 & & & & & & & $*$ & $*$ \\
\hline A06 \& B07 & & & & & & & $*$ & $*$ \\
\hline A06 \& C03 & & & & & & & $*$ & $*$ \\
\hline A06 \& Da09 & & & & & $*$ & & $*$ & $*$ \\
\hline A06 \& Da12 & & & & & & & $*$ & $*$ \\
\hline A06 \& F01 & & & & & $*$ & & $*$ & $*$ \\
\hline A06 \& F02 & $*$ & & & & & & $*$ & $*$ \\
\hline A06 \& G02 & & & & & & & $*$ & \\
\hline B02 \& B03 & & & & & & & $*$ & $*$ \\
\hline B02 \& B07 & & & & & & & $*$ & $*$ \\
\hline B02 \& C03 & & & & & & & $*$ & $*$ \\
\hline B02 \& Da09 & $*$ & & & & & & $*$ & $*$ \\
\hline B02 \& Da12 & & & $*$ & & & & $*$ & $*$ \\
\hline B02 \& F01 & & & & & & & $*$ & $*$ \\
\hline B02 \& F02 & $*$ & & & & & & $*$ & $*$ \\
\hline B02 \& G02 & & & & & & & $*$ & \\
\hline B03 \& B07 & & & & & & & $*$ & $*$ \\
\hline B03 \& C03 & & & & & & & $*$ & $*$ \\
\hline B03 \& Da09 & & & & & & & $*$ & $*$ \\
\hline B03 \& Da12 & & & & $*$ & & & $*$ & $*$ \\
\hline B03 \& F01 & & & & & & & $*$ & $*$ \\
\hline B03 \& F02 & $*$ & & & & & & $*$ & $*$ \\
\hline B03 \& G02 & & $*$ & & & & & $*$ & \\
\hline B07 \& C03 & & & & & & & $*$ & $*$ \\
\hline B07 \& Da09 & & & & & & & $*$ & $*$ \\
\hline B07 \& Da12 & & & & & $*$ & & $*$ & $*$ \\
\hline B07 \& F01 & & & & & & & $*$ & $*$ \\
\hline B07 \& F02 & $*$ & & & & & & $*$ & \\
\hline B07\& G02 & & & & & & & $*$ & \\
\hline C03 \& Da09 & & & & & & & $*$ & $*$ \\
\hline C03 \& Da12 & & & & & & & $*$ & $*$ \\
\hline C03 \& F01 & $*$ & & & & & & $*$ & $*$ \\
\hline C03 \& F02 & $*$ & & & & & & $*$ & \\
\hline C03 \& G02 & & & & & & & $*$ & \\
\hline Da09 \& Da12 & & & & & & & $*$ & $*$ \\
\hline Da09 \& F01 & $*$ & & & & & & $*$ & $*$ \\
\hline Da09 \& F02 & $*$ & & & & & & $*$ & \\
\hline Da09 \& G02 & & & & & & & $*$ & \\
\hline Da12 \& F01 & $*$ & & & & & & $*$ & $*$ \\
\hline Da12 \& F02 & $*$ & & & & & & $*$ & \\
\hline Da12 \& G02 & & & & & & & $*$ & \\
\hline F01 \& F02 & $*$ & & & & & & $*$ & \\
\hline F01 \& G02 & & & & & & $*$ & $*$ & \\
\hline F02 \& G02 & & & & & & $*$ & $*$ & \\
\hline Total & 12 & 1 & 1 & 1 & 3 & 2 & 45 & 31 \\
\hline
\end{tabular}

$P<0.05^{*}$ 
Appendix 9 The potential null alleles in SSR loci for T. grandis populations.

\begin{tabular}{|c|c|c|c|c|c|c|c|c|c|c|c|c|}
\hline No. & Pop. & A06 & B02 & B03 & B07 & $\mathrm{C} 03$ & D09 & D12 & F01 & F02 & G02 & Total \\
\hline 1 & TUA & & & & & & & & $*$ & $*$ & & 2 \\
\hline 2 & TSA & & & & & & & & $*$ & $*$ & $*$ & 3 \\
\hline 3 & PMSA & & $*$ & & & & $*$ & & & & & 2 \\
\hline 4 & ASA & & $*$ & & & & & & & & & 1 \\
\hline 5 & PLSA & & & & & & & & $*$ & & & 1 \\
\hline 6 & IUA & & & & $*$ & & & & & * & & 2 \\
\hline 7 & ISA & & & & & & & & $*$ & $*$ & & 2 \\
\hline 8 & LSA & & & & & & & $*$ & & & & 1 \\
\hline 9 & MSR & & & & & & & & $*$ & & $*$ & 2 \\
\hline 10 & PMUR & $*$ & & & & & $*$ & & $*$ & & & 3 \\
\hline 11 & AUR & & & & & & $*$ & & & & & 1 \\
\hline 12 & ASR & & & & & & $*$ & & & & & 1 \\
\hline 13 & BUR & & & & $*$ & $*$ & $*$ & & & & & 3 \\
\hline 14 & BSR & & & & $*$ & & & & & & & 1 \\
\hline 15 & PLSR & & & & & & & & $*$ & & & 1 \\
\hline 16 & LSR & & & & & & $*$ & $*$ & & & $*$ & 3 \\
\hline 17 & LUR & & & & & & & & & & $*$ & 1 \\
\hline \multirow[t]{2}{*}{18} & BEN1 & & & & & & & & & & $*$ & 1 \\
\hline & Total & 1 & 2 & 0 & 3 & 1 & 6 & 2 & 7 & 4 & 5 & 31 \\
\hline
\end{tabular}

$P<0.05^{*}$ 
Appendix 10 Differences in frequencies of AFLP markers in adults and regeneration in $T$. grandis population in the southern regions of Myanmar.

\begin{tabular}{lccc}
\hline Loci & Adults & Regeneration & Difference \\
\hline 50 & 0.995 & 0.997 & -0.003 \\
55 & 0.026 & 0.057 & -0.031 \\
57 & 0.083 & 0.057 & 0.027 \\
60 & 0.997 & 1.000 & -0.003 \\
61 & 0.964 & 0.969 & -0.006 \\
62 & 0.078 & 0.033 & 0.045 \\
66 & 0.016 & 0.134 & -0.118 \\
67 & 0.096 & 0.172 & -0.076 \\
70 & 0.995 & 1.000 & -0.005 \\
72 & 0.984 & 0.987 & -0.003 \\
79 & 0.990 & 0.979 & 0.010 \\
80 & 0.712 & 0.722 & -0.011 \\
81 & 0.997 & 0.990 & 0.008 \\
88 & 1.000 & 0.997 & 0.003 \\
96 & 0.408 & 0.445 & -0.037 \\
97 & 0.901 & 0.946 & -0.045 \\
98 & 0.834 & 0.877 & -0.043 \\
99 & 0.436 & 0.699 & -0.263 \\
101 & 0.034 & 0.041 & -0.007 \\
103 & 0.886 & 0.571 & 0.315 \\
104 & 0.119 & 0.080 & 0.040 \\
105 & 0.873 & 0.956 & -0.084 \\
106 & 0.016 & 0.041 & -0.026 \\
112 & 0.003 & 0.015 & -0.013 \\
113 & 1.000 & 0.985 & 0.015 \\
115 & 0.042 & 0.129 & -0.087 \\
117 & 0.083 & 0.082 & 0.001 \\
120 & 0.860 & 0.931 & -0.071 \\
123 & 0.265 & 0.206 & 0.059 \\
125 & 0.021 & 0.044 & -0.023 \\
128 & 0.283 & 0.129 & 0.155 \\
132 & 0.977 & 0.967 & 0.010 \\
134 & 0.561 & 0.455 & 0.106 \\
135 & 0.078 & 0.028 & 0.050 \\
141 & 0.021 & 0.036 & -0.015 \\
142 & 0.078 & 0.098 & -0.020 \\
148 & 0.779 & 0.817 & -0.038 \\
149 & 0.021 & 0.021 & 0.000 \\
152 & 0.636 & 0.514 & 0.122 \\
160 & 0.145 & 0.134 & 0.012 \\
& & &
\end{tabular}




\begin{tabular}{llll}
161 & 0.486 & 0.201 & 0.285 \\
165 & 0.977 & 0.997 & -0.021 \\
166 & 0.055 & 0.080 & -0.025 \\
168 & 0.044 & 0.033 & 0.011 \\
171 & 0.047 & 0.031 & 0.016 \\
182 & 0.982 & 0.995 & -0.013 \\
186 & 0.122 & 0.206 & -0.084 \\
189 & 0.068 & 0.064 & 0.003 \\
190 & 0.956 & 0.951 & 0.005 \\
192 & 0.460 & 0.514 & -0.054 \\
193 & 0.023 & 0.026 & -0.002 \\
194 & 0.966 & 0.990 & -0.023 \\
197 & 0.468 & 0.445 & 0.023 \\
202 & 0.114 & 0.144 & -0.030 \\
204 & 0.029 & 0.054 & -0.025 \\
279 & 0.992 & 0.995 & -0.003 \\
282 & 0.242 & 0.231 & 0.010 \\
284 & 0.088 & 0.049 & 0.039 \\
288 & 0.127 & 0.090 & 0.037 \\
290 & 0.494 & 0.504 & -0.010 \\
294 & 0.143 & 0.129 & 0.014 \\
336 & 0.997 & 0.987 & 0.010 \\
342 & 0.239 & 0.396 & -0.157 \\
346 & 0.875 & 0.941 & -0.066 \\
367 & 0.364 & 0.368 & -0.004 \\
368 & 0.540 & 0.530 & 0.011 \\
378 & 0.078 & 0.018 & 0.060 \\
387 & 0.979 & 0.995 & -0.016 \\
391 & 0.026 & 0.039 & -0.013 \\
394 & 0.966 & 0.959 & 0.007 \\
438 & 0.849 & 0.614 & 0.235 \\
\hline & & & \\
& &
\end{tabular}


Appendix 11 Differences in frequencies of AFLP markers in adults and regeneration in $T$. grandis population in the northern regions of Myanmar.

\begin{tabular}{|c|c|c|c|}
\hline Loci & Adults & Regeneration & Difference \\
\hline 50 & 1.000 & 0.977 & 0.023 \\
\hline 55 & 0.107 & 0.135 & -0.028 \\
\hline 57 & 0.110 & 0.023 & 0.087 \\
\hline 60 & 0.994 & 0.977 & 0.017 \\
\hline 61 & 0.970 & 0.961 & 0.009 \\
\hline 62 & 0.060 & 0.091 & -0.032 \\
\hline 66 & 0.330 & 0.154 & 0.177 \\
\hline 67 & 0.149 & 0.201 & -0.052 \\
\hline 70 & 0.967 & 0.953 & 0.014 \\
\hline 72 & 0.961 & 0.951 & 0.011 \\
\hline 79 & 0.985 & 0.977 & 0.009 \\
\hline 80 & 0.491 & 0.557 & -0.066 \\
\hline 81 & 0.982 & 0.971 & 0.011 \\
\hline 88 & 1.000 & 0.977 & 0.023 \\
\hline 96 & 0.211 & 0.245 & -0.033 \\
\hline 97 & 0.878 & 0.901 & -0.023 \\
\hline 98 & 0.949 & 0.906 & 0.043 \\
\hline 99 & 0.753 & 0.753 & 0.000 \\
\hline 101 & 0.155 & 0.151 & 0.004 \\
\hline 103 & 0.619 & 0.430 & 0.189 \\
\hline 104 & 0.265 & 0.227 & 0.038 \\
\hline 105 & 0.771 & 0.930 & -0.159 \\
\hline 106 & 0.074 & 0.086 & -0.012 \\
\hline 112 & 0.039 & 0.021 & 0.018 \\
\hline 113 & 0.979 & 0.964 & 0.016 \\
\hline 115 & 0.060 & 0.070 & -0.011 \\
\hline 117 & 0.113 & 0.042 & 0.071 \\
\hline 120 & 0.708 & 0.906 & -0.198 \\
\hline 123 & 0.899 & 0.958 & -0.060 \\
\hline 125 & 0.113 & 0.042 & 0.071 \\
\hline 128 & 0.295 & 0.161 & 0.133 \\
\hline 132 & 0.884 & 0.893 & -0.009 \\
\hline 134 & 0.414 & 0.497 & -0.084 \\
\hline 135 & 0.268 & 0.240 & 0.028 \\
\hline 141 & 0.152 & 0.070 & 0.081 \\
\hline 142 & 0.223 & 0.185 & 0.038 \\
\hline 148 & 0.714 & 0.878 & -0.163 \\
\hline 149 & 0.098 & 0.042 & 0.057 \\
\hline 152 & 0.643 & 0.620 & 0.023 \\
\hline 160 & 0.247 & 0.112 & 0.135 \\
\hline
\end{tabular}




\begin{tabular}{|c|c|c|c|}
\hline 161 & 0.262 & 0.328 & -0.066 \\
\hline 165 & 0.994 & 0.974 & 0.020 \\
\hline 166 & 0.071 & 0.091 & -0.020 \\
\hline 168 & 0.089 & 0.039 & 0.050 \\
\hline 171 & 0.247 & 0.115 & 0.132 \\
\hline 182 & 0.988 & 0.974 & 0.014 \\
\hline 186 & 0.167 & 0.477 & -0.310 \\
\hline 189 & 0.179 & 0.190 & -0.012 \\
\hline 190 & 0.926 & 0.940 & -0.015 \\
\hline 192 & 0.524 & 0.396 & 0.128 \\
\hline 193 & 0.042 & 0.021 & 0.021 \\
\hline 194 & 0.902 & 0.956 & -0.054 \\
\hline 197 & 0.565 & 0.531 & 0.034 \\
\hline 202 & 0.068 & 0.068 & 0.001 \\
\hline 204 & 0.083 & 0.151 & -0.068 \\
\hline 279 & 0.982 & 0.945 & 0.037 \\
\hline 282 & 0.372 & 0.372 & 0.000 \\
\hline 284 & 0.036 & 0.052 & -0.016 \\
\hline 288 & 0.060 & 0.076 & -0.016 \\
\hline 290 & 0.292 & 0.409 & -0.117 \\
\hline 294 & 0.140 & 0.143 & -0.003 \\
\hline 336 & 0.935 & 0.914 & 0.020 \\
\hline 342 & 0.027 & 0.042 & -0.015 \\
\hline 346 & 0.664 & 0.818 & -0.154 \\
\hline 367 & 0.164 & 0.276 & -0.112 \\
\hline 368 & 0.568 & 0.510 & 0.058 \\
\hline 378 & 0.033 & 0.026 & 0.007 \\
\hline 387 & 0.970 & 0.953 & 0.017 \\
\hline 391 & 0.036 & 0.026 & 0.010 \\
\hline 394 & 0.917 & 0.914 & 0.003 \\
\hline 438 & 0.360 & 0.102 & 0.259 \\
\hline
\end{tabular}


Appendix 12 Locus-wise $\left(G_{\mathrm{ST}}\right)$ for adults and regeneration in $T$. grandis populations in the southern and northern regions of Myanmar.

\begin{tabular}{|c|c|c|}
\hline Loci & $\begin{array}{c}\text { Southern } \\
\text { region } \\
\left(G_{\mathrm{ST}}\right)\end{array}$ & $\begin{array}{c}\text { Northern } \\
\text { region } \\
\left(G_{\mathrm{ST}}\right)\end{array}$ \\
\hline 50 & 0.001 & N/A \\
\hline 55 & 0.003 & 0.001 \\
\hline 57 & 0.002 & 0.013 \\
\hline 60 & 0.028 & 0.040 \\
\hline 61 & 0.002 & 0.003 \\
\hline 62 & 0.005 & 0.002 \\
\hline 66 & 0.021 & 0.023 \\
\hline 67 & 0.004 & 0.003 \\
\hline 70 & 0.040 & 0.001 \\
\hline 72 & 0.002 & 0.002 \\
\hline 79 & 0.002 & 0.065 \\
\hline 80 & 0.000 & 0.004 \\
\hline 81 & 0.006 & 0.010 \\
\hline 88 & 0.025 & 0.026 \\
\hline 96 & 0.000 & 0.001 \\
\hline 97 & 0.003 & 0.006 \\
\hline 98 & 0.003 & 0.003 \\
\hline 99 & 0.051 & 0.000 \\
\hline 101 & 0.001 & 0.000 \\
\hline 103 & 0.087 & 0.021 \\
\hline 104 & 0.005 & 0.001 \\
\hline 105 & 0.017 & 0.072 \\
\hline 106 & 0.002 & 0.001 \\
\hline 112 & 0.002 & 0.001 \\
\hline 113 & 0.062 & 0.001 \\
\hline 115 & 0.007 & 0.000 \\
\hline 117 & 0.000 & 0.008 \\
\hline 120 & 0.021 & 0.059 \\
\hline 123 & 0.007 & 0.043 \\
\hline 125 & 0.001 & 0.009 \\
\hline 128 & 0.022 & 0.013 \\
\hline 132 & 0.000 & 0.002 \\
\hline 134 & 0.002 & 0.004 \\
\hline 135 & 0.004 & 0.001 \\
\hline 141 & 0.001 & 0.008 \\
\hline 142 & 0.000 & 0.001 \\
\hline 148 & 0.004 & 0.046 \\
\hline 149 & 0.000 & 0.006 \\
\hline
\end{tabular}




\begin{tabular}{|c|c|c|}
\hline 152 & 0.032 & 0.000 \\
\hline 160 & 0.001 & 0.016 \\
\hline 161 & 0.039 & 0.004 \\
\hline 165 & 0.035 & 0.003 \\
\hline 166 & 0.001 & 0.001 \\
\hline 168 & 0.001 & 0.005 \\
\hline 171 & 0.002 & 0.016 \\
\hline 182 & 0.015 & 0.011 \\
\hline 186 & 0.007 & 0.066 \\
\hline 189 & 0.001 & 0.000 \\
\hline 190 & 0.000 & 0.006 \\
\hline 192 & 0.000 & 0.008 \\
\hline 193 & 0.000 & 0.002 \\
\hline 194 & 0.006 & 0.031 \\
\hline 197 & 0.000 & 0.001 \\
\hline 202 & 0.000 & 0.000 \\
\hline 204 & 0.001 & 0.006 \\
\hline 279 & 0.000 & 0.004 \\
\hline 282 & 0.001 & 0.000 \\
\hline 284 & 0.004 & 0.001 \\
\hline 288 & 0.000 & 0.001 \\
\hline 290 & 0.000 & 0.010 \\
\hline 294 & 0.001 & 0.000 \\
\hline 336 & 0.009 & 0.000 \\
\hline 342 & 0.011 & 0.001 \\
\hline 346 & 0.019 & 0.036 \\
\hline 367 & 0.000 & 0.012 \\
\hline 368 & 0.000 & 0.000 \\
\hline 378 & 0.010 & 0.000 \\
\hline 387 & 0.031 & 0.000 \\
\hline 391 & 0.000 & 0.000 \\
\hline 394 & 0.001 & 0.000 \\
\hline 438 & 0.045 & 0.049 \\
\hline
\end{tabular}

$N A$ data not available. 


\section{Curriculum Vitae}

\section{Personal information}

Name:

YAZAR MINN

E-mail:

yazarminn@gmail.com

Nationality:

Myanmar

Date of birth:

26.02.1976

Place of Birth:

Amarapura, Myanmar

Gender:

Male

Marital Status:

Married

Religion:

Buddhist

\section{Education and training}

(1981-1985)

(1985-1993)

(1995- 2001)

(2005-2007)

(2009 - 2012)
Basic Education Primary School, Shankalay, Amarapura, Myanmar

No.2 C.W.S. Basic Education High School, Amarapura, Myanmar

B.Sc. Forestry, University of Forestry, Yezin, Myanmar

M.Sc. Tropical and International Forestry, Georg-AugustUniversität Göttingen, Germany

Ph.D. Forest Sciences and Forest Ecology, Georg-August-

Universität Göttingen, Germany

\section{Title of qualification awarded}

B.Sc. Forestry

M.Sc. Tropical and International Forestry 


\section{Professional experience}

$2002-2009$

(Demonstrator, University of Forestry, Myanmar)

$2009-2012$

(Assistant Lecturer, University of Forestry, Myanmar)

\section{Additional information}

\section{Scholarships and grants}

(01.08.2005 - 30.11.2007) Deutscher Academischer Austauschdienst (German Academic Exchange Service) Scholarship for Basic German Language Course at the Goethe Institute and Tropical and International Forestry Master Course at Georg-August-Universität Göttingen, Germany

(01.03.2009-30.04.2009) EVOLTREE grant for young scientists, Georg-AugustUniversität Göttingen, Germany

(01.10.2009-30.9.2012) Deustche Bundesstiftung Unwelt (German Federal Environmental Foundation) scholarship for Ph.D. Forest Sciences and Forest Ecology course at Georg-AugustUniversität Göttingen, Germany

\section{Publications}

Thein, H.M., Kanzaka, M., Fukushima, M., Minn, Y., 2007. Structure and composition of a teak-bearing forest under Myanmar Selection System: Impacts of logging and bamboo flowering; South East Asian Studies 45: 303-316.

Fukushima, M., Kanzaki, M., Thein, H. M., Minn, Y., 2007. Recovery Process of Fallow Vegetation in the traditional Karen Swidden Cultivation System in the Bago Mountain Range, Myanmar. South East Asian Studies 45: 317-333.

\section{Master thesis}

Minn, Y., 2007. Genetic diversity within and among populations of teak (Tectona grandis Linn f.) and dahat (Tectona hamiltoniana Wall.) in Myanmar detected by AFLPs and cpSSRs. Master Thesis, Forest Genetics and Forest Tree Breeding, Goettingen University, Germany. 


\section{Posters and oral presentations}

Minn, Y., Gailing, O., Finkeldey, R., 2012. Genetic variation of teak (Tectona grandis Linn. f.) and dahat (Tectona hamiltoniana Wall) in Myanmar: Poster presented at the Annual Conference of Tropical Ecology Society, Erlangen, February, 2012.

Minn, Y., Prinz., K., Finkeldey, R., 2012. Genetic variation of teak (Tectona grandis Linn. f.) in selectively-logged and unlogged natural populations in Myanmar. Oral presentation at the Annual Conference of Tropical Ecology Society, Erlangen, February, 2012.

Minn, Y., Prinz., K., Finkeldey, R., 2012. Conservation and Genetic variation of teak (Tectona grandis Linn. f.) in natural populations in Myanmar: Poster presented at Tropentag, Goettingen, 19-21, September, 2012. 